\title{
IDENTIFICATION OF SECONDARY METABOLITES FROM SOME EUROTIUM SPECIES, ASPERGILLUS INSUETUS AND $A$. CALIDOUSTUS FROM CANADIAN HOMES
}

\author{
Gregory James Slack
}

A thesis submitted to the Faculty of Graduate Studies in partial fulfillment of the requirements for a degree of

Master of Science

Department of Chemistry

Carleton University

December 2007 


$\begin{array}{ll}\begin{array}{l}\text { Library and } \\ \text { Archives Canada }\end{array} & \begin{array}{l}\text { Bibliothèque et } \\ \text { Archives Canada }\end{array} \\ \begin{array}{l}\text { Published Heritage } \\ \text { Branch }\end{array} & \begin{array}{l}\text { Direction du } \\ \text { Patrimoine de l'édition }\end{array} \\ \begin{array}{l}\text { 395 Wellington Street } \\ \text { Ottawa ON K1A 0N4 }\end{array} & \begin{array}{l}\text { 395, rue Wellington } \\ \text { Ottawa ON K1A ON4 }\end{array} \\ \text { Canada } & \begin{array}{l}\text { Canada } \\ \end{array}\end{array}$

Yourfile Votre référence

ISBN: 978-0-494-36851-0

Ourfile Notre référence

ISBN: 978-0-494-36851-0

NOTICE:

The author has granted a nonexclusive license allowing Library and Archives Canada to reproduce, publish, archive, preserve, conserve, communicate to the public by telecommunication or on the Internet, loan, distribute and sell theses worldwide, for commercial or noncommercial purposes, in microform, paper, electronic and/or any other formats.

The author retains copyright ownership and moral rights in this thesis. Neither the thesis nor substantial extracts from it may be printed or otherwise reproduced without the author's permission.
AVIS:

L'auteur a accordé une licence non exclusive permettant à la Bibliothèque et Archives Canada de reproduire, publier, archiver, sauvegarder, conserver, transmettre au public par télécommunication ou par l'Internet, prêter, distribuer et vendre des thèses partout dans le monde, à des fins commerciales ou autres, sur support microforme, papier, électronique et/ou autres formats.

L'auteur conserve la propriété du droit d'auteur et des droits moraux qui protège cette thèse. $\mathrm{Ni}$ la thèse ni des extraits substantiels de celle-ci ne doivent être imprimés ou autrement reproduits sans son autorisation.
In compliance with the Canadian

Privacy Act some supporting forms may have been removed from this thesis.

While these forms may be included in the document page count, their removal does not represent any loss of content from the thesis.
Conformément à la loi canadienne sur la protection de la vie privée, quelques formulaires secondaires ont été enlevés de cette thèse.

Bien que ces formulaires aient inclus dans la pagination, il n'y aura aucun contenu manquant.

\section{Canadä}




\section{ABSTRACT}

An investigation into the secondary metabolites of increasingly found Eurotium species, Aspergillus insuetus and $A$. calidoustus isolated from Canadian homes is presented. Mould and dampness in homes is associated with allergic and non-allergic outcomes in humans. Health consequences may partially be the result of toxic secondary metabolites produced by fungi. Pure metabolite toxicity studies are of interest as some metabolites are known to play a role in exacerbation of respiratory illness. Indoor and outdoor isolates of each species were collected over a wide geographical area in Canada. Strains were grown in liquid culture and screened by HPLC and TLC for secondary metabolite production. Major metabolites were determined by spectroscopic analysis.

In this study, E. amstelodami and $E$. rubrum produced the major metabolites: neoechinulin A, neoechinulin $\mathrm{B}$, flavoglaucin, auroglaucin, isotetrahydroauroglaucin and the novel natural product: epiheveadride. The minor metabolites: neoechinulin E, preechinulin and echinulin were detected by LCMS analysis. E. herbariorum produced the above metabolites as well as cladosporin, which may be distinct to this species. Strains of $A$. insuetus and $A$. calidoustus produced three known isoquinoline alkaloids: TMC-120 A, B, C, two novel TMC-120 derivatives and a drimane sesquiterpene and supports the current view that these species are chemically distinct from $A$. ustus cereal isolates with which they were previously grouped. The major metabolites: neoechinulin A, neoechinulin B, cladosporin and TMC-120 A were purified and characterized. Studies on their effects on primary cultures of murine alveolar macrophage cells are underway. 


\section{ACKNOWLEDGEMENTS}

This study was supported by the Natural Science and Engineering Research Council of Canada (NSERC) and by Paracel Laboratories Ltd. (Ottawa, ON).

To begin, I owe most thanks to my supervisor Dr. J. David Miller for giving me the opportunity to work with our group, his guidance and advise on this project and furthering my education to a vast degree. I also greatly appreciate the unconditional help of friend and colleague Mark Sumarah for teaching me essential skills, giving insightful advice and helpful criticism throughout the project. I would also like to thank Dr. Eva Puniani for sharing her knowledge of natural products and great assistance in deciphering many complicated NMR spectra.

I would also like to thank Don Belisle for his fungal expertise, Dr. Barbara Blackwell for her assistance with NMR spectra, Dr. Kristian Nielsen for sample analysis (and providing entertaining nights in Ottawa and Maine) and Dr. J.C Frisvad and Dr. R. Samson for many fungal identifications.

Finally, I would like to acknowledge fellow students, Aaron, Julian and Luke for their stories, outspoken opinions and hard gym workouts after long days in the lab and to Robyn for he support and understanding along the way. Most of all, I would like to thank my family for their encouragement and pretending to understand my work. 


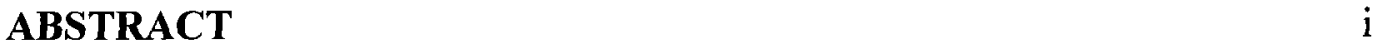

ACKNOWLEDGMENTS

LISTS OF FIGURES iii

LIST OF TABLES V V

REAGENTS AND MATERIALS vii

\section{INTRODUCTION}

1.1 Fungi 1

1.1.1 Identification 2

1.1.2 Chemotaxonomy 3

1.1.3 Eurotium morphology and ecology 5

1.1.4 A. ustus morphology and ecology 7

1.2 Primary and Secondary Metabolism $\quad 8$

1.2.1 Secondary metabolite classification 9

1.2.2 Secondary metabolite regulation $\quad 12$

1.2.3 Mycotoxins in the environment 12

1.3 Fungal Contamination of the Indoor Environment 13

1.3.1 Water activity and temperature 14

1.3.2 Fungal growth on building materials $\quad 17$

1.3.3 Illness 20

1.4 Metabolites of Eurotium and $\boldsymbol{A}$. ustus s.l. 23

1.4.1 Eurotium 23

1.4.1.1 Echinulin 23

1.4.1.2 Physcion 25

1.4.1.3 Flavoglaucin and auroglaucin $\quad 26$

1.4.1.4 Cladosporin $\quad 27$

1.4.2 A. ustus s.l. 28

1.4.2.1 Ophiobolin G \& H $\quad 29$

1.4.2.2 TMC-120 A-C 30

1.4.2.3 Drimanes 30

1.5 Analytical Methods for Detection 31

$\begin{array}{ll}\text { 1.6 Project Aim } & 33\end{array}$ 


\section{MATERIALS AND METHODS}

2.1 Growth and Extraction of Fungal Strains 35

2.1.1 Fungal strains $\quad 35$

$\begin{array}{ll}\text { 2.1.2 Single spore isolate preparation } & 37\end{array}$

2.1.3 Culture fermentation $\quad 38$

2.1.4 Culture extraction $\quad 38$

2.2 Metabolite Screening of Fungal Strains $\quad 40$

2.2.1 Thin layer chromatography (TLC) 40

2.2.2 Analysis by HPLC-DAD 41

2.2.3 Large scale fermentation and extraction of selected strains $\quad 42$

2.3 Preparatory Methods for Metabolites Isolation 43

2.3.1 Preparatory-TLC 43

$\begin{array}{ll}\text { 2.3.2 Preparatory-HPLC } & 43\end{array}$

2.3.3 Silica gel chromatography column 44

2.3.4 Solid phase extraction sorbent columns $\quad 45$

2.4 Metabolite Isolation and Purification from Selected Strains 46

2.4.1 E. amstelodomi strains IBT 28307 and J9589-1 filtrate extract 46

2.4.2 E. herbariorum strains CBS 47-F8 and CBS 47-F9 filtrate extact 47

2.4.3 E. amstelodami and E. herbariorum mycelial extracts 48

2.4.4 A. ustus s.l. strains IBT 28269 and IBT 28272 filtrate extract 49

2.5 Quantitation of Metabolites and Method Validation 51

2.5.1 Standard curve 51

2.5.2 Recovery $\quad 52$

2.5.3 Recovery of metabolites from prep-TLC plates 53

2.6 Instrumentation 54

\section{RESULTS}

3.1 Initial Culture Fermentation

3.2 Secondary Metabolites of $\boldsymbol{E}$. amstelodami Filtrate Extract

3.2.1 Strain screening for major metabolites $\quad 59$

$\begin{array}{ll}\text { 3.2.2 Major metabolite determination } & 61\end{array}$

3.3.3 Minor metabolite determination $\quad 68$

$\begin{array}{ll}\text { 3.2.4 Metabolite assignments and quantities } & 70\end{array}$

3.3 Secondary Metabolites of $\boldsymbol{E}$. herbariorum Filtrate Extract 71

3.3.1 Strain screening for major metabolites $\quad 71$

$\begin{array}{ll}\text { 3.3.2 Major metabolite determination } & 73\end{array}$

3.3.3 Minor metabolite determination $\quad 76$

$\begin{array}{ll}\text { 3.3.4 Metabolite assignments and quantities } & 78\end{array}$

3.4 Secondary Metabolites of $\boldsymbol{E}$. amstelodami and $\boldsymbol{E}$. herbariorum Cellular $\quad 79$ Extract

3.4.1 Major metabolite determination $\quad 80$

3.4.2 Metabolite assignments and quantities $\quad 84$

3.5 Secondary Metabolites of $\boldsymbol{A}$. ustus s.l. Filtrate Extract 86

3.5.1 Major metabolite determination $\quad 88$ 
3.5.2 Minor metabolite determination

$\begin{array}{ll}\text { 3.5.3 Metabolite assignments and quantities } & 98\end{array}$

3.6 Secondary Metabolite Production $\quad 99$

3.6.1 Extraction method $\quad 99$

3.6.2 Metabolite production in Eurotium 100

3.6.3 Metabolite production in A. ustus s.l. $\quad 105$

3.7 Purity of Compounds Used for Toxicity Studies 106

$\begin{array}{ll}\text { 4. DISCUSSION } & 108\end{array}$

5. REFERENCES 123

6. APPENDIX 137 


\section{LIST OF FIGURES}

Figure Title $\quad$ Page

$1 \quad$ Conidiophores characteristic of Aspergillus species 4

2 E. amstelodami on MEA and E. amstelodami aspergillum 6

3 A. ustus s.l. on MEA and A. ustus aspergillum 8

4 Secondary metabolism scheme 11

5 Structure of echinulin 24

$\begin{array}{lll}6 & \text { Structure of physcion } & 25\end{array}$

$\begin{array}{lll}7 & \text { Structures of flavoglaucin and auroglaucin } & 26\end{array}$

$\begin{array}{lll}8 & \text { Structure of cladosporin } & 27\end{array}$

9 Structures of ophiobolin $\mathrm{G}$ and $\mathrm{H} \quad 29$

10 Structures of TMC-120 A-C 30

11 Structure of a drimane sesquiterpene 31

12 HPLC-DAD chromatogram of filtrate extract of E. amstelodami strain 60 IBT 28307 with assigned peak numbers

13 TLC plate drawing of major metabolites from E. amstelodami strain $\quad 60$ IBT 28307 filtrate extract with $R_{f}$ values and compound number indicated

14 Structures of neoechinulin A and neoechinulin B 64

$\begin{array}{lll}15 & \text { Structure of epiheveadride } & 67\end{array}$

16 Structure of preechinulin $\quad 69$

17 Structure of neoechinulin E $\quad 69$

$\begin{array}{lll}18 & \text { Structure of echinulin } & 70\end{array}$

19 HPLC-DAD chromatogram of the filtrate extract of E. amstelodami 71 strain IBT 28307 
20 HPLC-DAD chromatogram of filtrate extract of $E$. herbariorum strain 72 CBS 47-F9 with assigned peak numbers

21 TLC plate drawing of major metabolites of $E$. herbariorum strain CBS 73 47-F9 filtrate extract with $R_{f}$ values and peak numbers indicated

$\begin{array}{lll}22 & \text { Structure of cladosporin } & 75\end{array}$

$\begin{array}{lll}23 & \text { Structure of questin } & 77\end{array}$

24 HPLC-DAD chromatogram of the filtrate extract of E. herbariorum $\quad 78$ strain CBS 47-F9 with metabolites indicated

25 HPLC-DAD chromatogram of mycelial extract of a typical $E$. amstelodami and $E$. herbariorum strain with assigned peaks numbers

26 TLC plate drawing of major metabolites from $E$. herbariorum strain CBS 47-F9 cellular extract with $R_{f}$ values and compound numbers indicated

27 Structures of flavoglaucin, auroglaucin and isotetrahydroauroglaucin

28 HPLC-DAD chromatogram of mycelial extract of a typical $E$. amstelodami or E. herbariorum with major metabolites indicated

29 HPLC-DAD chromatogram of the filtrate extract of $A$. ustus s.l. strain IBT 28269 with assigned peak numbers

30 TLC plate drawing of major metabolites from $A$. ustus s.l. strain IBT 28269 filtrate extract with $\mathrm{R}_{\mathrm{f}}$ values and compound numbers indicated

31 Structures of TMC-120 A, C and two novel derivatives

32 Structure of a drimane (drim-7-en-11,12-oide fragment) 96

$33 \quad$ Structure of TMC-120 B $\quad 98$

34 HPLC-DAD chromatogram of the filtrate extract of $A$. ustus s.l. strain $\quad 98$ IBT 28269 with metabolites indicated

35 Summary of Eurotium metabolites 


\section{LIST OF TABLES}

\begin{tabular}{llc}
\hline Table Title & Page \\
\hline
\end{tabular}

1A E. amstelodami strains 36

1B E. herbariorum strains 36

1C E. rubrum strains 36

1D A. ustus s.l. strains $\quad 37$

2 HPLC-DAD timetable for metabolite analysis 42

$3 \quad$ Prep-HPLC timetable for isolation of $A$. ustus s.l. metabolites $\quad 50$

4A Comparison of E. amstelodami dry mycelial weight on two media 57

4B Comparison of E. herbariorum dry mycelial weight on two media 57

4C Comparison of E. rubrum dry mycelial weight on two media $\quad 58$

4D Comparison of A. ustus s.l. dry mycelial weight on two media 58

5 Comparative ${ }^{1} \mathrm{H}$ and ${ }^{13} \mathrm{C}$ NMR data for 1 and $2\left(400 \mathrm{MHz}, \mathrm{CD}_{3} \mathrm{CN}\right)$

$6 \quad{ }^{1} \mathrm{H}$ and ${ }^{13} \mathrm{C}$ NMR data for $4\left(400 \mathrm{MHz}, \mathrm{CD}_{3} \mathrm{CN}\right) \quad 68$

$7 \quad$ Major secondary metabolites isolated from filtrate extracts of $E$. 71 amstelodami strains

$8 \quad{ }^{1} \mathrm{H}$ and ${ }^{13} \mathrm{C}$ NMR data for $5\left(400 \mathrm{MHz}, \mathrm{CDCl}_{3}\right)$

$9 \quad$ Major secondary metabolites isolated from filtrate extracts of $E$. $\quad 78$ herbariorum

$10 \quad{ }^{13} \mathrm{C}$ and ${ }^{1} \mathrm{H}$ NMR data of $\mathbf{1 2}$ and the ${ }^{1} \mathrm{H}$ NMR data for $\mathbf{1 3}$ and $\mathbf{1 4}(400$ $\mathrm{MHz}, \mathrm{CD}_{3} \mathrm{CN}$ )

11 Major secondary metabolites isolated from cellular extracts of 85 E.amstelodami and E. herbariorum

12A Comparative ${ }^{1}$ H NMR data for $\mathbf{1 5}$ and $\mathbf{1 6}$ and the novel metabolites $\mathbf{1 7} 94$ and $18\left(300 \mathrm{MHz}, \mathrm{CD}_{3} \mathrm{CN}\right)$ 
12B Comparative ${ }^{13} \mathrm{C}$ NMR data for $\mathbf{1 5}$ and $\mathbf{1 6}$ and the novel metabolites $\mathbf{1 7} 94$ and $18\left(300 \mathrm{MHz}, \mathrm{CD}_{3} \mathrm{CN}\right)$

$13 \quad$ Key COSY and HMBC correlations for novel metabolites $\mathbf{1 7}$ and $\mathbf{1 8} 95$

$14 \quad{ }^{1} \mathrm{H}$ and ${ }^{13} \mathrm{C}$ NMR data for $19\left(400 \mathrm{MHz}, \mathrm{CD}_{3} \mathrm{CN}\right)$

15 Secondary metabolites isolated from extracts of $A$. ustus s.l. 99

16A Compound recoveries from Eurotium $\quad 100$

16B Compound recoveries from A. ustus s.l. $\quad 100$

17A E. amstelodami filtrate metabolite production 101

17B E. herbariorum filtrate metabolite production 101

$\begin{array}{ll}\text { 17C E. rubrum filtrate metabolite production } & 102\end{array}$

18A E. amstelodami cellular extract metabolite production 103

18B E. herbariorum cellular extract metabolite production 103

18C E. rubrum cellular extract metabolite production 104

19A E. amstelodami and E. herbariorum mycelial dry weight on CYA 104

19B E. amstelodami and E. herbariorum filtrate metabolite production on 105 CYA (20\% sucrose)

19C E. amstelodami and E. herbariorum mycelial metabolite production on 105 CYA (20\% sucrose)

20 A. ustus s.l. filtrate metabolite production 106 


\section{REAGENTS AND MATERIALS}

acetone $\left(\mathrm{C}_{3} \mathrm{H}_{6} \mathrm{O}\right)$, certified A.C.S. reagent, 4 L. Fisher Scientific, Fisher Chemicals, N.J., USA. Cat. No. A18-4

acetone- $\mathrm{d}_{6}\left(\mathrm{C}_{3} \mathrm{D}_{6} \mathrm{O}\right), 99.9$ atom \% D, 25 g. Aldrich, St. Louis, USA. Cat. No. 444863

acetonitrile $\left(\mathrm{CH}_{3} \mathrm{CN}\right)$, certified A.C.S. reagent, 4 L. Fisher Scientific, Fisher Chemicals, N.J., USA. Cat. No. A21-4

acetonitrile-d $\mathrm{d}_{3}\left(\mathrm{CD}_{3} \mathrm{CN}\right), 99.8$ atom \% D, 25 g. Sigma-Aldrich, St. Louis, USA. Cat. No. 2206-26-0

agar-agar, granulated, purified and free from inhibitors for microbiology, $1 \mathrm{~kg}$. EMD Chemicals Inc., Gibbstown, N.J. Cat. No. 1.01614.1000

ammonium acetate, SigmaUltra, $\geq 98 \%, 500$ g. Sigma-Aldrich, St. Louis, USA. Cat. No. A7330-500G

ammonium molybdate, 100 g. Sigma-Aldrich, St. Louis, USA. Cat. No. A1343$100 \mathrm{G}$

benzene, A.C.S. reagent, 99 \%, 1 L. Sigma-Aldrich, St. Louis, USA. Cat. No. $71-43-2$

cerium (IV) sulphate, reagent powder 92\% (Titr.). Acros, N.J., USA. Cat. No. 40434-1000

chloroform $\left(\mathrm{CHCl}_{3}\right)$, certified A.C.S. reagent, 4 L. Fisher Scientific, Fisher Chemicals, N.J., USA. Cat. No. C298-4

chloroform- $\mathrm{d}_{1}\left(\mathrm{CDCl}_{3}\right),+1 \%$ TMS v/v, certified A.C.S. reagent, 99.8 atom \% D, 100 mL. Sigma-Aldrich, St. Louis, USA. Cat. No. 151823

culture tubes, plain, Kimble, The Tubular Group, Vineland, N.J. Cat. No. 4506016150

dipotassium hydrogenphosphate, A.C.S. reagent, $\geq 98 \%, 500$ g. Sigma-Aldrich, St. Louis, USA. Cat. No. P3786

ethyl acetate, spectranalyzed, 4L. Fisher Scientific, Fisher Chemicals, N.J., USA. Cat. No. E189-4 
filter paper, Whatman \#1 filter paper qualitative circles $24.0 \mathrm{~cm}$. Whatman Schleicher \& Schuell, England. Cat. No. 1001-240

filter paper, Whatman \#4 filter paper qualitative $24.0 \mathrm{~cm}$. Whatman Schleicher \& Schuell, England. Cat. No. 1004-240

hexane, 95\% n-hexane, Baker analyzed HPLC solvent, 4 L. J.T. Baker, Mallinckrodt Baker Inc., Phillipsburg, N.J. Cat. No. 9304-03

iron sulphate $\left(\mathrm{FeSO}_{4} \cdot \mathrm{H}_{2} 0\right)$, Baker analyzed reagent, granular, 1 lb. J.T. Baker Chemical Co., Phillipsburg, N.J. Cat. No. 1-2070

laboratory film, Parafilm. Pechiney Plastic Packaging, Chicago, IL. Cat. No. 54952

magnesium sulphate $\left(\mathrm{MgSO}_{4} \cdot 7 \mathrm{H}_{2} 0\right), 500$ g. VWR International. Cat. No. CAJT2504-1

malt extract, 500 g. Sigma-Aldrich, St. Louis, USA. Cat. No. M0383

methanol $(\mathrm{MeOH})$, certified A.C.S. reagent, 4 L. Fisher Scientific, Fisher Chemicals, N.J., USA. Cat. No. A412-4

ochratoxin A, from A. ochraceus, $1 \mathrm{mg}$. Sigma-Aldrich, St. Louis, USA. Cat. No. 01877

petri dishes, sterilized-disposable plastic, 100 O.D. x $15 \mathrm{~mm} \mathrm{H}$. Fisher Brand, Fisher Scientific, N.J., USA. Cat. No. 08-757-12

preparative layer chromotography plates, Partisil PK5F silica gel $150 \AA$ with fluorescent indicator, size $20 \times 20 \mathrm{~cm}$, layer thickness: $1000 \mu \mathrm{m}$. VWR, Whatman International Ltd. Maidstone England. Cat. No. WC 4860-820

preparative layer chromotography plates, $60 \AA$ silica gel 60 F254, size $20 \times 20$ $\mathrm{cm}$, layer thickness: $2000 \mu \mathrm{m}$. VWR, Whatman International Ltd. Maidstone England. Cat. No. EM-5717-7

roux bottle, Pyrex brand Roux bottles with offset neck, $1000 \mathrm{~mL}$. Sigma-Aldrich, St. Louis, USA. Cat. No. CLS12901L

silica gel, DEAE Sephadex A-25, 100 g. Amersham Pharmacia Biotech AB, Uppsala Sweden. Cat. No. 17-0170-01

silica gel, Grade 60, 70-230 Mesh, 1 kg. Sigma-Aldrich Inc., St. Louis, USA. Cat. No. S2509 
sodium chloride $(\mathrm{NaCl})$, A.C.S. analytical reagent, 500 g. BDH Inc., Toronto Canada. Cat. No. ACS5645

sodium nitrate $\left(\mathrm{NaNO}_{3}\right)$, minimum $99.0 \%, 250$ g. Sigma-Aldrich, St. Louis, USA. Cat. No. S-5506

sodium sulphate $\left(\mathrm{Na}_{2} \mathrm{SO}_{4}\right)$, anhydrous granular, $2.5 \mathrm{~kg}$. Caledon Laboratories Ltd. Georgetown, Canada. Cat. No. 82201

sterigmatocystin, 5 mg. Sigma-Aldrich, St. Louis, USA. Cat. No. S3255

strata X SPE column, polymeric solid phase extraction (SPE) sorbents, strata-x$33 \mu \mathrm{m}$ polymeric reversed phase $1 \mathrm{~g} / 12 \mathrm{~mL}$ giga tube. Phenomenex, California, USA. Cat. No. 8B-S100-JDG

sucrose, A.C.S. reagent, 500 g. Sigma-Aldrich, St. Louis, USA. Cat. No. S5016

sulfuric acid $\left(\mathrm{H}_{2} \mathrm{SO}_{4}\right)$, A.C.S. reagent, Anachemia, Montreal Quebec. Cat. No. 4614-466

sand, white quartz, $-50+70$ mesh, $5 \mathrm{~kg}$. Sigma-Aldrich, St. Louis USA. Cat. No. $5-98875$

syringe filters, $13 \mathrm{~mm}$ Puradisc PTFE syringe filter with $0.2 \mu \mathrm{m}$ membrane. VWR International. Cat No. 28143-926

test tubes, glass borosilicate, $10 \mathrm{~mL}$. VWR International. Cat. No. $89000-480$

thin layer chromatography plates, silica gel $60 \AA$ F254 precoated aluminum, 0.2 mm EMD, Darmstadt, Germany. Cat. No. 5534-3

thin layer chromotography plates, Partisil K6 Silica gel $60 \AA$, size $20 \times 20 \mathrm{~cm}$, layer thickness: $250 \mu \mathrm{m}$. VWR, Whatman International Ltd. Maidstone England. Cat. No. WC 4851-840

triflouroacetic acid, reagent grade, $500 \mathrm{~mL}$. Fisher Scientific, Fisher Chemicals, N.J., USA. Cat. No. 04901-500

tween 20, Sigma Ultra, 500 mL. Sigma-Aldrich, St. Louis, USA. Cat. No. P7949

vials, screw thread amber, $12 \mathrm{~mL}$. Kimble Glass Inc, Vineland N.J., USA. Cat. No. 60815-1965

yeast extract, powder, $1 \mathrm{~kg}$. Sigma Aldrich, St. Louis, USA. Cat. No. Y-0375 


\section{INTRODUCTION}

\subsection{Fungi}

Fungi have an enormous and sometimes unseen impact on mankind and comprise about one quarter of the planets biomass (Miller, 1992). They are not only essential in production of alcoholic beverages and medicines such as penicillin, but they are food, biocontrol agents, recyclers of decaying matter, and can cause crop and animal disease and food spoilage (Smedsgaard \& Nielsen, 2004a).

The fungal kingdom consists of approximately 100000 described species which are divided into three groups based on reproduction and morphology: ascomycetes, basidiomycetes and zygomycetes. Fungi are heterotrophic organisms which are saprophytes, parasites or endophytes. The term mould refers to fungi that grow in multicellular filaments called hyphae and is not a specific taxonomic or phylogenetic grouping. They are mostly anamorphic ascomycetes and zygomycetes (Burnett, 2003).

The vegetative structure of these fungi is the hyphal filament. The large surface area of the hyphae allows essential materials of growth to be absorbed from the environment and waste products excreted. As hyphae grow, lateral branches develop behind the tip area and the protoplasm moves forward occupying newly formed areas. An empty outer casing is left behind and the entire mass of hyphae is referred to as mycelium (Smith \& Berry, 1974). 
The fungal spore is specialized in reproduction, dispersal and survival. Sexual or asexual spores develop and are released from the parent body following vegetative growth. Asexual spores are produced by mitotic division while sexual spores are derived via meiosis resulting in genetic recombination. These spores may remain in a dormant state of a low metabolic rate until activation factors or essential external factors such as nutrient availability or water are present (Smith \& Berry, 1974).

\subsubsection{Identification}

With the characterization of huge numbers of fungal species and their sometimes limited study, classification has been traditionally based on readily observable morphological features. Fungal colony diameter, speed of growth, and colour can be examined on different types of media such as Czapek yeast autolysate (CYA), yeast extract sucrose (YES), creatine sucrose agar (CREA) and malt extract agar (MEA). This approach may be limited due to its lack of standardized terminology and subjectivity. Problems with culture growth and environmentally-dependent characteristics play a large role in identification (Guarro et al., 1999). On occasion, microscopy techniques may fail in identification due to similarities in the morphology of similar species (Frisvad et al., 1989).

Fungi are also classified based on the structures associated with sexual reproduction. Some fungi reproduce asexually while others have both asexual and sexual states. Environmental conditions or other factors may affect the prevalence of a sexual state. Mixed fungal colonies sporulate amongst each other making it difficult to link the various 
states of the same fungus. At present, asexual fungi (anamorphs) are given separate names from their sexual states (teleomorphs) (Flannigan, 2001).

The genus Aspergillus comprises approximately 150 species that occur in soil, stored food, feed products, decaying vegetation, built environments and can be parasites to plants and animals (Samson \& Pitt, 2000). The genus was first described by Micheli in 1729. It is characterized by conidial heads that consist of asexually produced spores (conidia) borne in chains from cells (phialides) (Figure 1). These phialides develop on a vesicle of a stipe which arises from the foot of the cell. The aspergillum is comprised of the swollen vesicle and the reproductive cells it bears. The structure including the aspergillium, stipe and foot of the cell is called the conidiophore (Klich \& Pitt, 1988). Some species of Aspergillus reproduce sexually and therefore have teleomorphic states. These states are characterized by the formation of asci containing inordinately arranged ascospores within the ascocarp. The asci break down in age leaving mature ascospores. Size, shape, colour and surface texture of fungal colonies are important in the identification of teleomorphic species (Klich \& Pitt, 1988). 


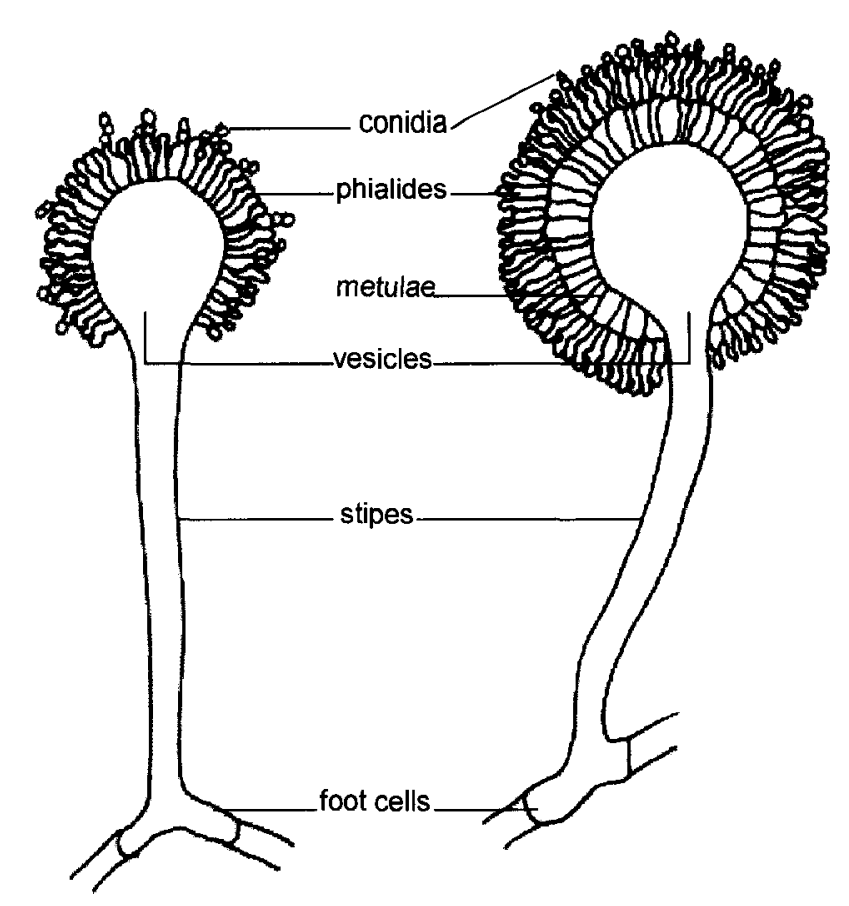

Figure 1: Conidiophores characteristic of Aspergillus species: (left) uniceriate aspergillum of $A$. equitus; (right) biseriate aspergillum of $A$. ochraceus (adapted from Klich \& Pitt, 1988).

\subsubsection{Chemotaxonomy}

Chemotaxonomy has proven to be an effective tool in identification of lichens and some fungi such as Penicillium, Aspergillus and Fusarium (Larsen et al., 2005). Developments of analytical methodology have allowed the use of secondary metabolite profiling for fungal identification and has been used to revise the taxonomy within many genera. Classification of filamentous fungi by metabolite profiling relies on the fact that most fungal growth is expressed by the production of diverse metabolites (Nielsen et al., 2003a). Most often the metabolites of any one species are consistently expressed and chemotaxonomy is based on metabolite profiles and not on any one product (Smedsgaard \& Nielsen, 2004). Many erroneous claims of metabolite production have been made and are due to misidentification or mixtures of fungal species (Frisvad, 1989). Molecular biologists 
may also aid in identification by sequencing representatives of the species. However, this method is only useful when successful isolations of reference strains are available (Nielsen, 2003b).

Secondary metabolite production amongst fungi is species and even strain specific (Smedsgaard \& Nielsen, 2004). Variability in properties and the spontaneous occurrence of variant lines within single strains has been reported and often result from suboptimal growth conditions producing inconsistent quantitative results. This is important during the selection and maintenance of strains of industrial importance and in the construction of taxonomic schemes (Frisvad et al., 2006). Single spore isolates were used during the chemotaxonomic study of $A$. ustus s.l. and Eurotium in this thesis.

\subsubsection{Eurotium morphology and ecology:}

The teleomorphic state of Aspergillus glaucus (Thom \& Church) are the Eurotium species: E. amstelodami, E. chevalieri, E. herbariorum, E. repens and E. rubrum. The later three are sometimes referred to collectively as E. herbariorum, as only small morphological differences exist between them (Domsch et al., 1980). E. repens differs from $E$. herbariorum by the formation of ascospores without a distinct furrow. $E$. rubrum has ascopsores with a more distinct furrow and the hyphae turn brick red with age (Klich, 2002). The distinguishing features of E. amstelodami are the yellow

cleistothecia with hyaline, rough-walled ascospores each with a furrow and two longitudal ridges (Malloch \& Cain, 1972). Stipes are smooth-walled, uncolored to pale 
brown. Vesicles are subglobose to spathulate, uncolored to pale brown. Conidia are spherical to ellipsoidal, surface texture rough to spiny (Klich \& Pitt, 1988).

Eurotium species are xerophilic and can grow well in extremely dry situations (Malloch $\&$ Cain, 1972). These fungi are most commonly encountered in tropical and subtropical regions frequently isolated from soils and dried or concentrated food products (Abellana et al., 1999). Eurotium is increasingly found in indoor environments on textile and gypsum wallboard samples and ceiling tiles (Flannigan et al., 2001; Miller, 2008a). It has also been isolated indoors from floor, carpet and mattress dust, hospital air, shoes as well as hypersaline waters and the Dead Sea (Butinar et al., 2005).

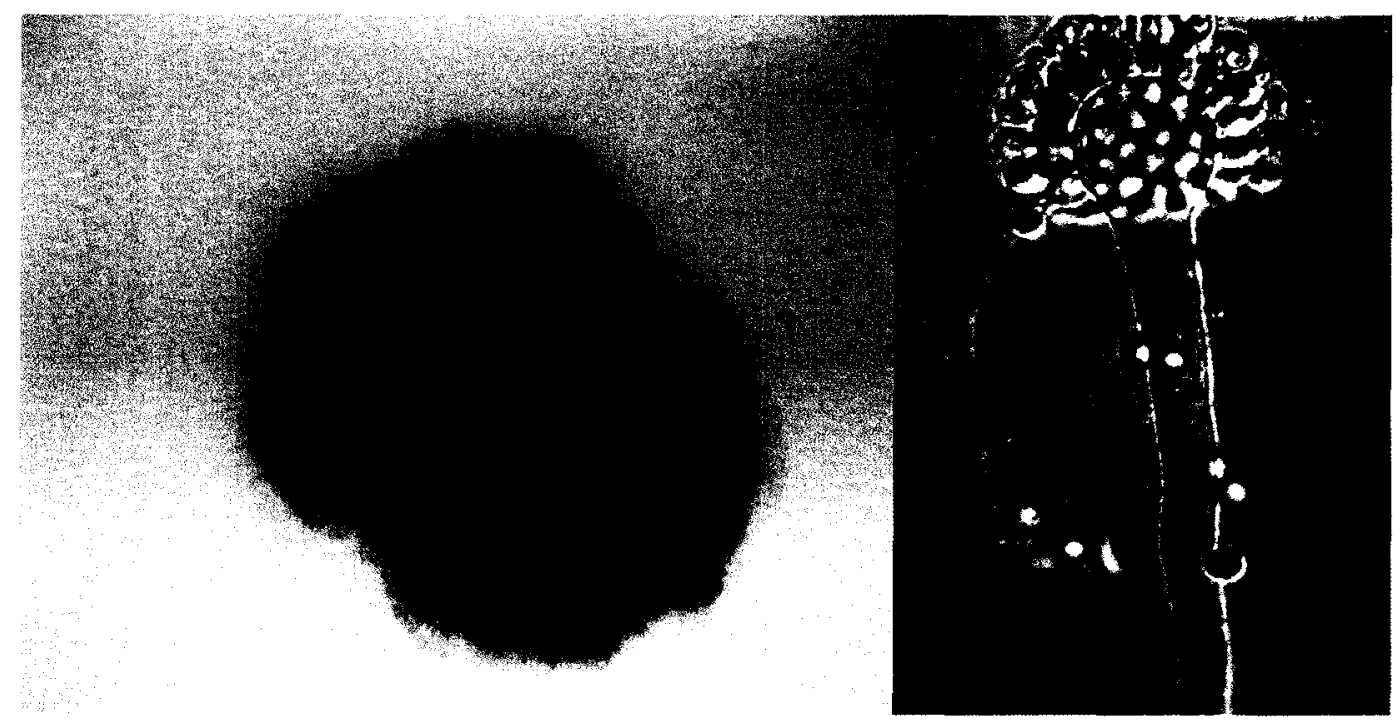

Figure 2: E. amstelodami on MEA and E. amstelodami aspergillum (used by permission, CBS Fungal Biodiversity Centre) 


\subsubsection{Aspergillus ustus morphology and ecology:}

A. ustus (Bainer) Thom \& Church produces colonies on potato dextrose agar that are white, yellow, and brown but commonly grey. Reverse is yellow to brown with a yellow diffusing pigment. Hyphae are septate and hyaline. Conidial heads are radiate to loosely columnar and biseriate while conidiophores are smooth-walled, and brown. Vesicles are globose to subglobose while conidia are globose with rough walls. Metulae and phialides cover the upper portion of the vesicle (Klich \& Pitt, 1988). This species is present in low frequencies in soils from tropic and subtropic areas and is found indoors (Samson et al., 2001; Miller et al., 2008b).

In 1975, Samson \& Mouchacca first described A. pseudodeflectus (CBS 495.65) from $A$. ustus, isolated from Egypt in desert soil. The species was later reduced to A. ustus var. pseudodeflectus (Kozakiewicz, 1989) because of the brown colony colour developing on malt agar and typical of the $A$. ustus group. A. ustus var. pseudodeflectus differs from $A$. ustus by the absence of hulle cells and the curved conidiphores, giving the appearance of nodding (Mouchacca, 2007). However, the reduction to the varietal rank was not supported by Pitt et al. (2000) and the species was described as A. pseudodeflectus. Upon completion of this thesis, A. insuetus and A. calidoustus were separated from $A$. ustus based of chemical, molecular and morphological data (Houbraken et al., 2007). Except where indicated, these are called $A$. ustus sensu lato (s.l.) throughout, as not all strains were identified by the authors of the taxonomic revision. 


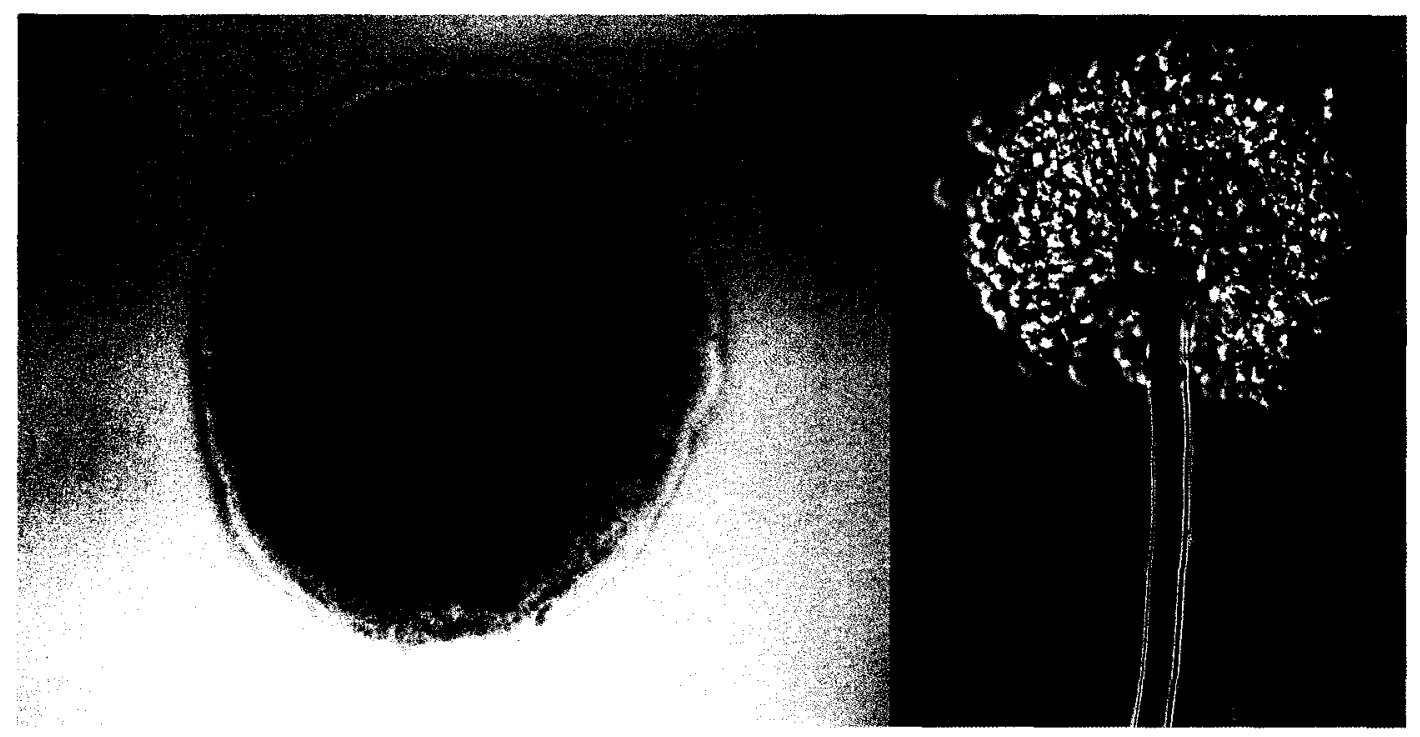

Figure 3: A. ustus s.l. on MEA and A. ustus aspergillum (used by permission, CBS Fungal Biodiversity Centre)

\subsection{Primary and Secondary Metabolism}

Living organisms synthesize and degrade essential chemical compounds by a series of enzymatically mediated reactions. These reactions are known collectively as metabolism. The major metabolic pathways of glycolysis and the Krebs cycle result in production of major primary metabolites such as acetyl-CoA, shikimic acid and mevalonic acid. These primary metabolites are precursors to essential structural components of the organism and include carbohydrates, fatty acids, proteins and nucleic acids (Mann, 1987). It is only toxic secondary metabolites that can be referred to as mycotoxins which are usually below one $\mathrm{kDa}$ in size (Jarvis \& Miller, 2005).

Secondary metabolites or natural products were first thought to be non-essential compounds produced by an organism during secondary metabolism. Unlike primary metabolites, secondary metabolites can be species or strain specific, with genetic and 
environmental factors playing influence in their production. Strong evidence now supports their ecological significance, acting as a toxic defense mechanism activated upon stress towards other fungi, bacteria, plants or animals (Gloer, 1995; Wicklow, 1981). Resource competition by behavioral or chemical interaction is hypothesized to play a role in fungal survival and reproduction. Fungi which colonize seeds, fruit or other substrates may produce toxic metabolites, rendering these substrates unattractive to animals or slow invasive species. These metabolites are classified according to small molecular precursors in which they are derived. The dividing line between these two pathways is complex since both are interconnected, primary metabolites being precursors for all secondary metabolites (Bu'Lock, 1975).

\subsubsection{Secondary metabolite classification}

Despite their diversity, secondary metabolites are derived from three major building blocks and include acetate (deriving fatty acids, polyketides and isoprenoids), shikimic acid (leading to cinnamic acid, phenols and aromatic and amino acid precursor) and amino acids (forming alkaloids and peptide antibiotics); (Mann, 1987).

A large number of natural products are derived from acetyl-coenzyme A (formed from acetate) such as toxins, immunosuppresants and antibiotics. Acetyl-coenzyme A is a basic building block of fatty acids, polyketides and isoprenoids. However, there are two major pathways for their biosynthesis. The first pathway proceeds by the addition of $\mathrm{C}_{2}$ units to produce the linear polyketide chain, which when modified can produce fatty acids and derivatives. Polyketide synthesis occurs when a molecule of acetate condenses 
with three or more molecules of malonate to form a polyketomethylene (polyketide) chain which can undergo many different transformations (Torssell, 1983).

Acetate metabolism may also produce a structurally diverse group of metabolites known as isoprenoids or terpenoids via an alternate biosynthetic pathway. Mevalonic acid, which is produced from acetyl coA, undergoes a series of reactions producing the biological $\mathrm{C}_{5}$ or isoprene units which are the building blocks for terpene biosynthesis. Examples are menthol, cholesterol, vitamins $\mathrm{A}$ and $\mathrm{D}$ and the trichothecene mycotoxins (Mann, 1987).

The shikimate pathway gives rise to aromatic compounds such as the aromatic amino acids, phenylalanine and tyrosine. The starting material of the synthesis of shikimic acid is erythrose-4phosphate and phosphoenolpyruvate. These are both involved in the primary metabolism of sugars. Most intermediate steps in this pathway are understood but yet the chemistry is probably more complex. Shikimate metabolites do not usually contain nitrogen and are coumarins and cinnamic acid amongst others (Torssell, 1983).

The main metabolites derived from amino acids are called alkaloids and have interesting pharmacological properties. Compounds such as cocaine, nicotine and ephedrine are well-known examples of alkaloids. Some of these are formally shikimate metabolites but usually contain at least one nitrogen. Most alkaloids are derived from the metabolism of aliphatic amino acids and the aromatic amino acids phenylalanine, tyrosine and tryptophan. Several of these compounds contain a tryptophan derived indole nucleus 
which has consequences on the central nervous system of experimental animals (Steyn, 1998). Other alkaloids may be referred to as diketopiperazines and are cyclic organic compounds that result from peptide bonds between two amino acids.

The final class of secondary metabolites are the peptides, and are with a few exceptions, antibiotics. They are the amino acid derived compounds and can be formed from either a linear peptide or a cyclic peptide (Mann, 1987).

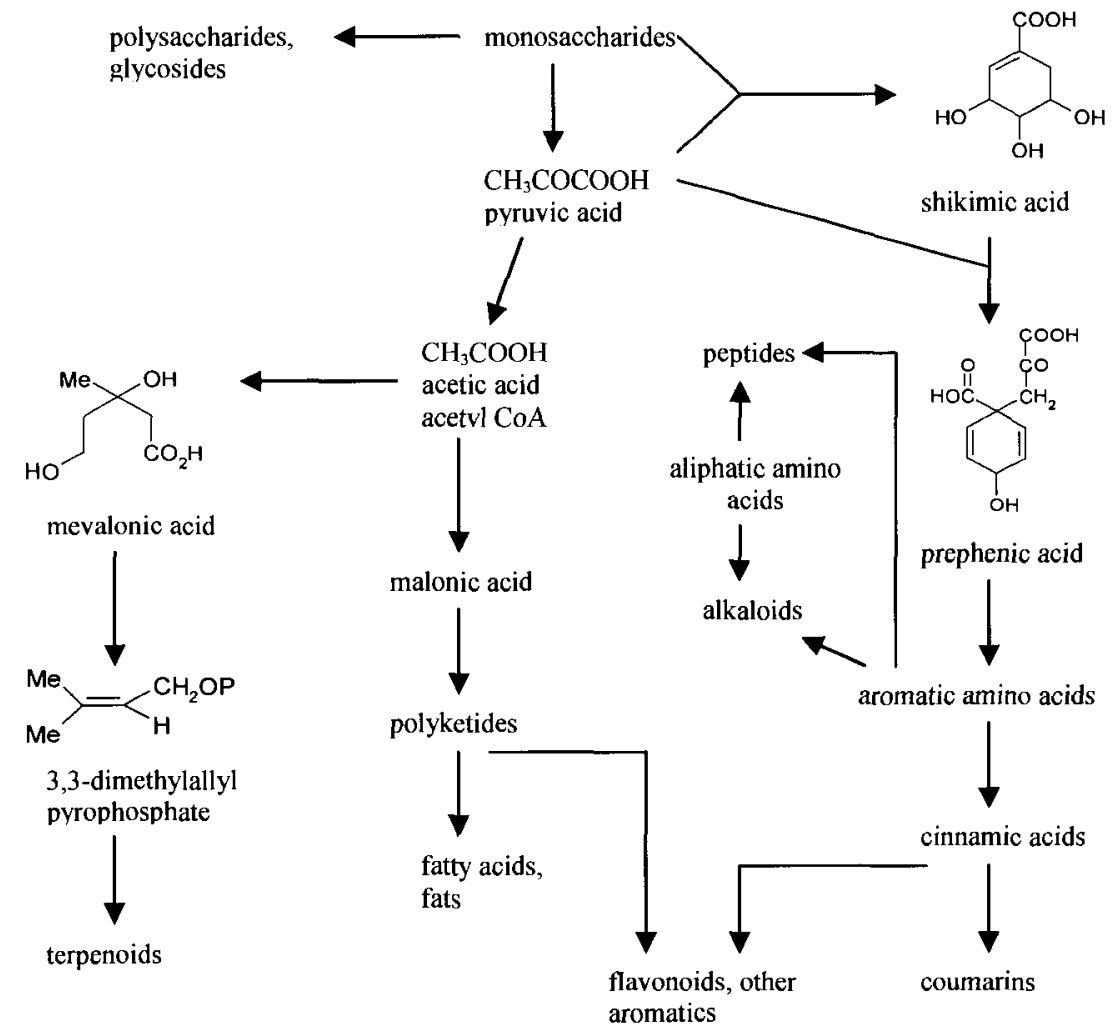

Figure 4: Secondary metabolism scheme (modified from Torssell, 1983) 


\subsubsection{Secondary metabolite regulation}

Fungal populations may compete for the same resource in the environment. Fungal antagonism is usually characterized as the mechanism that enables early colonists of a substrate to gain a foothold and inhibit the invasion of other fungi. It is now widely accepted that toxic metabolites produced by a fungal colonist may act to slow or prevent the invasion of other species (Wicklow, 1981).

Wicklow described a hypothetical situation in which two species of fungi (one being a toxin producer) with similar nutrient requirements invade opposite sides of a nutrient-rich substrate and grow to meet each other. Initially, growth is rapid during infinite nutrient availability and toxin production is negligible (Smith \& Berry, 1974). After nutrient depletion, both organisms enter a stationary phase of growth. Absorption of remaining substrate carbohydrates may occur but contrary to synthesizing metabolically active cell constituents, toxins are produced by the antagonist via the pathways described. Excretion is consistent with selection against assimilating toxic material in the cytoplasm (Vanek et al., 1981; Vining, 1990) and the antagonist is likely less sensitive to its antibiotics than the competitor. The antagonist might eventually replace the competitor entirely throughout the substrate (Wicklow, 1981).

\subsubsection{Mycotoxins in the environment}

There are approximately 350-400 fungal metabolites that are considered toxic (Samson 1992; Bunger et al., 2004). Aspergillus, Penicillium and Fusarium are important mycotoxigenic species that pose a threat to humans and animals alike (Tobin et al., 1987; 
Sweeney \& Dobson, 1998). The majority of mycotoxins are non-volatile and exposure is largely due to inhalation of spores and mycelial fragments (Jarvis \& Miller, 2005). Studies have demonstrated that inhalation exposure of mycotoxins in agricultural circumstances may lead to human disease (Miller et al., 1991).

Inhalation exposure to $S$. chartarum-contaminated material such as mouldy straw has resulted in disease in farm animals and workers and is mainly due to the potent trichothecene mycotoxins produced by this fungus (Miller et al., 2003). In the built environment, case reports of lung damage and pulmonary hemosiderosis in sick infants and children have appeared, most notably in Cleveland by Dearborn et al. (1994). These health effects were related to $S$. chartarum exposure. However, difficulties arise in assessing the constituents which mediate disease as spores and mycelial fragments may be a mixture of bioactive $\beta 1,3$ glucans, allergenic proteins and mycotoxins which can penetrate into proximal lung airways. Epidemiological studies by Dales et al $(1991 \mathrm{a}, \mathrm{b})$ observed that symptoms associated with indoor mould could not be attributed to allergy alone and may be partially due to mycotoxin production (NAS, 2000). Many in vitro and in vivo studies have shown that building-associated Penicillium and S. chartarum spores can induce significant inflammatory responses in lung cells and animal models of lung disease.

\subsection{Fungal Contamination of the Indoor Environment}

As there is little variation on a worldwide basis on the fungi recovered from outdoor air, there appears to be little variation in the mycobiota of building materials in different parts 
of the world. This reflects the widespread adoption of particular building materials such as gypsum board, the reduction of air exchange in buildings and the increase in conditioning the indoor environment to $20-25^{\circ} \mathrm{C}$ regardless of outdoor conditions.

Fungal spores originating from the outdoor environment, mostly from soil are capable of transport into built environments on soil particles transported by wind or aboard other vectors. Germination is dependent on environmental conditions such as high humidity and temperature. The factors related to spore release include the building material, humidity, temperature, fungal age and species (Kildeso et al, 2003). When water content is sufficient mould may thrive on dry wall, ceiling tiles, wood, carpets and wallpaper. A large fungal biomass may form and drying periods promote spore and mycelial fragment dispersion throughout the building (Nielson, 2003a). The following sections will detail conditions for mould growth, common indoor substrates, and illness related to mould in the indoor environment.

\subsubsection{Water activity and temperature}

The term $a_{w}$ refers to water activity and describes the water concentration on a substrate. It is defined by the vapour pressure of water on a substrate divided by that of pure distilled water at the same temperature (Flannigan \& Miller, 2001). It can be measured by a capacitance or a dew point hydrometer. $A_{w}$ and temperature are large factors in determining if a fungus will grow (Gock et al., 2002). Some moulds tolerate lower $a_{w}$ concentrations if the temperature is warmer compared to cooler (Flannigan et al., 1991). The relative humidity (RH) of a room may differ greatly from the very high $\mathrm{a}_{\mathrm{w}}$ of a 
substrate due to ventilation and surface temperature differences creating microclimates. It is a poor predictor of mould growth problems (Becker, 1984).

Indoor mould problems usually occur after a flood, leak or accumulated condensation, raising $a_{w}$ at the surface of the building material to $0.90-0.95$. However, a range of fungi are found indoors that are able to grow at $a_{w}$ 0.70-0.80 (Ayerst, 1969). Fungi are sometimes classified according to their ability to grow with water availability. Fungi requiring a minimum $\mathrm{a}_{\mathrm{w}}>0.90$ are referred to as hydrophilic. Classifications extend to mildly $\left(a_{w} 0.80-0.89\right)$, moderately $\left(a_{w} 0.75-0.79\right)$ and extremely xerophilic $\left(a_{w}<0.75\right)$ and are increasingly tolerant to reduced $a_{w}$ environments (Lacey et al., 1980). Of course, moisture distribution is seldom uniform in built environments. Grant et al. (1989) recorded a range of moulds inhabiting adjacent regions of wet and drier portions of wall where a leak occurred. Stachybotrys chartarum grew only in the wet area while the drier regions were replaced by a moderately xerophilic mould, Aspergillus versicolor.

Grant et al. (1989) also recorded the mycobiota colonizing a papered surface of a kitchen wall as it became gradually more humid as condensation accumulated in the winter. The initial mould colonizers were gradually overtaken by more water loving moulds and through further studies of minimal $a_{w}$, indoor colonizers were divided into three categories: primary, secondary and tertiary colonizers.

Primary colonizers are capable of growing at $\mathrm{a}_{\mathrm{w}}$ values $<0.8$ and are many Penicillium and Apergillus species, some of which being, $A$. versicolor, A. fumigatus, A. niger, $A$. 
ustus, $P$. chrysogenum, P. brevicompactum, $P$. commune and several Eurotium species (Nielsen et al., 2004b). Secondary colonizers require minima $a_{w}$ between 0.8 and 0.9 and can thrive where humidity can change throughout the day. This group is composed of Alternaria, Phoma, Ulocladium and Cladosporium species. Finally, tertiary colonizers require aw $>0.9$ and are considered water damage moulds, many of which being tropical fungi. Many of these species such as Stachybotrys chartarum, Memnoniella echinata and many Trichoderma species produce toxic compounds and thrive in wet buildings.

The relatively wide range of $a_{w}$ and temperature under which many Eurotium species can grow was demonstated by Ayerst (1969) by measuring linear extension of hyphae and the time taken for spore germination. A lower $a_{w}$ limit of 0.71 and a temperature range between $10^{\circ} \mathrm{C}$ and $42^{\circ} \mathrm{C}$ was found. This was in contrast to the lower limit of Penicillium $(0.80)$ and Stachybotrys species (0.91). Temperature and moisture may not only affect synthesis of compounds needed in primary metabolism but may determine the production of secondary metabolites with potential toxicity. The effects of $a_{w}$ and temperature on mould growth and toxin production was examined by Northolt (1979). Results indicated that the limiting conditions for toxin production were close to that for mycelial growth. However, the $a_{w}$ for particular toxins were restricted to extremely high $a_{w}$ values.

Temperature is an important factor for mould growth and has an effect on the minimum tolerable $\mathrm{a}_{\mathrm{w}}$. Magan and Lacey (1984) found that both xerophilic and hydrophilic mould species were less tolerant to lower $a_{w}$ values when temperature was divergent from the optimum. 
Many studies of secondary metabolite production on building materials have been performed over the $\mathrm{a}_{\mathrm{w}}$ range $0.95-1$. Nielsen et al. (2004b) investigated production at the lower limits of fungal growth on various building materials. Results indicated that quantities of metabolites were insignificant compared with those produced at high RH (RH 95\%), except in the case of Eurotium. The quantities of metabolites produced by Eurotium were 10-100 x greater than by other moulds and mainly produced flavoglaucin and echinulin. Amounts of questin, questinol, isochromane and a tetracyclic compound were also detected by LCMS analysis.

\subsubsection{Fungal growth on building materials}

The construction and finishing materials in buildings that are most susceptible to mould growth and biodeterioration are those materials containing natural organic polymers including: starch, cellulose, hemicellulose, pectin and lignin in plants. Under damp conditions, the ability of wallpaper and cellulose adhesives to sustain growth of moulds gives great concern. In investigating the etiology of asthma in a number of patients, Kozak et al. (1980) noted the importance of damp wallpaper, jute carpet backing, and wicker and straw baskets as environments for indoor mould growth. One of the structural components of modern buildings which easily dampens and provides a biodegradable source of cellulose for mould growth is gypsum board. By the mid-1960's, lath and plaster were almost entirely replaced by this material in wall construction. This hydroscopic substrate is able to sustain mould growth because of the little water required to raise the $a_{w}$. Indoor condensation may worsen over the winter, from which a succession of moulds can appear. 
A study encompassing over 2000 mouldy wallboard samples from six buildings in the coastal Pacific and Atlantic Northeast showed a range of fungi present on wallboard. Prevalence of most species was not found to be associated with geographical location. There existed positive correlations between species sharing similar $\mathrm{a}_{\mathrm{w}}, E$. repens being associated with $A$. sydowii $\left(\mathrm{r}^{2}=0.614\right)$ and $E$. herbariorum $\left(\mathrm{r}^{2}=0.749\right)$. Less xerophilic species also showed positive correlation to each other while xerophilic to relatively nonxerophilic species showed negative correlations (Miller et al., 2008b).

When Gravesen et al. (1997) investigated water damaged buildings they reported that the materials most vulnerable to attack by moulds were those containing cellulose. The genera of micofungi that they isolated most frequently from gypsum board and other materials were Aspergillus and Penicillium. In subsequent studies in Copenhagen, Nielsen et al. (1999) obtained evidence that gypsum board could support mycotoxin production as well as growth of $S$. chartarum. Extracts of contaminated gypsum board from a wall frame in a school house contained verrucarol, a strong indicator of toxic macrocyclic trichothecenes. When old and new gypsum board was artificially inoculated with this species, there was again evidence of toxin production by $S$. chartarum. A. versicicolor also grew and produced large quantities of sterigmatocystin and related metabolites on this material as well as on wallpaper, pine wood and chipboard pieces. Also in Europe, fungal species present on gypsum board and related materials such as wallpaper or cellulose-based ether paints in damp houses was recorded by Hunter and Bravery (1989). They observed that Cladosporium was present in about $70 \%$ of mould patches in contrasts to occurring in only $15 \%$ of samples of mould affected materials 
examined by Gravesen et al. (1997). They recorded that Ulocladium (74\%) and Penicillium (58\%) were also less frequently isolated but Aspergillus and Stachybotrys were much less frequent.

Household dust, encompassing dirt, organic material, microbes and moisture may also be suitable for mould growth. Particular fungal species finding it difficult to degrade materials such as cellulose may reside in dust and were quantified in a study by Cole et al. (1994), isolating $1.6 \times 10^{4}-1.2 \times 10^{5} \mathrm{CFU}$ of fungi $\mathrm{g}^{-1}$ carpet dust and even higher CFUs of various bacteria. Fungal species present in dust is not limited to a particular species as dust may contain many micro-environments, being moisture rich or comparatively dry, supporting both hydrophilic and xerophilic taxa. Bunger et al (2004) detected cytotoxic mycotoxins in mould extracts that support the hypothesis that they may be involved in lung disease due to inhalation of organic dust.

A study conducted in Wallaceburg Ontario, isolated two hundred and fifty-three fungal taxa from 369 dust samples from homes (Miller \& Day, 1997). Thirty-three taxa were observed in $10 \%$ or more of samples; six of these taxa, Alternaria alternata, Aureobasidium pullulans, Eurotium herbariorum, Epicoccum nigrum, Aspergillus versicolor and Penicillium chrysogenum were detected in $50 \%$ or more of the samples analysed. 


\subsubsection{Illness}

In 1726, Sir John Floyer reported severe asthma in a patient after visiting a wine cellar and this is regarded as the earliest report of an allergenic response to mould. One hundred and fifty years later, Blackely described severe chest tightness following inhalation of Penicillium spores (Blackely, 1873). It is now known that a wide range of adverse responses, including hypersensitivity, are a result of exposure to fungal products. Hypersensitivity pneumonitis, caused by inhalation of large concentrations of dust containing fungal spores can cause permanent lung damage by inflammation mediated by T-lymphocytes. In the 1970 's, there was serious lung damage to farmers with massive exposures to fungal spores which did not show the expected immunological reactions of this disease and is described as organic dust toxicity syndrome (ODTS); (Sorenson et al., 1995). Reactions occur not only to spore and mycelia exposure, but to toxic secondary metabolites, volatile organic compounds (VOC's) and $\beta 1,3$ glucans. Now, many fungi have been implicated in allergenic disease (Gumowski, 1997).

Canadians spend a majority of their time indoors due to the cold climate and have a higher level of exposure to indoor mould. Surveys indicate that between $10-35 \%$ of North American homes are affected with serious mould contamination and exacerbate asthma and increase upper respiratory disease (Institute of Medicine, 2000; Jarvis \& Miller, 2005). Upper respiratory disease including asthma and irritation symptoms such as coughing, wheezing, allergic rhinitis, allergic alveolitis and allergic sinusitis may result upon exposure. Skin tests have shown that between $6-15 \%$ of the population is allergic to fungi (Tarlo et al., 1988). Over the past 30 years, "Sick Building Syndrome" 
(SBS), in which the air quality in a building is compromised as a result of biological or chemical pollutants, has been recognized as a serious threat to modern public health ( $\mathrm{Su}$ et al., 1992; Tobin et al., 1987). However, levels of exposure present indoors have proven difficult to assess (McGinnis, 2004). In recent years, SBS has attracted media attention resulting in more thorough evaluations of indoor air quality and pollutants.

The presence of fungi in indoor environments has been implicated through many epidemiological studies and case reports in the US, UK and Canada (Health Canada, 1995). A respiratory health study of 4,600 children in the US demonstrated that the presence of mould contamination in their home was related to increased respiratory and non-specific symptoms. Deleterious effects were shown to be similar to exposure to parental smoke (Brukenkreef et al., 1989). A larger study by Health Canada (1995) involving 15,000 children and 18,000 adults came to the similar conclusion that damp buildings increased respiratory symptoms. Symptoms were concluded to occur via a non-allergenic mechanism. A dose-response relationship was found, as more symptoms arose with greater mould presence (Dales et al., 1991a, 1991b). There have been studies showing positive association with these symptoms in all ages (Douwes \& Pearce, 2003) and there may be a dose-response relationship (Engvall et al. 2001). People with impaired immune systems, those with asthma, infants or the elderly are those most likely to show symptoms. However, dampness in homes may result in a complex array of contaminants that could result in respiratory symptoms and need to be adequately factored into the analysis (Miller, 1992). Health Canada (2004) summarized current epidemiological studies and concluded that a significant association between mould 
exposure and irritative and non-specific respiratory symptoms and exacerbation of respiratory disease exists. Despite these studies, little data exists for biological effects of single mycotoxins concerning inhalation. Unlike the laboratory, fungal cultures rarely occur as a single species. Indoor flora is usually composed of a variety of fungal species, competing and producing mixtures of mycotoxins which are ecologically and toxicologically important (Miller, 1992; Neilson, 2003a).

Few studies have been performed on experimental animals with regards to pure secondary metabolites from building associated fungi. The effects of macrocyclic trichothecenes produced by some strains of $S$. chartarum on type II and alveolar macrophage cells have been studied and resulted in a range of effects on both types (Miller et al., 2003). Pure toxin exposure studies by Rand et al. (2005) examined doseresponse and time-course relationships associated with inflammatory and cytotoxic responses in mouse lungs intratracheally instilled with pure brevianamide $A$, mycophenolic acid and roquefortine $\mathrm{C}$ from $P$. brevicompactum and $P$. chrysogenum. These toxins induced compound-specific toxic responses with different toxicokinetics and stimulated significant inflammatory responses in vivo. The results might help explain some of the indoor effects associated with Penicillium spore exposures. Rand et al. (2006) also studied isolated pure atranone A and C from S. chartarum isolates by the same dose-response and time-course method. The results suggested that atranone $\mathrm{A}$ and $\mathrm{C}$ are inflammatory but also exhibit different inflammatory potency with different toxicokinetics. The data also suggests that exposure to these toxins in $S$. chartarum spores could contribute to inflammatory lung disease onset in susceptible individuals. 
Further testing of pure secondary metabolites isolated from the common but little-studied E. amstelodami, E. herbariorum, E. rubrum and A. ustus s.l. was one goal of this thesis.

\subsection{Metabolites of Eurotium and A. ustus s.l.}

A literature search provided information on known metabolites from each species. Reported major metabolites are shown below along with available toxicity data.

\subsubsection{Eurotium}

Echinulin and several derivatives have been reported from these fungi (Casnati et al, 1973). Many anthraquinones, including physcion and questin, along with several benzoquinones, including flavoglaucin and auroglaucin have also been reported (Ashley et al., 1939). In vitro and in vivo pulmonary toxicity and inflammatory potential of these metabolites is needed as high quantities of these metabolites have been detected in building materials (Nielsen, 2003b). Trace amounts of sterigmatocystin has also been reported in the Eurotium group (Schroeder \& Kelton, 1975) but the strains used were not placed in a culture collection and cannot be investigated further.

\subsubsection{Echinulin}

Echinulin was first isolated from E. amstelodami by Quilico (1964); (Figure 5). The mixed biosynthetic origin of this isoprenylated tryptophan derivative was determined by 
Birch et al. (1961). Since that time, many related compounds have been isolated, each containing the diketopiperazine nucleus (Gatti \& Fuganti, 1979).

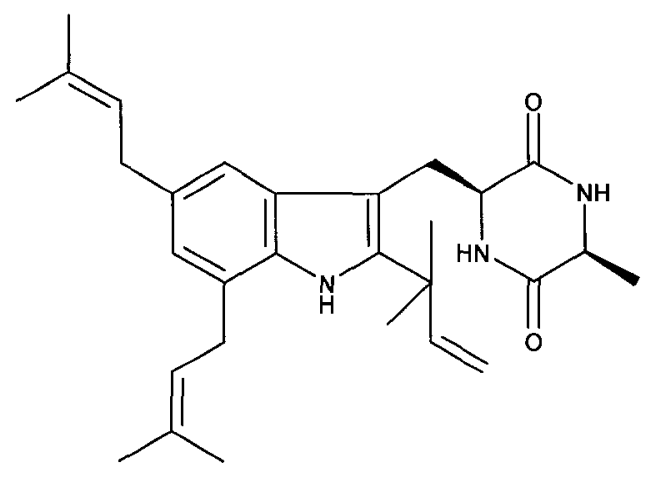

Figure 5: Structure of echinulin

Echinulin toxicity was studied by Ali et al. (1989) in female mixed breed rabbits by intraperitoneal (i.p.) injection of $10 \mathrm{mg} / \mathrm{kg} \mathrm{BW}$ purified compound. Pathological studies of the organs revealed severe damage of alveolar organization and thickening of alveolar walls. Large numbers of RBC aggregates were noticed in the lungs. There were elevated levels of many plasma enzymes (total plasma lactate dehydrogenase, cardiac derived isozyme, glutamic-oxaloacetic and glutamic-pyruvic transaminase) indicating echinulin caused significant liver damage. Echinulin was cytotoxic to HeLa cells at $100 \mu \mathrm{g} / \mathrm{mL}$ (Umeda et al., 1974) but not genotoxic by the hepatocyte primary culture/DNA repair test using hepatocytes isolated from $\mathrm{ACl}$ rat and $\mathrm{C} 3 \mathrm{H} / \mathrm{HeN}$ mice livers at $10^{-4} \mathrm{M}$ (Mori et al., 1984). Feed refusal in swine was attributed to echinulin ( $8 \mu \mathrm{g} / \mathrm{g}$ of feed) and Harlan Sprague-Dawley female and male mice (5 to 7 weeks old) were used for a drinking water bioassay. Mice refused to drink water containing $90 \mu \mathrm{g} / \mathrm{mL}$ of echinulin (Vesonder et al., 
1988). Other echinulin-like metabolites have been isolated from the Eurotium genus, including the neoechinulin series. There do not appear to be toxicological data for these compounds.

\subsubsection{Physcion}

Physcion is an anthraquione belonging to a group of fungal metabolites which were investigated in early studies of fungal secondary metabolism (Raistrick, 1950). Anthraquinones and their derivatives possess potent biological activities and have gained interest as antitumor therapeutics (Strauss, 1978) and found uses as pigments in the 1950's (Sticklings \& Raistrick, 1956). They play a role as metabolic precursors to sterigmatocystin and aflatoxins in $A$. versicolor (Hsieh et al., 1978).<smiles></smiles>

Figure 6: Structure of physcion

Toxicity of physcion was tested in male Swiss albino mice (ICR) and chicken embryos (fertile Leghorn eggs) and for mutagenicity in the Salmonella/mammalian microsome test (strain TA 1537); (Bachmann et al., 1979). In mice, the $\mathrm{LD}_{50}$ after i.p. injection was 10 $\mathrm{mg} / \mathrm{kg} \mathrm{BW}$ and $>100 \mathrm{mg} / \mathrm{kg} \mathrm{BW}$ after oral administration. Chicken embryos injected with doses of 1000,100 and $10 \mu \mathrm{g}$ gave survival/death rate of $4 / 6,6 / 4$ and $6 / 4$ 
respectively. The Ames mutagenicity test (strain TA 1537) gave positive responses (frameshift) with amounts of $100,200 \mu \mathrm{g} /$ plate. Physcion isolated was not genotoxic to mouse lymphoma cells (L5178Y) at concentrations between 20 and $100 \mu \mathrm{M}$ (Mueller et al., 1998). The $\mathrm{LC}_{50}$ in HeLa cells was $0.1 \mu \mathrm{g} / \mathrm{mL}$ (Podojil et al., 1978). The $\mathrm{IC}_{50}$ on activated human mesangial cells proliferation and cytokines production was determined to be $>60 \mu \mathrm{M}$ (Kuo et al., 2001).

\subsubsection{Flavoglaucin and auroglaucin}

Gould \& Raistrick (1934) described yellow, orange and red pigments occurring in the mycelia of various species of the Eurotium group when grown on a Czapek-Dox medium. The yellow and orange coloured compounds are related and are termed flavoglaucin and auroglaucin (Raistrick et al., 1938). Derivatives of these metabolites have been isolated from $A$. ruber and A. chevalieri (Hamasaki et al., 1980).
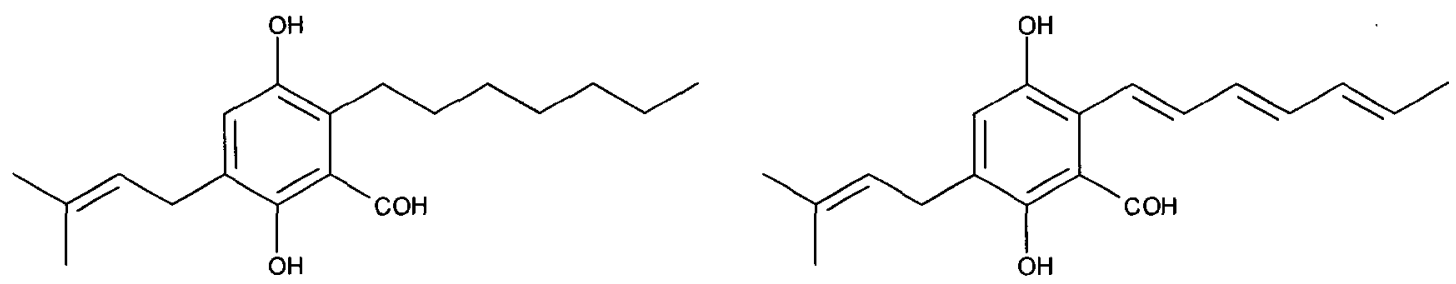

Figure 7: Structures of flavoglaucin and auroglaucin

Nazar et al. (1984) i.p. injected mixed breed female rabbits with $10 \mathrm{mg} / \mathrm{kg} \mathrm{BW}$ purified flavoglaucin from $A$. chevalieri. After $2 \mathrm{~h}$, they were sacrificed and the livers were taken 
for enzyme assays. A significant increase in plasma glutamic-oxaloacetic transaminase activity was found. The enzyme results suggested that flavoglaucin caused liver damage. This was supported by histological evidence showing focal infiltration of mononuclear cells. Flavoglaucin did not show genotoxicity in hepatocyte primary culture HPC/DNA repair test at concentrations of $10^{-5}$ and $2.5 \times 10^{-3} \mathrm{M}$ (Kawai et al., 1983) and negative for genotoxic studies in hepatocytes isolated from livers of $\mathrm{ACl}$ rats at $2.5 \times 10^{-5} \mathrm{M}$ (Mori et al., 1984). The $\mathrm{LC}_{50}$ in HeLa cells was $50 \mu \mathrm{g} / \mathrm{mL}$ (Podojil et al., 1978). There appears to be no data on auroglaucin toxicity.

\subsubsection{Cladosporin}

Cladosporin has been isolated from Cladosporium cladosporioides (Scott et al., 1971), Aspergillus species (Grove, 1972) and E. repens (Podojil et al., 1978; Butinar et al, 2005). The stereochemistry was first reported by Springer et al. (1981).



Figure 8: Structure of cladosporin

Cladosporin had an $\mathrm{LD}_{50}$ of $86 \mu \mathrm{g} / \mathrm{mL}$ in Artemia salina larvae (Podojil et al., 1978) and suppressed the proliferation of mouse splenic lymphocytes with an $\mathrm{IC}_{50}$ of $7.5 \mu \mathrm{g} / \mathrm{mL}$ 
(Haruhiro et al., 1999). The growth of wheat coleoptiles was significantly inhibited at $10^{-}$

${ }^{3}, 10^{-4}$ and $10^{-5} \mathrm{M}$ (Culter et al., 1982). Cladosporin also inhibited the germination of spores of Penicillium and Aspergillus species at $140 \mu \mathrm{g} / \mathrm{mL}$ and the growth of several dermatophytes on agar medium at $75 \mu \mathrm{g} / \mathrm{mL}$ (Scott et al., 1971). Cladosporin had an $\mathrm{IC}_{50}$ of $0.5 \mu \mathrm{g} / \mathrm{mL}$ and is hypothesized to act by interfering with the uptake of uracil and leucine in Bacillus brevis cells and resulted in the decreased incorporation of these precursors into RNA (Anke et al., 1979). The agar plate diffusion test showed growth inhibition of several fungi including: A. flavus, A. panamensis, E. repens and $P$. notatum at concentrations $>150 \mu \mathrm{g} / \mathrm{mL}$ (Anke et al., 1978).

\subsubsection{A. ustus s.l.}

Most investigations of toxigenic cultures of $A$. ustus have resulted in the isolation of a number of metabolites including: the austalides, austamides and austocystins (Horak et al., 1981). These metabolites possess a range of toxicity and have been isolated from whole maize and grain culture (Steyn, 1973; Steyn \& Vleggar, 1974; 1975). However, most of these species derived from building material and clinical settings show entirely different metabolite profiles than those of grains (Nielsen, 2003b). These isolates have been described as $A$. ustus pseudodeflectus (Pitt et al., 2000) and more recently as $A$. insuetus and A. calidoustus (Houbraken et al., 2007). Strains of these species are known to produces ophibolins $\mathrm{G}$ and $\mathrm{H}$ and sesquiterpene drimanes (Houbraken et al., 2007). TMC-120 (A-C) may also be produced but not positively identified due to lack of LCMS reference standards (Nielson et al., 1999). 


\subsubsection{Ophiobolin G \& H}

Ophiobolin $\mathrm{G}$ and $\mathrm{H}$ have been isolated from A. ustus (Cutler et al., 1984), A. insuetus and A. calidoustus (Houbraken et al., 2007) and Emericella variecolor (GF10) from marine sediment (Wei et al., 2004). These compounds are unusual in that the ring fusion between rings $\mathrm{A}$ and $\mathrm{B}$ are trans (opposed to cis in other fungal ophiobolins) and there is a cis side chain double bond.


Figure 9: Structures of ophiobolin $\mathrm{G}$ and $\mathrm{H}$

Both ophiobolin $\mathrm{G}$ and $\mathrm{H}$ are reported to inhibit etiolated wheat coleoptile growth at $10^{-3}$, $10^{-4}$ and $10^{-5} \mathrm{M}$. They also inhibited growth of Bacillus subtilis cultures at $250 \mu \mathrm{g} / \mathrm{plate}$ and ophiobolin $\mathrm{H}$ induced hyperacusia (increased irritability to sound which resulted in feed refusal and nervousness) in day old chicks at $375 \mathrm{mg} / \mathrm{kg}$ but there was no mortality (Cutler et al., 1984). 


\subsubsection{TMC-120 A-C}

The isoquinoline alkaloids: TMC-120 A-C and derivatives were first isolated from a fermentation of $A$. ustus (TC 118) isolated from the rhizosphere of grass in Japan (Kohno et al., 1999a).

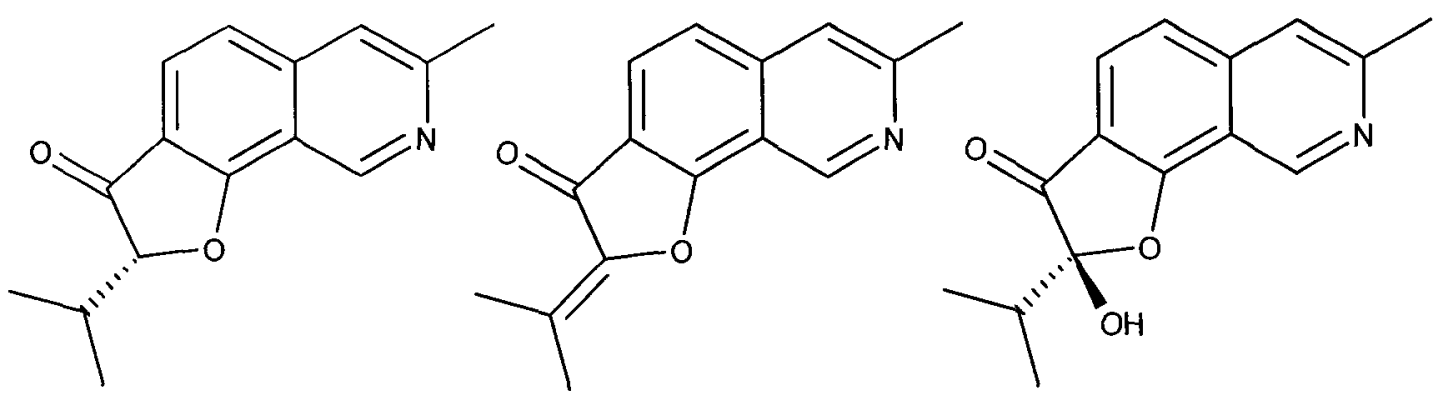

Figure 10: Structures of TMC-120 A, B and C (left to right)

TMC-120 A-C exhibited inhibitory effects on the survival of guinea pig peritoneal eosinophils at $\mathrm{IC}_{50} 13.7,2.0$ and $>39 \mu \mathrm{M}$ respectively (Kohno et al., 1999b). More recently, an isochrome derivative deemed pseudodeflectusin, has been isolated from $A$. pseudodeflectus from the marine macroalga: Sargassum fusiform. Cytotoxicity was determined with an $\mathrm{LD}_{50}$ of $39 \mu \mathrm{M}$ in human (HL-60) cancer cells (Ogawa et al., 2004).

\subsubsection{Drimanes}

Many drimanes have been isolated from plants, mollusks, several fungi and occasionally sponges. Drimanes possess a wide variety of biological activity including antifungal, antibacterial, antifeedant, phytotoxic, cytotoxic and plant growth regulatory properties 
(Jansen \& Groot, 1991). Ester carbonyl linkages with a variety of unsaturated fatty acid chains may constitute many derivatives of the presented drimane skeleton. Nielsen (2003b) reported many possible drimane sesquiterpenes based on UV and LCMS data occurring in agar culture extracts of A. ustus var. pseudodeflectus from indoor environments. Houbraken et al. (2007) detected drimanes from strains of A. insuetus and A. calidoustus from clinical settings. These differ from $S$. chartarum drimanes, which are in part, biosynthesized from polyketides (Dewick, 1997). The absolute stereochemistry was determined by NOESY experiment (Hayes et al., 1995).

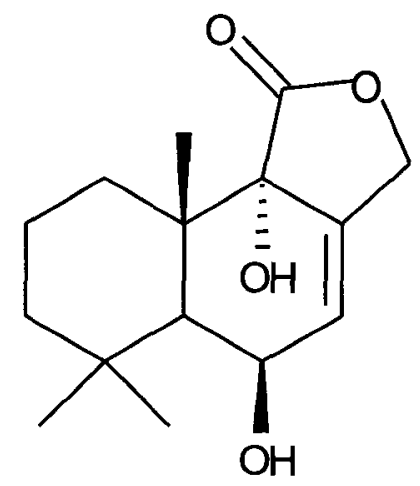

Figure 11: Structure of a drimane sesquiterpene

A series of drimane sesquiterpene esters were isolated from the fermentation of $A$. ustus var. pseudodeflectus and exhibited endothelin receptor binding inhibitory activity against rabbit endothelin receptors with $\mathrm{IC}_{50}$ values between $20 \sim 150 \mu \mathrm{M}$ (Hayes et al., 1995).

\subsection{Analytical Methods for Detection}

Detection of fungal metabolites from a sample matrix may prove difficult without some general knowledge of the species isolated and known metabolites. These matrices may 
interfere with analysis, some being wallboard, paint, dust, ceiling tiles etc., and all can affect the extraction strategy applied to the sample. Access to proper analytical instrumentation is key to determination of the metabolite. Sample clean up may be best suited upon utilizing properties of the metabolite of interest. Partial purification of the compound before applying the final analytical column is best.

Thin layer chromatography (TLC) has proven to be an inexpensive, powerful and rapid technique for determining metabolite profiles of fungal strains (Betina, 1985). Mycelial plugs may be taken from pure cultures on agar plates and wetted with a drop of solvent. By this method, metabolites can be extracted and directly run on TLC for profiling (Filtenborg et al.,1983). Care must be taken to avoid false positives without a proper standard and metabolite quantification is difficult. This method can act as a preliminary screening tool and extracts of interest can pass for further testing.

Developments in chromatography and mass spectrometry have greatly increased resolution and sensitivity (Marzo \& Bo, 1998). High pressure liquid chromatography (HPLC) is the most common analytical technique used for metabolite profiling because of its versatility, ease of use and the broad spectrum of metabolites that can be determined directly (Nielsen et al., 2003a). A tandem liquid chromatography (LC) or gas chromatography (GC) may be used with a mass spectrometer (MS). A diode array detector (DAD) may also be helpful in identification of UV as long as they do not contain end absorptions or more than one characteristic UV maximum. LC-NMR (nuclear magnetic resonance) and LC-ESMS (electrospray mass spectrometry) allow for the detection of secondary metabolites directly from crude extracts (Whiting, 2001). LC- 
ESMS takes advantage of the very limited fragmentation pattern produced by this ionization technique resulting in mass spectra that almost exclusively show protonated ions from a broad range of extractable metabolites and can be used to establish mass profiles (Smedsgaard \& Nielsen, 1996). In addition, there are now methods available including LC-HRMS (high resolution mass spectrometry) that allow for rapid metabolite screening from a small amount of sample. As a result, identities of a broad range of metabolites can be determined in one analysis without losing sensitivity (Nielsen \& Smedsgaard, 2004b).

\subsection{Project Aim}

Mould and dampness in homes are associated with allergic and non-allergic health consequences in humans and can partially be attributed to toxic secondary metabolites produced by some fungi. The goal of this project is to identify the major secondary metabolites of Eurotium species and $A$. insuetus and $A$. calidoustus, which are common on building materials in Canadian homes. Chemotypes of indoor strains will be compared to that of outdoor strains to determine metabolite profile differences between these environments. Chemotypic profiles of Eurotium may also expand the current view that very small variation exists within the group. Profiles of indoor $A$. insuetus and $A$. calidoustus are of interest because new evidence has emerged that these species are chemically distinct from $A$. ustus found on cereals with which they were previously grouped. Many of their metabolites remain unknown. 
The goal will be accomplished by fermenting and screening strains of each species by TLC and HPLC for secondary metabolites. Metabolite productive or strains of interest will be grown in bulk and methods will be developed for secondary metabolite purification and identification. Major metabolite purification will employ a range of strategies such as prep-TLC, prep-HPLC and column chromatography while structural elucidation will utilize mass spectrometry, NMR spectroscopy and other spectral properties. Strains will also be screened for known minor metabolites by LC-DADHRMS.

Pure major secondary metabolites will be used to examine the dose-response and timecourse relationships associated with inflammatory and cytotoxic responses in mouse lungs. These results may help explain some of the health effects associated with indoor mould exposures. 


\section{MATERIALS AND METHODS}

\subsection{Growth and Extraction of Fungal Strains}

\subsubsection{Fungal strains}

Twenty one strains of $E$. amstelodami, 4 strains of $E$. herbariorum, 3 strains of E. rubrum, 4 strains of $A$. insuetus, 8 strains of $A$. calidoustus and 8 strains of $A$ ustus s.l. were studied. They were provided by Paracel Laboratories Ltd. (Ottawa, Ontario). Isolates were collected from indoor environments in Ontario, Manitoba, Saskatchewan and Alberta. E. amstelodami, A. insuetus and $A$. calidoustus strains were identified by Prof. J.C. Frisvad (Danish Technical University) and deposited in the official Danish fungal culture collection (IBT). E. herbariorum and E. rubrum strains were identified by Dr. R. Samson (Centraalbureau voor Schimmelcultures, Royal Netherlands Academy of Sciences). These are deposited in the official Dutch collection (CBS). The remaining codes refer to Paracel Laboratories Ltd. collection numbers. Strain origin is listed in Tables 1A-C. 
Table 1A: E. amstelodami strains

\begin{tabular}{cc}
\hline strain & location \\
\hline J9968-5 & Ottawa, indoor \\
IBT 28252 & Ottawa, indoor \\
IBT 28305 & Ottawa, indoor \\
J9843-11 & Carp, ON \\
IBT 28247 & Ottawa, outdoor \\
J9688-3 & Ottawa, outdoor \\
IBT 28251 & Ottawa, indoor \\
J9589-1 & Peterborough \\
J9571-1 & Calgary, outdoor \\
IBT 28250 & Ottawa, outdoor \\
IBT 28307 & Ottawa, outdoor \\
J1726-4 & Ottawa \\
IBT 28253 & Ottawa, outdoor \\
IBT 28308 & Carp, ON \\
J1005-19 & Carp, ON \\
IBT 28249 & Calgary, outdoor \\
J0837-8 & Carp, ON \\
IBT 28246 & Ottawa \\
IBT 28254 & Ottawa, indoor \\
IBT 28248 & Ottawa, indoor \\
J0653-1 & Ottawa, outdoor
\end{tabular}

Table 1B: E. herbariorum strains

\begin{tabular}{cc}
\hline strain & location \\
\hline CBS 47-F9 & Calgary, outdoor \\
CBS 47-F8 & Ottawa, indoor \\
CBS 47-F3 & Calgary, indoor \\
CBS 47-G1 & Carp, ON
\end{tabular}

Table 1C: E. rubrum strains

\begin{tabular}{cc}
\hline strain & location \\
\hline CBS 47-F4 & Ottawa, indoor \\
CBS 47-F5 & Calgary, indoor \\
CBS 47-F6 & London, indoor
\end{tabular}


Table 1D: A. ustus s.l. strains

\begin{tabular}{cc}
\hline strain & location \\
IBT 28265 & Winnipeg, indoor \\
IBT 28266 & Ottawa, indoor \\
IBT 28267 & Ontario, indoor \\
K9197-10 & Ottawa, indoor \\
A. calidoustus & \\
IBT 28268 & \\
IBT 28269 & Dundas ON \\
IBT 28270 & Ontario, indoor \\
IBT 28271 & Dundas, ON \\
IBT 28272 & Ontario,indoor \\
IBT 28273 & Ottawa, indoor \\
IBT 28274 & Ontario, indoor \\
IBT 28275 & Dundas, ON \\
& Ottawa, outdoor \\
A. ustus s.l. & \\
L3852-1 & \\
K0954-4 & \\
L3945-1 & Ottawa, indoor \\
K3796-2 & Ottawa, indoor \\
K3752-3 & Ottawa, indoor \\
K3629-2 & Ottawa, indoor \\
K3576-3 & Regina, indoor \\
L3931-10 & Ottawa, indoor \\
\end{tabular}

\subsubsection{Single spore isolate preparation}

All fungal strains were mass transferred aseptically onto three sterilized $2 \%$ malt extract agar plates each for incubation in the dark at $25^{\circ} \mathrm{C}$ until suitable growth was noted. Plates were wrapped with laboratory film and stored at $5^{\circ} \mathrm{C}$ until required. Single spore isolates were then prepared as follows. Spores were transferred into a $125 \mathrm{~mL}$ Erlenmeyer flask containing $50 \mathrm{~mL}$ of sterile distilled and deionized water $\left(\mathrm{H}_{2} \mathrm{O}\right)$ and Tween $20(0.01 \% \mathrm{v} / \mathrm{v})$. The solution was shaken 
and $100 \mu \mathrm{L}$ was pipetted onto a sterile $2 \%$ malt extract agar plate and spread evenly with a sterile glass rod. After one to four days, colonies could be seen. Single spore cultures were transferred aseptically onto $2 \%$ malt extract agar plates, allowed to grow and transferred onto $2 \%$ malt agar slants. The slants were incubated in the dark at $25^{\circ} \mathrm{C}$ for 7 days. Slant tubes were then sealed and stored at $5^{\circ} \mathrm{C}$.

\subsubsection{Culture fermentation}

Slants of each species were macerated in $50 \mathrm{~mL}$ of $\mathrm{H}_{2} \mathrm{O}$ in which $10 \mathrm{~mL}$ or $5 \%$ (v/v) aliquots were used to inoculate one of three Roux bottle per strain. Roux bottles contained $200 \mathrm{~mL}$ of sterile Czapek-Dox autolysate supplemented with yeast extract (CYA) $\left(30 \mathrm{~g} / \mathrm{L}\right.$ sucrose, $1 \mathrm{~g} / \mathrm{L} \mathrm{K}_{2} \mathrm{HPO}_{4}, 5 \mathrm{~g} / \mathrm{L}$ yeast extract, $0.5 \mathrm{~g} / \mathrm{L}$ $\left.\mathrm{MgSO}_{4}, 3 \mathrm{~g} / \mathrm{L} \mathrm{NaNO}{ }_{3}, 0.01 \mathrm{~g} / \mathrm{L} \mathrm{FeSO}_{4}, 0.5 \mathrm{~g} / \mathrm{L} \mathrm{KCl}\right)$ or $2 \%$ malt extract $(20 \mathrm{~g} / \mathrm{L}$ malt extract). After inoculation, Roux bottles were incubated at $25^{\circ} \mathrm{C}$ for two weeks in the dark. Five strains per species were initially chosen for fermentation on both media. Cultures were performed in triplicate.

\subsubsection{Culture extraction}

After two weeks of growth, cultures were filtered by suction using a Buchner funnel and a Whatman \#4 filter paper. The cell filtrate volume and $\mathrm{pH}$ was measured followed by organic extraction using half its volume in ethyl acetate in a large separatory funnel. The aqueous layer was then poured back into the 
funnel for a second round of extraction. Both organic layers were combined, filtered by gravity through anhydrous $\mathrm{Na}_{2} \mathrm{~S}_{4}$ using Whatman \#1 filter paper to remove water and dried under vacuum (Caframo VV 2000 rotary evaporator). The extracts were then taken up in minimal ethyl acetate, transferred into a $5 \mathrm{~mL}$ glass amber vial and initially screened by the TLC method described below. The samples were dried under nitrogen gas, dissolved in a known amount of acetonitrile $\left(\mathrm{CH}_{3} \mathrm{CN}\right)$ and ready for HPLC-DAD analysis. The dried mycelium was wrapped in aluminum foil, frozen and freeze dried. The mycelium was weighed, ground with a glass rod in a $500 \mathrm{~mL}$ Erlenmeyer flask and extracted with $250 \mathrm{~mL}$ of ethyl acetate overnight. The solution was then filtered using a Whatman \#1 filter paper and processed as above for HPLC-DAD analysis.

Ethyl acetate was chosen as the extraction solvent in a conscious effort to eliminate chlorinated solvents and because of its ability to extract a wide range of organic compounds. However, chloroform was added to the ethyl acetate extracted water portion of the filtrate of two strains of each species to test for

remaining metabolites. HPLC-DAD analysis of this chloroform extract indicated no further metabolites were extracted by this method. Ethyl acetate was therefore used for the remaining extractions.

\subsection{Metabolite Screening of Fungal Strains}

\subsubsection{Thin layer chromatography (TLC)}

Fungal metabolite screening was performed on the filtrate and cell mass extract. Extracts were spotted on TLC plates $\left(0.2 \mathrm{~mm}\right.$ silica gel $60 \mathrm{~F}_{254}$ pre-coated 
alumina) and viewed using a UV viewing system (UVP chromto-uve C-70 G) under short wave (254 nm) and long wave (365 nm) light.

TLC plates were placed in a jar containing the solvent and run until the solvent had reached $0.5 \mathrm{~cm}$ from the top of the plate. The plates were removed, allowed to air dry and visualized using the viewing system. The number of spots and their intensity was used to identify productive strains. The plates were then dipped in a solution of molybdemun $\left(90 \mathrm{~mL} \mathrm{H}_{2} \mathrm{O}, 10 \mathrm{ml} \mathrm{H}_{2} \mathrm{~S}_{4}, 2.5 \mathrm{~mL}\right.$ ammonium molybdate, $1.0 \mathrm{~g}$ cerium (IV) sulphate) and dried with a heat gun until dark spots appeared in visible light where compounds were present. This aided in identification of production strains by roughly quantifying them in comparison to one another based on the amount of compound present.

A variety of solvent systems were tested for their ability to separate compounds contained in the extracts based on polarity. Systems tested were $\mathrm{H}_{2} \mathrm{O} /$ acetone (9:1, 5:1, 2:1, 1:1), $\mathrm{CHCl}_{3} / \mathrm{MeOH}(99: 1,98: 2,19: 1,9: 1)$, hexane/ethyl acetate $(19: 1,9: 1,4: 1,3: 1,2: 1,1: 1)$ benzene/ethyl acetate $(2: 1)$. It was found that $(9: 1)$ $\mathrm{CHCl}_{3} / \mathrm{MeOH}$ provided the best separation for Eurotium metabolites from the filtrate, while 2:1 hexane/ethyl acetate followed by $9: 1 \mathrm{CHCl}_{3} / \mathrm{MeOH}$ proved the best separation of A. ustus s.l. metabolites upon strain screening. Eurotium cellular extracts were best separated using (19:1) hexane/ethyl acetate after multiple elutions. Variations of these ratios were used throughout this study for maximum separation when required. 
2.2.2 Analysis by high pressure liquid chromatography (HPLC) with diode array detector (DAD)

The HPLC-DAD method for the determination and quantification of secondary metabolites from both filtrate and mycelium was adapted from Nielsen et al. (2003). This method targets the separation and detection of fungal metabolites from liquid media. An HPLC with a DAD (see Instrumentation section 2.6) was used for metabolite analysis. A gradient mobile phase of $\mathrm{CH}_{3} \mathrm{CN} / \mathrm{H}_{2} \mathrm{O}$ with triflouroacetic acid (TFA) $(0.05 \% \mathrm{v} / \mathrm{v})$ and a $1 \mathrm{~mL} / \mathrm{min}$ flow rate method was developed for strain screening (Table 2). A reversed phase analytical column was utilized for compound separation and the detector was set at $210 \mathrm{~nm}$ and 254 $\mathrm{nm}$ for compound detection. For semi preparatory-HPLC-DAD, the same conditions were used at a flow rate of $5 \mathrm{~mL} / \mathrm{min}$ with $0.005 \%$ TFA, employing a larger column. All extracts were dissolved in $\mathrm{CH}_{3} \mathrm{CN}$ and filtered through 13 mm PTFE $(0.22 \mu \mathrm{m})$ syringe filters prior to injection.

Cellular extracts of $A$. ustus s.l. produced very few peaks by HPLC-DAD when compared to the culture filtrate extracts. The UV spectra of these peaks confirmed the suspected similarity of these compounds to the filtrate extract, however, peak area counts were far less and were in agreement with initial TLC results. Focus was given to the culture filtrate during the remainder of work on this species. Eurotium species showed large peaks by HPLC-DAD from both the filtrate and cellular extracts. E. rubrum screening revealed similar metabolite 
profiles to that of E. amstelodami while E. herbariorum showed some differences by TLC and HPLC-DAD analysis.

Table 2: HPLC-DAD timetable for metabolite analysis

\begin{tabular}{cccc}
\hline time (min) & $\begin{array}{c}\mathrm{H}_{2} \mathrm{O}, \mathrm{TFA} \\
(0.05 \% \mathrm{v} / \mathrm{v})\end{array}$ & $\begin{array}{c}\mathrm{CH}_{3} \mathrm{CN}, \mathrm{TFA} \\
(0.05 \% \mathrm{v} / \mathrm{v})\end{array}$ & $\begin{array}{c}\text { flow rate } \\
(\mathrm{mL} / \mathrm{min})\end{array}$ \\
\hline 0 & 100 & 0 & 1 \\
2 & 100 & 0 & 1 \\
22 & 0 & 100 & 1 \\
23 & 0 & 100 & 1 \\
25 & 100 & 0 & 1
\end{tabular}

\subsubsection{Large scale fermentation and extraction of selected strains}

E. amstelodami strain IBT 28307 and J9589-1, A. ustus s.l. strain IBT 28269 and IBT 28272 and E. herbariorum strain CBS 47-F8 and CBS 47-F9 were chosen as productive strains based on metabolite profiles seen by TLC and HPLC-DAD screening. Two strains per species were chosen to ensure consistent results. Five starter cultures of each strain were grown in $250 \mathrm{~mL}$ Erlenmeyer flasks containing $50 \mathrm{~mL}$ CYA and inoculated with $5 \%$ by volume macerated inoculum. These starter cultures were grown until sufficient cell mass was observed and were then used to inoculate 10 Glaxo bottles containing 1 L of CYA media and fermented for 14 days at $25^{\circ} \mathrm{C}$. All cultures were extracted, combined, washed and filtered as described for the screening process. TLC and HPLC-DAD were used to confirm the presence of metabolites which was later quantified. 


\subsection{Preparatory Methods for Metabolites Isolation}

\subsubsection{Preparatory thin layer chromotography}

For large scale isolation of metabolites, prep-TLC plates were used in varying thicknesses $(500,1000,2000 \mu \mathrm{m})$ during the experiment. Plates were allowed to run in a development tank for about 1 hour until the solvent was $1 \mathrm{~cm}$ from the top. They were then removed from the tank, air dried and visualized under 254 and $365 \mathrm{~nm}$ UV light. Bands of interest were outlined with a pencil, scraped off the plate using a razor, ground to a fine powder with a mortar and pestle and poured into a small flask containing the running solvent overnight. The following day, the solution was filtered using a Whatman \#1 filter paper and washed several times with the running solvent to maximize recovery. The recovered extract was dried and dissolved in $\mathrm{CH}_{3} \mathrm{CN}$ for HPLC-DAD analysis. In some cases multiple runs were necessary for maximum separation of bands.

\subsubsection{Preparatory-HPLC}

For large scale isolation of metabolites, a prep-HPLC using a reversed phase column was employed (section 2.6). The solvent gradient change was optimized for each extract to produce maximum compound separation and the flow rate was increased to $25 \mathrm{~mL} / \mathrm{min}$. The detector was set to a wavelength corresponding to the maximum absorbance wavelength of the compound of interest as determined by HPLC-DAD analysis. TFA was reduced to $0.0125 \%$ to avoid producing acidic conditions leading to possible degradation of isolated metabolites upon drying. TFA was in some cases substituted with ammonium 
acetate $(1 \mathrm{~g} / \mathrm{L})$ in an attempt to improve peak resolution among difficult separations but failed to produce improvement.

\subsubsection{Silica gel chromatography column}

Two sizes of silica gel chromatography columns were used in an attempt to isolate compounds from all species. Initially, a chromatography column (200 $\mathrm{mL}$ workable volume) was prepared by mixing $120 \mathrm{~g}$ of silica gel (230-400 mesh, 40-63 $\mu \mathrm{m}, 60 \AA$ ) with enough $\mathrm{CHCl}_{3}$ to make a slurry. The column was packed using forced air to compress the silica gel taking care not to let the column run dry. Fine sand was added $(0.5 \mathrm{~cm})$ to serve as a protective layer and to act as a filter for the sample. Samples were dissolved in minimal $\mathrm{CHCl}_{3}$ and slowly pipetted onto the sand layer. Because initial TLC screening showed that $\mathrm{MeOH} / \mathrm{CHCl}_{3}$ solvent system worked well for compound separation, it was used for the column. The column was initially washed with a $200 \mathrm{~mL}$ of $\mathrm{CHCl}_{3}$ and collected in a flask. Next, an increasing concentration of $\mathrm{MeOH} / \mathrm{CHCl}_{3}(0-30 \%$ $\mathrm{MeOH}$ ) was loaded onto the column in $200 \mathrm{~mL}$ increments and increasing $\mathrm{MeOH}$ by $1 \%$ each increment. Test tubes $(12 \mathrm{~mL})$ were used to collect the elutants in $5 \mathrm{~mL}$ fractions which were spotted on small test TLC plates. Similar fractions were then combined. A smaller column $(50 \mathrm{~mL}$ volume, $30 \mathrm{~g}$ silica $)$ was also prepared in an attempt to further purify resulting fractions of the first column and was run as above but with $50 \mathrm{~mL}$ solvent per increment. 


\subsubsection{Solid phase extraction sorbent columns (SPE)}

Reversed phase Strata X polymeric (SPE) sorbent columns were used when crude fractionation of fungal extracts using silica gel chromatography or prepTLC was not satisfactory. The columns were attached to a Supelco Visiprep vacuum manifold and initially washed with $50 \mathrm{~mL} \mathrm{MeOH}$, equilibrated with 50 $\mathrm{mL} \mathrm{H}_{2} \mathrm{O}$ and allowed to run dry for 1 minute. The sample extract was dissolved in $\mathrm{H}_{2} \mathrm{O}$ with a small amount of $\mathrm{CH}_{3} \mathrm{CN}$ and loaded onto the column with a pipette. A vacuum was applied and the column was washed again with $\mathrm{H}_{2} \mathrm{O}$ to remove any unwanted polar compounds. An increasing gradient of $\mathrm{CH}_{3} \mathrm{CN} / \mathrm{H}_{2} \mathrm{O}$ was added to the column in $5 \%$ increments $\left(50 \mathrm{~mL}\right.$ each) until $100 \% \mathrm{CH}_{3} \mathrm{CN}$ was reached. Fractions were collected in foil covered Erlenmeyer flasks. A minimal amount of each collection was injected directly into the HPLC-DAD for detection of major metabolites. Relevant collections were then dried by rotary evaporation at $30^{\circ} \mathrm{C}$ to remove $\mathrm{CH}_{3} \mathrm{CN}$. The remaining water was removed as flow-through after loading the sample back on the column. The compounds were eluted from the column with $100 \% \mathrm{CH}_{3} \mathrm{CN}$, dried under nitrogen gas and stored in an amber vial.

\subsection{Metabolite Isolation and Purification from Selected Strains}

Many preparatory methods were attempted in order to purify the major metabolites of all species. The majority of the literature on the isolation of secondary metabolites from these and other species combines column 
chromatography or prep-TLC followed by prep-HPLC. The strategies taken in sequential order are outlined below.

\subsubsection{E. amstelodomi strains IBT 28307 and J9589-1 filtrate extract}

The cultures were extracted, washed and filtered as previously described. Initial TLC screening and HPLC-DAD analysis revealed the extracts contained similar metabolite profiles as found in initial screening.

The first method attempted for metabolite purification of the filtrate extract was silica gel chromatography. The extract was loaded onto the large silica column and run as previously described. Upon spotting of the fractions on TLC, no compounds were detected in the $1 \%$ fraction, while the $2 \%$ fraction contained one major metabolite of interest and three minor compounds. The 3-6\% fractions contained three major metabolites of interest and many faint ones with similar $\mathrm{R}_{\mathrm{f}}$ values. There were no spots observed in fractions after $7 \% \mathrm{MeOH}$ washings. Column chromatography was attempted again using the resulting fractions with the smaller $(50 \mathrm{~mL})$ silica column to improve separation. It failed to do so as major metabolites eluted in the same fractions. The major metabolites appeared to have similar polarities, making their purification by this method alone difficult. Results were verified by HPLC-DAD of the extracts.

The $2 \%$ and $3-6 \%$ dried fractions were dissolved in minimal $\mathrm{CHCl}_{3}$, loaded onto separate $1000 \mu \mathrm{m}$ prep-TLC plates and run using the optimal 9:1 $\mathrm{CHCl}_{3} / \mathrm{MeOH}$ 
solvent system. The four bands of interest were scraped and analyzed by HPLCDAD for peak identity. The scraped bands contained the expected compound and were individually run using prep-HPLC. Major peaks were collected at $12.5,14.0,15.6$ and $18.0 \mathrm{~min}$ that corresponded to the four most dense and apparent spots on TLC. These fractions were then dried under vacuum and tested by HPLC, TLC, MS and NMR for purity. Structures were then elucidated using HRMS and NMR data (see Results).

Further testing revealed that purification of E. amstelodami metabolites could be performed with greater efficiency when removing silica gel chromatography from the procedure.

\subsubsection{E. herbariorum strains CBS 47-F8 and CBS 47-F9 filtrate extact}

Strains CBS 47-F8 and CBS 47-F9 were chosen for large scale fermentation because they produced large numbers of compounds common in other strains of this species (and E. amstelodami) In addition, these strains contained at least three metabolites not detected in E. amstelodami strains. Ten litre cultures of each strains were fermented and extracted as previously described.

Optimum separation of major metabolites was achieved by prep-TLC and prepHPLC. E. herbariorum extracts were differentiated from E. amstelodami by a major dark purple band $\left(\mathrm{R}_{\mathrm{f}} 0.32\right)$ and two other bands with lower $\mathrm{R}_{\mathrm{f}}$ values (see Results). Isolation of these new metabolites proved difficult by prep-TLC and prep-HPLC by these methods but an alternative prep-HPLC gradient method was 
sufficient (Table 3). Metabolite structures could then be determined by NMR spectroscopy and HRMS.

\subsubsection{E. amstelodami and E. herbariorum mycelial extracts}

Metabolite profiles of mycelial extracts were very similar by TLC and HPLCDAD between $E$. amstelodami and $E$. herbariorum strains. The non-polar nature of the compounds was apparent by their later elution times compared to the filtrate extracts. Spotting of these extracts revealed few but intense spots migrating with large $R_{f}$ values when run under the optimal filtrate conditions (9:1 $\left.\mathrm{CHCl}_{3} / \mathrm{MeOH}\right)$. New solvent systems using hexane/ethyl acetate were employed in an attempt to better separate these metabolites for determination. Systems tested included $1: 1,3: 1,4: 1,9: 1$ and 19:1. Best separation was achieved using 19:1 hexane/ethyl acetate and bands could be scraped from the prep-TLC plate after multiple elutions. Separations were still difficult but scrapings were made from the center of the bands, taking care to avoid possible contamination from partially overlapping compounds. After extraction from the silica using chloroform followed by drying, NMR was performed on three prominent bands. HRMS was then utilized to obtain an accurate mass and structures were assigned.

\subsubsection{A. ustus s.l. strains IBT 28269 and IBT 28272 filtrate extract}

Ten litres of culture were extracted, washed and filtered as previously described. Initial compound isolation was performed using both sizes of silica gel 
chromatography columns. Testing revealed many compounds to be contained in similar fractions. The gradient slope was then slowed to $0.5 \% \mathrm{MeOH} / \mathrm{CHCl}_{3}$ increments but did little to improve isolation as many compound were collected as mixtures between $1.5-6.0 \% \mathrm{MeOH} / \mathrm{CHCl}_{3}$.

The prep-TLC method was then tested for its ability to separate and recover the compounds. The extract was dissolved in minimal ethyl acetate and spotted on a $1000 \mu \mathrm{m}$ prep-TLC plate and run using multiple elutions of 2:1 hexane/ethyl acetate and 9:1 $\mathrm{CHCl}_{3} / \mathrm{MeOH}$. Although this method appeared to work with screening ( $0.2 \mathrm{~mm}$ silica plates), resolution was found to be poor with these and $500 \mu \mathrm{m}$ prep-TLC plates. Further testing revealed satisfactory separation occurred when plates were run with multiple elutions in $2 \% \mathrm{MeOH} / \mathrm{CHCl}_{3}$. However, two major compounds $\left(\mathrm{R}_{\mathrm{f}} 0.48,0.45\right)$ overlapped making isolation difficult (see Results). Other major compounds $\left(R_{f} \quad 0.72,0.55,0.22\right)$ had good separation but were recovered from plate scrapings with limited success. Loss of compound could have been due to binding to the TLC plate or degradation of the compound because of the slightly acidic silica. This method proved unsatisfactory as there was poor separation of compounds and low recovery.

Compound separation was then attempted on a newly extracted $10 \mathrm{~L}$ Glaxo bottle fermentation extract using SPE columns. After sample loading and initial washing, a gradient of $\mathrm{CH}_{3} \mathrm{CN} / \mathrm{H}_{2} \mathrm{O}$ was applied to the column starting with $10 \%$ and increasing to $100 \% \mathrm{CH}_{3} \mathrm{CN}$ in $5 \%$ intervals for crude separation of 
increasingly non-polar compounds. HPLC-DAD analysis of the elutants revealed that major metabolites were contained in $20,25,30,40$ and $50 \%$ $\mathrm{CH}_{3} \mathrm{CN}: \mathrm{H}_{2} \mathrm{O}$ fractions.

Prep-HPLC was utilized on the above fractions, however, a new program was required to maximize peak resolution. Major compounds of interest were shown to elute after $40 \%$ and before $65 \% \mathrm{CH}_{3} \mathrm{CN}: \mathrm{H}_{2} \mathrm{O}$. Therefore, the solvent gradient between this range was increased slowly over a 35 min time period for best peak resolution (Table 3).

Table 3: Prep-HPLC timetable for isolation of $A$. ustus s.l. metabolites

\begin{tabular}{cccc}
\hline time $(\min )$ & $\begin{array}{c}\mathrm{H}_{2} \mathrm{O}, \mathrm{TFA} \\
(0.0125 \% \mathrm{v} / \mathrm{v})\end{array}$ & $\begin{array}{c}\mathrm{CH}_{3} \mathrm{CN}, \mathrm{TFA} \\
(0.0125 \% \mathrm{v} / \mathrm{v})\end{array}$ & $\begin{array}{c}\text { flow rate } \\
(\mathrm{mL} / \mathrm{min})\end{array}$ \\
\hline 0 & 90 & 10 & 25 \\
5 & 60 & 40 & 25 \\
40 & 35 & 65 & 25 \\
45 & 90 & 10 & 25
\end{tabular}

Major metabolites were collected at 5.2, 7.5, 11.2, and 14.4 min. The $\mathrm{CH}_{3} \mathrm{CN}$ was removed from each fraction by rotary evaporation at $30^{\circ} \mathrm{C}$ and the remaining fraction loaded back onto the SPE column as previously described for water removal. All fractions were further purified by repeating the procedure and dried as above. Compound purity was tested by TLC, HPLC-DAD, MS and by various NMR techniques. Major metabolite structures were elucitated from the resulting data. 


\subsection{Quantitation of Metabolites and Method Validation}

\subsubsection{Standard curve}

No standards were commercially available for any of the compounds of interest, therefore a known weight of each (approximately $1 \mathrm{mg}$ ) was purified using the described methods above. A $1 \mathrm{mg} / \mathrm{mL}$ stock solution of each compound was made up in $\mathrm{CH}_{3} \mathrm{CN}$. From the stock solution, serial dilutions were made to create a range of concentrations for standard curve construction. The standard curve was obtained by plotting HPLC-DAD peak area counts versus amount of compound loaded on the column at $254 \mathrm{~nm}$. Concentrations of $1 \mathrm{mg} / \mathrm{mL}, 0.1$ $\mathrm{mg} / \mathrm{mL}$ and $0.01 \mathrm{mg} / \mathrm{mL}$, representing $10 \mu \mathrm{g}$ to $0.1 \mu \mathrm{g}$ of the compound on the column were used. From the standard curve, and the percent recovery of the extraction procedure, the production of each metabolite by each strain could be quantified in $(\mu \mathrm{g} / \mathrm{g}) / \mathrm{L}$.

\section{$\underline{2.5 .2 \text { Recovery }}$}

From the standard curves, varying quantities of isolated E. amstelodami extract containing the four major metabolites were used to spike $50 \mathrm{~mL}$ of sterile CYA media in triplicate. Quantities representing 5,10 and 20 $\mu \mathrm{g}$ on the column of the major metabolites of E. amstelodami and E. herbariorum were used. The spiked

media was extracted, dried and analyzed by HPLC-DAD as before. Peak identities were confirmed by comparing resulting spectra to the standard UV full-scan spectra. Using the equations from the standard calibration curves, the 
percent recovery of each extracted compound was then determined. Amounts representing 10,20 and $40 \mu \mathrm{g}$ on the column of $A$. ustus s.l. major metabolites were spiked, extracted and recoveries calculated as previous.

Great care was taken to limit exposure of A. ustus s.l. metabolites to light. Small amounts of the major compounds were left in the light in clear vials for two days and HPLC-DAD were chromatograms compared to those being stored in amber vials for the same time period. Chromatograms of light protected compounds remained unchanged with regards to UV spectra and retention times. In contrast, light exposed compounds eluted much earlier with poor chromatography and inconsistent UV maximums. The physical appearance of the compounds also changed from a pale yellow to a brown colour. Eurotium metabolites did not appear to be light sensitive by these tests but as a precaution all experiments were performed with the lights off and away from natural light sources. All cultures were grown in darkness (covered in aluminum foil), filtered and extracted in darkness, and all samples and standards were stored in amber vials.

\subsubsection{Recovery of metabolites from prep-TLC plates}

The efficiency of compound isolation using the prep-TLC method was tested by applying a extract of E. amstelodami culture containing $2 \mathrm{mg}$ of a major metabolite $\left(R_{f} 0.60\right)$ to a $250 \mu \mathrm{m}$ prep-TLC plate and run using 9:1 $\mathrm{CHCl}_{3} / \mathrm{MeOH}$. The scraped material was then washed with the running solvent and many other solvent combinations were tested for compound recovery. The 
suspension was filtered, dried under nitrogen gas and run on HPLC-DAD. Using the standard curve, the TLC purification method was found to have between an $85-90 \%$ recovery of pure compound and was suitable for preparatory scale isolations.

The same procedure was performed on A. ustus s.l. extracts. HPLC-DAD analysis of the scraped bands calculated between $40-50 \%$ compound recovery and was probably due to irreversible binding of compound to the silica. Because of this large loss and poor band resolution, prep-TLC plates were not used for metabolite isolation in this species. 


\subsection{Instrumentation}

$\underline{\text { HPLC analysis }}$

A 1100 series Hewlett Packard HPLC-diode array detector (DAD) with built in degasser, and four pumps was used for metabolite analysis.

\section{$\underline{\text { HPLC columns }}$}

For analytical analysis of fungal extracts a Synergi Max-RP, $250 \times 4.6 \mathrm{~mm}, 4 \mu \mathrm{m}, 80 \AA$ column was employed. For semi-preparatory work a Synergi Max-RP, 4 u MAX-RP, 80 $\AA 250 \times 4.60,4$ microns (Phenomenex, California) was used.

\section{Preparatory HPLC}

A Walters Delta Prep 3000 preparative chromatography system with a Walters 484 tunable absorbance detector using a Synergi 10u Max-RP $80 \AA 250 \times 21.20 \mathrm{~mm} 10$ micron column was used for isolation of secondary metabolites.

\section{NMR analysis}

NMR spectra were acquired on a Bruker Avance 300 spectrometer at $300.13 \mathrm{MHz}\left({ }^{1} \mathrm{H}\right)$ or $75.0 \mathrm{MHz}\left({ }^{13} \mathrm{C}\right)$ operating at $303^{\circ} \mathrm{K}$, using a $5 \mathrm{~mm}$ inverse triple $(\mathrm{H} / \mathrm{C} / \mathrm{N})$ probe (Carleton University). When required, compounds were analyzed with a Bruker Avance $400 \mathrm{MHz}$ with $5 \mathrm{~mm}$ auto-tuning broadband probe with a $\mathrm{Z}$ gradient (University of Ottawa). A Bruker ARX $500 \mathrm{MHz}$ with a three mm inverse probe was also used in some cases (Agriculture and Agri-Food Canada, Ottawa). NMR spectra were determined in 
$\mathrm{CD}_{3} \mathrm{CN}, \mathrm{CDCl}_{3}$ or $\mathrm{C}_{3} \mathrm{D}_{6} \mathrm{O}$ and chemical shifts were reported relative to tetramethysilane (TMS). Chemical shift assignments were made with ${ }^{1} \mathrm{H} /{ }^{1} \mathrm{H}(\mathrm{COSY}, \mathrm{NOESY})$ and ${ }^{1} \mathrm{H} /{ }^{13} \mathrm{C}$ (HMQC, HMBC) inverse correlation spectra using standard Bruker pulse sequences.

\section{$\underline{\text { FT-IR analysis }}$}

FT-IR (Varian 1000 Scimitar Series) analysis was performed on all major compounds. Compounds were dissolved in minimal $\mathrm{CHCl}_{3}$ and pipetted onto a salt pellet and run. Major functional groups could be assigned to the spectrum and compared to literature values where available.

\section{Mass spectrometry analysis}

High resolution mass spectrometry (HRMS) data was obtained on a Kratos Concept instrument (University of Ottawa Mass Spectrometer Centre).

\section{$\underline{\text { LC-DAD-HRMS analysis of minor metabolites }}$}

LC-DAD-HRMS (Liquid Chromotography-UV-High-Resolution Mass Spectrometry) was utilized for determination of minor metabolites from A. ustus s.l. and E. amstelodami strains where there was inadequate material for NMR analysis. The signal was enhanced by analyzing dried HPLC waste extracts or minor bands by TLC where major metabolites were removed. The accurate masses and UV spectra signatures were searched in the literature for matches of known compounds. LC-DAD-HRMS analysis was performed on an Agilent 
1100 system equipped with a photodiode array detector and a $50 \AA, 2 \mathrm{~mm} \mathrm{ID,}$ Luna C18 II column (Phenomenex, Torrance, CA). The LC system was coupled to an LCT orthogonal time-of-flight mass spectrometer (Waters-Micromass, Manchester, U.K.), with a Z-spray electrospray ionization (ESI) source and a LockSpray probe. The LC system was operated using $\mathrm{H}_{2} \mathrm{O} / \mathrm{CH}_{3} \mathrm{CN}$ gradient systems starting from $5 \% \mathrm{CH}_{3} \mathrm{CN}$ and increasing to $100 \% \mathrm{CH}_{3} \mathrm{CN}$ in $20 \mathrm{~min}$. Samples were analyzed in $\mathrm{ESI}^{+}$mode. $\mathrm{H}_{2} \mathrm{O}$ was buffered with $10 \mathrm{mM}$ ammonium formate and $20 \mathrm{mM}$ formic acid and $\mathrm{CH}_{3} \mathrm{CN}$ with $20 \mathrm{mM}$ formic acid. Leucine enkephalin was used as the lock mass in both polarities. 


\section{RESULTS}

\subsection{Initial Culture Fermentation}

Five strains of E. amstelodami, three strains of E. herbariorum, two strains of E. rubrum and five strains of $A$. ustus s.l. were chosen at random and fermented in CYA and $2 \%$ malt extract media. Resulting cellular dry weights are summarized in Tables 4A-D for comparison. Dry cellular mass is a good indicator of how well the fungal culture is able to utilize a medium for growth. Resulting cell masses of E. amstelodami and A. ustus s.l. strains were 15.5 and 26 times greater respectively when grown on CYA media compared to $2 \%$ malt extract. E. herbariorum and E. rubrum did not grow on malt extract solution.

Table 4A: Comparison of E. amstelodami dry mycelial weight on different media

\begin{tabular}{ccc}
\hline strain & $\begin{array}{c}\text { mycelial weight }(\mathrm{g} / \mathrm{L}) \\
2 \% \text { malt extract }\end{array}$ & $\begin{array}{c}\text { mycelial weight }(\mathrm{g} / \mathrm{L}) \\
\text { CYA }\end{array}$ \\
\hline & & \\
J1005-19 & $0.60 \pm 0.10$ & $7.25 \pm 0.50$ \\
IBT 28307 & - & $6.48 \pm 2.31$ \\
IBT 28252 & - & $7.80 \pm 1.58$ \\
J9688-3 & $0.55 \pm 0.05$ & $7.28 \pm 1.50$ \\
IBT 28248 & $0.50 \pm 0.05$ & $6.87 \pm 0.82$ \\
\hline mean & $0.55 \pm 0.05$ & $7.12 \pm 1.34$ \\
\hline
\end{tabular}

- indicates no growth

Table 4B: Comparison of E. herbariorum dry mycelial weight on different media

\begin{tabular}{ccc}
\hline strain & $\begin{array}{c}\text { mycelial weight }(\mathrm{g} / \mathrm{L}) \\
2 \% \text { malt extract }\end{array}$ & $\begin{array}{c}\text { mycelial weight }(\mathrm{g} / \mathrm{L}) \\
\text { CYA }\end{array}$ \\
\hline & & \\
$47-\mathrm{G} 1$ & - & $5.38 \pm 1.62$ \\
$47-\mathrm{F} 9$ & - & $4.01 \pm 0.91$ \\
$47-\mathrm{F} 8$ & - & $4.70 \pm 0.81$ \\
\hline mean & - & $4.70 \pm 0.69$ \\
\hline
\end{tabular}


Table 4C: Comparison of E. rubrum dry mycelial weight on different media

\begin{tabular}{ccc}
\hline strain & $\begin{array}{c}\text { mycelial weight }(\mathrm{g} / \mathrm{L}) \\
2 \% \text { malt extract }\end{array}$ & $\begin{array}{c}\text { mycelial weight }(\mathrm{g} / \mathrm{L}) \\
\text { CYA }\end{array}$ \\
\hline & - & $10.00 \pm 1.30$ \\
$47-\mathrm{F} 4$ & - & $5.20 \pm 0.63$ \\
$47-\mathrm{F} 5$ & - & $7.60 \pm 3.39$ \\
\hline mean & -
\end{tabular}

Table 4D: Comparison of $A$. ustus s.l. dry mycelial weight on different media

\begin{tabular}{ccc}
\hline strain & $\begin{array}{c}\text { mycelial weight }(\mathrm{g} / \mathrm{L}) \\
\text { 2\% malt extract }\end{array}$ & $\begin{array}{c}\text { mycelial weight }(\mathrm{g} / \mathrm{L}) \\
\text { CYA }\end{array}$ \\
\hline & & \\
K0954-4 & - & $12.20 \pm 1.20$ \\
IBT 28272 & 0.40 & $12.05 \pm 1.45$ \\
K9197-10 & - & $17.35 \pm 2.31$ \\
L3931-10 & 1.05 & $17.15 \pm 1.88$ \\
IBT 28271 & 0.60 & $17.18 \pm 1.56$ \\
\hline mean & 0.68 & $15.12 \pm 1.68$ \\
\hline
\end{tabular}

All fermentations were extracted using the previously described method. After two weeks the CYA grown strains showed large peaks when analyzed by HPLC-DAD and intense spots by TLC. This was in contrast to the barely detectable peaks and the few faint spots originating from cultures grown on malt extract solution. Some of these small peaks were not seen in the CYA grown strains. They may have arisen from the ingredients of the medium and served as a control. Due to the greater cell mass and metabolite production resulting from CYA fermentations, this medium was used for growth of all other strains of each species. 


\subsection{Secondary Metabolites from E. amstelodami Filtrate Extract}

\subsubsection{Strain screening for major metabolites}

After fermentation in CYA and extraction of the remaining strains, TLC and HPLC-DAD screening results allowed for metabolite profiling comparisons between strains of the same species. Strain extracts were compared with regards to similarity and intensity of TLC spots and relative abundance of the metabolites based on peak area counts at 254 nm. The studied strains were both indoor and outdoor in origin, making it possible to compare metabolite profiles from both habitats. Results presented no obvious difference in metabolites of cultured fungi between these two environments, with the same major peaks and spots observed in each strain (data not shown).

HPLC-DAD chromatograms of E. amstelodami strains showed good separation of metabolites. Four major peaks at 13.0, 14.2, 15.5 and 22.3 min are designated 1-4 and are seen in a representative chromatogram in Figure 12. The corresponding TLC plate of the extract contained four dominant spots which appeared fluorescent blue $\left(R_{f} 0.80\right)$, yellow $\left(R_{f} 0.60\right)$, dark purple $\left(R_{f} 0.52,0.40\right)$ under UV light $(254 \mathrm{~nm})$ and are illustrated in Figure 13. TLC spots were matched to their corresponding HPLC peaks by running a portion of the extract on a $250 \mu \mathrm{m}$ glass backed TLC plate and single bands were scraped for HPLC-DAD analysis. 




Figure 12: HPLC-DAD chromatogram of the filtrate extract of $E$. amstelodami strain IBT 28307 with assigned peak numbers $(254 \mathrm{~nm})$



Figure 13: TLC plate drawing of major metabolites from E. amstelodami strain IBT 28307 filtrate extract with $\mathrm{R}_{\mathrm{f}}$ values and compound number indicated $\left(9: 1 \mathrm{CHCl}_{3} / \mathrm{MeOH}\right.$, $254 \mathrm{~nm}$ ) 
A review of the literature provided a number of expected metabolites for this species. The published UV spectral data and chromatographical information for metabolites such as echinulins, flavoglaucin and physcion were used in an attempt to identify known metabolites but proved inconclusive. Although there was published data on these metabolites, no standards were available at the time of analysis making identifications difficult. It was therefore necessary to perform large scale fermentations of the best isolates to produce milligrams of isolatable metabolites required for structure elucidation by NMR experiments.

\subsubsection{Major metabolite determination}

Large scale fermentation and extraction of strains IBT 28307 and J9589-1 allowed for the isolation of major metabolites 1-4 by prep-TLC followed by prep-HPLC. Metabolites were then identified by HRMS and NMR experiments. They are presented in the order of which their structures were determined. ${ }^{1} \mathrm{H}$ NMR spectra can be found in the appendix.

\section{Compound 1}

Compound 1 was crystallized as ivory crystals from methanol with a melting point of $262-264^{\circ} \mathrm{C}$. The TLC plate revealed one dark purple spot under UV light $(366 \mathrm{~nm})$ in $10 \% \mathrm{MeOH} / \mathrm{CHCl}_{3}$ and the HPLC-DAD chromatogram had UV maxima at: $225(100)$, $288(50)$ and 233 (55). The ESI mass spectrum of 1 displayed the $[\mathrm{M}+1]^{+}$at $\mathrm{m} / \mathrm{z} 324$ and HRMS established the molecular formula of $\mathrm{C}_{19} \mathrm{H}_{21} \mathrm{~N}_{3} \mathrm{O}_{2}$ (calculated 323.1647, found 323.1628). The primary fragmentation pattern involved the loss of mass $69\left(\mathrm{C}_{5} \mathrm{H}_{9}\right.$ or isoprene unit) from the molecular ion to give a base peak at $\mathrm{m} / \mathrm{z} 254$. The remaining 
prominent peaks were observed at (EI) $\mathrm{m} / \mathrm{z}$ (rel. int.): $182(60), 167$ (24). The strong absorptions [IRv $\left.v_{\max }\left(\mathrm{CHCl}_{3}, \mathrm{~cm}^{-1}\right)\right]$ at 3360 and 2980 indicated the presence of $\mathrm{N}-\mathrm{H}$ functionalities while the absorptions at 1670 and 1630 were attributed to $\mathrm{C}=\mathrm{O}$ and $\mathrm{C}=\mathrm{C}$ stretchings (Marchelli et al., 1977).

The diagnostic signals in the ${ }^{1} \mathrm{H}$ NMR spectrum of $\mathbf{1}$ were observed for the four aromatic protons $(\delta 7.10-7.41)$ with ortho and meta-couplings characteristic of $\mathrm{H}-4$ to $\mathrm{H}-7$ of the tryptophan derived moiety for neoechinulins. Three NH broad singlets $(\delta 9.57,6.61$, and 2.25) were consistent with echinulin and neoechinulins. The appearance of an olefinic proton singlet $(\delta 7.0, \mathrm{H}-10)$ indicated the linking of the diketopiperazine structure to the tryptophan derived region. Two overlaying methyl singlets $(\delta 1.52,6 \mathrm{H})$, an AMX spin system at $\left[\delta 6.12\left(\mathrm{dd}, \mathrm{J}_{\text {trans }} 17.2, \mathrm{~J}_{\text {cis }} 10.7 \mathrm{~Hz}\right), \delta 5.14\left(\mathrm{dd}, \mathrm{J}_{\text {cis }} 10.2, \mathrm{~J}_{\text {gem }} 1.1 \mathrm{~Hz}\right)\right.$ and $\delta$ $5.09\left(\mathrm{dd}, \mathrm{J}_{\text {trans }} 17.2, \mathrm{~J}_{\text {gem }} 1.1 \mathrm{~Hz}\right.$ )] were assignable to the dimethyl allyl chain present in neoechinulins (Table 5).

It is worth noting that many neoechinulins differ at the C-14 position and may act as a distinguishing region. In the case of 1 , a doublet integrating to 3 protons was visible at $\delta$ $1.48(\mathrm{~J}=6.9 \mathrm{~Hz})$, as well as a doublet of a quartet integrating to one proton at $\delta 4.21$ $(\mathrm{J}=6.9 \mathrm{~Hz}, \mathrm{~J}=2.0 \mathrm{~Hz})$. This confirmed the presence of a methine and a methyl unit at C14 and $\mathrm{C}-17$ respectively. These carbons resonated at $\delta 50.5(\mathrm{C}-14)$ and $\delta 17.9(\mathrm{C}-17)$ in the ${ }^{13} \mathrm{C}$ NMR and HSQC spectra of 1 supporting this deduction. Other key signals were 
observed for the amide carbonyl groups at $\delta 167.1(\mathrm{C}-15)$ and $\delta 160.3$ (C-12), the vinylic system at $\delta 145.2(\mathrm{C}-21)$ and $\delta 112.6(\mathrm{C}-22)$, the olefinic methine and quarternary carbons at $\delta 111.6(\mathrm{C}-10), 145.9(\mathrm{C}-2)$ and $103.3(\mathrm{C}-3)$ respectively, and six aromatic carbons resonating at $\delta$ 112.4-135.2 (Table 5). These data are consistent with neoechulin A (Figure 14); (Dossena et al., 1974). The absolute stereochemistry at the C-14 position has been determined to be 14-S (Marchelli et al., 1974). The optical rotation was determined at $[\alpha]_{D}^{22}-50^{\circ}\left(c=1, \mathrm{CHCl}_{3}\right)$ and was in agreement with literature values (Marchelli et al., 1977; Aoki et al., 2006).

\section{Compound 2}

Compound 2 was crystallized from methanol as yellow crystals (m.p. $235-237^{\circ} \mathrm{C}$ ). Spotting on a TLC plate revealed one yellow spot under UV light $(366 \mathrm{~nm})$ in $10 \%$ $\mathrm{MeOH} / \mathrm{CHCl}_{3}$ and the HPLC-DAD chromatogram had UV maxima at: $229(100), 272$ (66) and 368 (32). Inspection of the ESI mass spectrum of 2 revealed $[M+1]^{+}$at $\mathrm{m} / \mathrm{z} 322$, and HRMS gave 321.1476, corresponding to the formula $\mathrm{C}_{19} \mathrm{H}_{19} \mathrm{~N}_{3} \mathrm{O}_{2}$ (calculated: 321.1477). As with neoechinulin A, a prominent ion appeared at MS (EI) $\mathrm{m} / \mathrm{z}$ (rel. int.): 252 (70) due to the loss of $\mathrm{C}_{5} \mathrm{H}_{9}$. IR spectroscopy showed absorptions similar to neoechinulin $\mathrm{A}$ at $\mathrm{IRv} v_{\max }\left(\mathrm{CHCl}_{3}, \mathrm{~cm}^{-1}\right) 3349,2917$ and 2849 indicating $\mathrm{NH}$ functional groups, $\mathrm{a} \mathrm{C}=\mathrm{O}$ at 1680 and $\mathrm{C}=\mathrm{C}$ at 1640 .

The NMR data acquired for $\mathbf{2}$ was virtually identical to those of $\mathbf{1}$ except for the absence of the methyl and methine signals at $\delta 1.48(\mathrm{H}-17)$ and at $\delta 4.21(\mathrm{H}-14)$ respectively; and some variations in the chemical shifts of the NH protons (Table 5). An additional pair of 
singlets appeared in the olefinic region at $\delta 5.37(\mathrm{~s}, 1 \mathrm{H})$ and $\delta 4.95(\mathrm{~s}, 1 \mathrm{H})$ indicative of two protons on a terminal double bond. The carbon bearing these protons resonated at $\delta$ 100.3 in the HSQC spectrum of 1 confirming this assignment. This causes a shift for the amide (C-15), which resonated at $\delta 156.72$ instead of $\delta 167.1$ in 1 . In addition, the chirality of $\mathbf{1}$ was lost as evident by an optical rotation of $[\alpha]_{D}^{22} 0^{\circ}\left(c=1, \mathrm{CHCl}_{3}\right)$ and $\mathbf{2}$ was determined to be neoechinulin B (Figure 14); (Marchelli et al., 1977).


Figure 14: Structures of neoechinulin A (1) and neoechinulin B (2) 
Table 5: Comparative ${ }^{1} \mathrm{H}$ and ${ }^{13} \mathrm{C}$ NMR data for 1 and $2\left(400 \mathrm{MHz}, \mathrm{CD}_{3} \mathrm{CN}\right)$

\begin{tabular}{|c|c|c|c|c|}
\hline \multirow[b]{2}{*}{ position } & \multicolumn{2}{|l|}{1} & \multicolumn{2}{|l|}{2} \\
\hline & $\delta_{\mathrm{H}}(\mathrm{J}, \mathrm{Hz})$ & $\delta_{\mathrm{C}}$ & $\delta_{\mathrm{H}}(\mathrm{J}, \mathrm{Hz})$ & $\delta_{\mathrm{C}}$ \\
\hline 1 & $9.57(\mathrm{br} \mathrm{s}, 1 \mathrm{H}, \mathrm{NH})$ & & $9.57(\mathrm{br} \mathrm{s}, 1 \mathrm{H}, \mathrm{NH})$ & \\
\hline 2 & & 145.9 & & 145.6 \\
\hline 3 & & 103.3 & & 104.0 \\
\hline 4 & $7.31(\mathrm{~d}, 7.8,1 \mathrm{H})$ & 118.7 & $7.35(\mathrm{~d}, 7.8,1 \mathrm{H})$ & 119.7 \\
\hline 5 & $7.10(\mathrm{dt}, 7.1,1.1,1 \mathrm{H})$ & 120.8 & $7.12(\mathrm{dt}, 7.4,1.21 \mathrm{H})$ & 121.2 \\
\hline 6 & $7.18(\mathrm{dt}, 7.2,1.2,1 \mathrm{H})$ & 119.5 & $7.19(\mathrm{dt}, 7.5,1.3,1 \mathrm{H})$ & 122.7 \\
\hline 7 & $7.41(\mathrm{~d}, 7.8,1 \mathrm{H})$ & 112.4 & $7.48(\mathrm{~d}, 7.7,1 \mathrm{H})$ & 112.5 \\
\hline 8 & & 135.2 & & 135.8 \\
\hline 9 & & 126.2 & & 126.0 \\
\hline 10 & $7.00(\mathrm{~s}, 1 \mathrm{H})$ & 111.6 & $7.07(\mathrm{~s}, 1 \mathrm{H})$ & 112.3 \\
\hline 11 & & 127.2 & & 127.0 \\
\hline 12 & & 160.3 & & 157.9 \\
\hline 13 & $2.25(\mathrm{br} \mathrm{s}, 1 \mathrm{H}, \mathrm{NH})$ & & $7.72($ br s, $1 \mathrm{H}, \mathrm{NH})$ & \\
\hline 14 & $4.21(\mathrm{dq}, 6.9,2.0,1 \mathrm{H})$ & 50.5 & & \\
\hline 15 & & 167.1 & & 156.72 \\
\hline 16 & $6.61(\mathrm{br} \mathrm{s}, 1 \mathrm{H}, \mathrm{NH})$ & & $8.77(\mathrm{br} \mathrm{s}, 1 \mathrm{H}, \mathrm{NH})$ & \\
\hline 17 & $1.48(\mathrm{~d}, 6.9 \mathrm{~Hz}, 3 \mathrm{H}, \mathrm{Me})$ & 17.9 & $5.37(\mathrm{~s}, 1 \mathrm{H}), 4.95(\mathrm{~s}, 1 \mathrm{H})$ & 100.38 \\
\hline 18 & & 40.2 & & 40.10 \\
\hline 19 & $1.52(\mathrm{~s}, 3 \mathrm{H}, \mathrm{Me})$ & 27.5 & $1.53(\mathrm{~s}, 3 \mathrm{H})$ & 27.82 \\
\hline 20 & $1.52(\mathrm{~s}, 3 \mathrm{H}, \mathrm{Me})$ & 27.5 & $1.53(\mathrm{~s}, 3 \mathrm{H})$ & 27.73 \\
\hline 21 & $6.12(\mathrm{dd}, 17.2,10.7,1 \mathrm{H})$ & 145.2 & $6.12(\mathrm{dd}, 17.2,10.8,1 \mathrm{H})$ & 145.78 \\
\hline 22 & $5.14(\mathrm{dd}, 10.2,1.1,1 \mathrm{H})$ & 112.6 & $5.15(\mathrm{dd}, 10.2,1.0,1 \mathrm{H})$ & 112.72 \\
\hline & $5.09(\mathrm{dd}, 17.2,1.1,1 \mathrm{H})$ & & $5.11(\mathrm{dd}, 17.6,1.0,1 \mathrm{H})$ & \\
\hline
\end{tabular}

\section{Compound $\mathbf{3}$}

Purification was attempted using prep-HPLC and prep-TLC. TLC spotting revealed a dark purple spot under UV light $(366 \mathrm{~nm})$ in $10 \% \mathrm{MeOH}^{-} \mathrm{CHCl}_{3}$. The HPLC-DAD chromatogram had UV maxima at: 229 (100), 285 (31) and 347 (44). The ESI mass spectrum displayed $[\mathrm{M}+1]^{+}$at $\mathrm{m} / \mathrm{z} 322$ and HRMS gave: 321.1476 corresponding to $\mathrm{C}_{19} \mathrm{H}_{19} \mathrm{~N}_{3} \mathrm{O}_{2}$ (calculated at 321.1477). HRMS and the MS (EI) fragmentation pattern was identical to that of $\mathbf{2}$. 
Initial ${ }^{1} \mathrm{H}$ NMR analysis revealed distinct neoechinulin peaks of the unsubstituted aromatic ring. However, peaks at C-14 and C-17 characteristic of both 1 and 2 were present but did not integrate with consistency. Further isolations of this compound yielded similar results, with ${ }^{1} \mathrm{H}$ NMR peaks shifts and integrations not reproducible. HPLC-DAD analysis demonstrated partial and sometimes full conversion of compound 3 to 2 was supported by test TLC plates of the isolates. It may be that this compound is a closely related derivative of $\mathbf{2}$.

\section{Compound 4}

Compound 4 was isolated as opaque crystals with a melting point of $137-139^{\circ} \mathrm{C}$. Analysis by TLC revealed bright blue spot under UV light (366 nm) in 10\% $\mathrm{MeOH} / \mathrm{CHCl}_{3}$. The HPLC-DAD chromatogram had UV maxima at 205 (100) and 249 (60). The ESI mass spectrum exhibited $[\mathrm{M}+1]^{+}$at $\mathrm{m} / \mathrm{z}$ 333. HRMS found: 332.1264 , establishing a molecular formula of $\mathrm{C}_{18} \mathrm{H}_{20} \mathrm{O}_{6}$ (calculated at 332.1254). The major ion fragments were: MS (EI) m/z (rel. int.): 208 (8), $166(100), 125$ (12). A literature search of this mass gave no results of any previously determined metabolites from this or related species.

One and two-dimensional NMR experiments including NOESY, COSY, HMBC, HSQC and DEPT-135 revealed that 4 is comprised of at least six $\mathrm{CH}_{2}$ 's, two $\mathrm{CH}_{3}$ 's and four ester or amide carbonyl groups ( $\delta 164.1,164.9,165.2,165.3)$, two internal double bonds $(\delta 144.1,145.0,146.0,146.2)$ and an aliphatic system (Table 6). Despite much effort, the structure could not be deduced as there were many overlapping signals in the ${ }^{1} \mathrm{H}$ NMR 
and COSY spectra. Further literature searches encompassing all known fungal metabolites of this mass revealed epiheveadride or heveadride. From a detailed comparison of ${ }^{1} \mathrm{H}$ and ${ }^{13} \mathrm{C}$ NMR with published data (Hosoe et al., 2004a) and analysis of COSY and HMBC, the structure of 4 was elucidated to be epiheveadride (Figure 15). This was further supported by the base peak observed at $\mathrm{m} / \mathrm{z} 166$ in the MS due to the cleavage of the C-8/C-9 and C-3/C-4 bonds previously reported for heveadride (8-R, 9S); (Crane et. al., 1973). The absolute configuration of 4 has recently been determined to be 8-R and 9-R by X-ray crystallographic analysis (Hosoe et. al., 2004b).

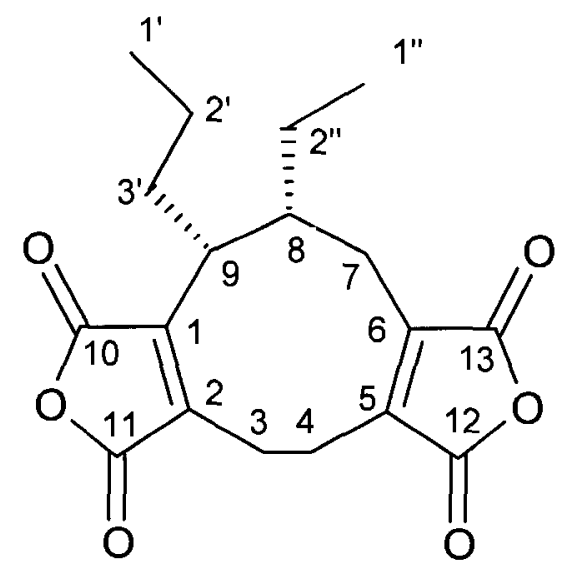

Figure 15: Structure of epiheveadride (4) 
Table 6: ${ }^{1} \mathrm{H}$ and ${ }^{13} \mathrm{C}$ NMR data for $4\left(400 \mathrm{MHz}, \mathrm{CDCl}_{3}\right)$

\begin{tabular}{|c|c|c|c|}
\hline position & $\overline{\delta_{\mathrm{H}}(\mathrm{J}, \mathrm{Hz})}$ & $\begin{array}{c}\delta_{\mathrm{C}} \\
(\mathrm{DEPT} 135)\end{array}$ & HMBC correlations \\
\hline 1 & & $146.0(\mathrm{C})$ & \\
\hline 2 & & $146.2(\mathrm{C})$ & \\
\hline 3 & $3.16(\mathrm{~m}, 1 \mathrm{H}) 2.19(\mathrm{~m}, 1 \mathrm{H})$ & $21.4\left(\mathrm{CH}_{2}\right)$ & C-1, C-11 \\
\hline 4 & $3.16(\mathrm{~m}, 1 \mathrm{H}) 2.21(\mathrm{~m}, 1 \mathrm{H})$ & $22.0\left(\mathrm{CH}_{2}\right)$ & C- $6, \mathrm{C}-12$ \\
\hline 5 & & $144.1(\mathrm{C})$ & \\
\hline 6 & & $145.0(\mathrm{C})$ & \\
\hline 7 & $\begin{array}{c}1.75(\mathrm{br} \mathrm{t}, 12.6,1 \mathrm{H}) \\
2.89 \mathrm{dd}(13.0,2.9,1 \mathrm{H})\end{array}$ & $28.0\left(\mathrm{CH}_{2}\right)$ & $C-5, C-13$ \\
\hline 8 & $2.11(\mathrm{~m}, 1 \mathrm{H})$ & $47.9(\mathrm{CH})$ & C-1", C-7 \\
\hline 9 & $2.42(\mathrm{~m}, 1 \mathrm{H})$ & $40.8(\mathrm{CH})$ & $\mathrm{C}-2^{\prime}, \mathrm{C}-3^{\prime}, \mathrm{C}-7$ \\
\hline 10 & & $164.1(\mathrm{C})$ & \\
\hline 11 & & $165.3(\mathrm{C})$ & \\
\hline 12 & & $165.2(\mathrm{C})$ & \\
\hline 13 & & 164.9 (C) & \\
\hline 1 ' & $0.87(\mathrm{t}, 7.3,3 \mathrm{H})$ & $13.9\left(\mathrm{CH}_{3}\right)$ & \\
\hline 2 & $1.14(\mathrm{~m}, 2 \mathrm{H})$ & $21.7\left(\mathrm{CH}_{2}\right)$ & \\
\hline 3 ' & $2.15(\mathrm{~m}, 1 \mathrm{H}), 1.56(\mathrm{~m}, 1 \mathrm{H})$ & $31.5\left(\mathrm{CH}_{2}\right)$ & $\mathrm{C}-1, \mathrm{C}-1$ ', C-2' \\
\hline $1 "$ & $1.08(\mathrm{t}, 7.0,3 \mathrm{H})$ & $12.9\left(\mathrm{CH}_{3}\right)$ & \\
\hline $2 "$ & $2.09(\mathrm{~m}, 1 \mathrm{H}), 0.98(\mathrm{~m}, 1 \mathrm{H})$ & $23.4\left(\mathrm{CH}_{2}\right)$ & $\mathrm{C}-1 "$ \\
\hline
\end{tabular}

\subsubsection{Minor metabolite determination}

HPLC-DAD-HRMS was employed on the crude filtrate extract to identify compounds for which there was insufficient material for NMR experiments. Identifications were based on known molecular weights and UV spectral data. A compound partially eluted with 3 at 13.0 min but was differentiated by mass: 325.1794 , corresponding to $\mathrm{C}_{19} \mathrm{H}_{19} \mathrm{~N}_{3} \mathrm{O}_{2}$ (calculated at 325.1785) and a UV spectrum with maxima at: 226 (100), 284 (25) and 290 (22). These HRMS and UV data were in agreement with literature values of preechinulin $[(+)$-L-alanyl (1,1-dimethylallyl tryptophan anhydride)] and has previously been isolated 
from this species with stereochemistry reported as 11-S and 14-S (Marchelli et al., 1977; Nielsen \& Smedsgaard, 2003) and is seen in Figure 16.

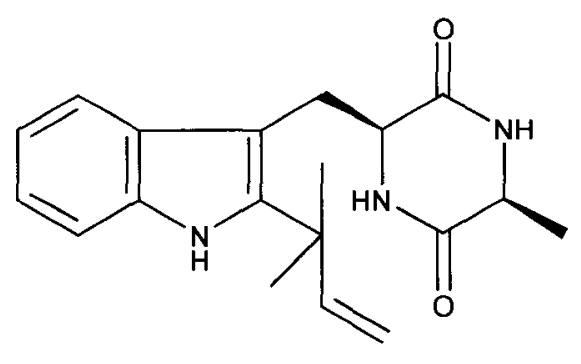

Figure 16: Structure of preechinulin

A second minor metabolite eluting at $14.6 \mathrm{~min}$ had a HRMS of 323.1220 , corresponding to $\mathrm{C}_{18} \mathrm{H}_{17} \mathrm{~N}_{3} \mathrm{O}_{3}$ (calculated at 323.1264) with UV maxima at: 228 (100), 284 (34) and 418 (20). These data are in agreement with literature values for neoechinulin E (Figure 17) and is a metabolite that has previously been isolated from this species (Dossena et al., 1975).<smiles>C=CC(C)(C)c1[nH]c2ccccc2c1/C=C1\NC(=O)C(=O)NC1=O</smiles>

Figure 17: Structure of neoechinulin $\mathrm{E}$

A third minor metabolite eluting at 20.6 minutes had a HRMS of 461.3086, corresponding to $\mathrm{C}_{29} \mathrm{H}_{39} \mathrm{~N}_{3} \mathrm{O}_{2}$ (calculated at 461.3037) with UV maxima at: 228 (100), 
279 (26) and 285 (20). Through a literature comparison to Nielsen \& Smedsgaard (2003), this metabolite was determined to be echinulin and is a commonly reported secondary metabolite of many Eurotium species (Figure 18). The stereochemistry was reported as 11-S and 14-S by Marchelli et al. (1977).

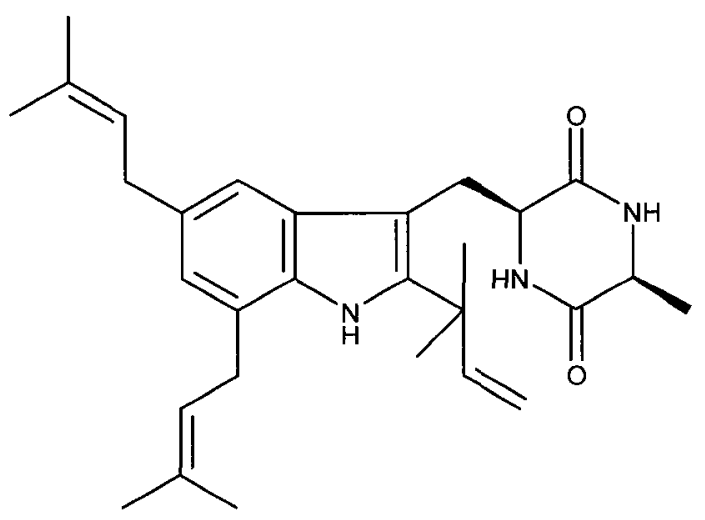

Figure 18: Structure of echinulin

\subsubsection{Metabolite assignments and quantities}

Figure 19 assigns the major and minor metabolites of the E. amstelodami filtrate extract to the corresponding HPLC-DAD chromatogram peaks. After characterization of the metabolites by retention time and characteristic UV spectra for this strain, their presence in other strains was determined and quantified using a standard curve. Metabolites contained in the filtrate and mycelial extracts are compared in Table 7. It is important to note that the three studied E. rubrum strains were chemically indistinguishable from these E. amstelodami strains and were only pursued for metabolite quantification (Table 17C, $18 \mathrm{C})$. 


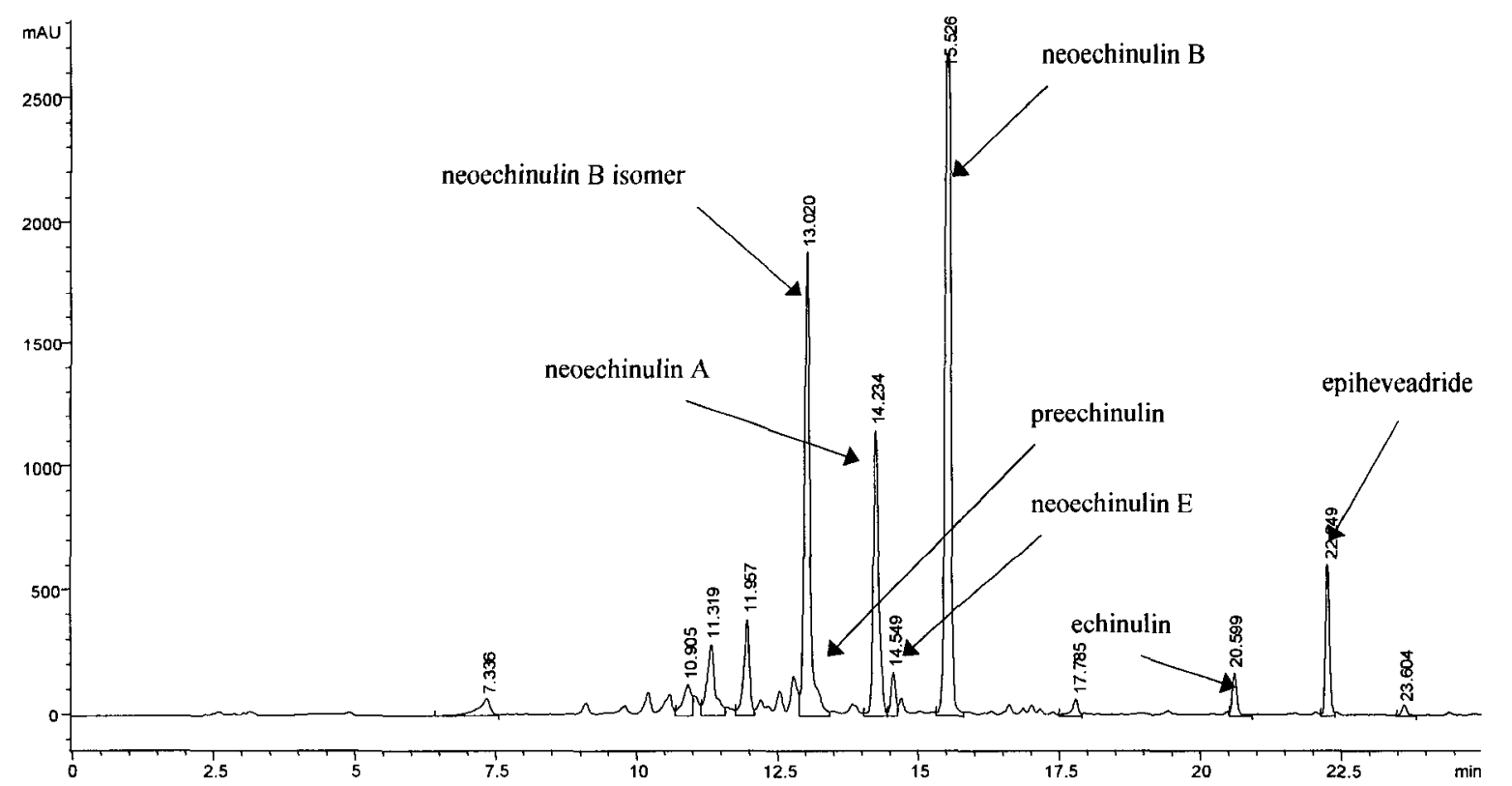

Figure 19: HPLC-DAD chromatogram of the filtrate extract of E. amstelodami strain IBT 28307 showing identified metabolites $(254 \mathrm{~nm})$

Table 7: Major secondary metabolites isolated from filtrate extracts of E. amstelodami

\begin{tabular}{ccc}
\hline & IBT $28307(\mu \mathrm{g} / \mathrm{g}) \mathrm{L}$ & J9589-1 $(\mu \mathrm{g} / \mathrm{g}) \mathrm{L}$ \\
\hline & & \\
neoechinulin A (1) & 5352 & 1665 \\
neoechinulin B (2) & 6795 & 8967 \\
neoechinulin deriv. (3) & 5675 & 4000 \\
epiheveadride (4) & 4589 & 1890 \\
\hline
\end{tabular}

\section{$\underline{\text { 3.3 Secondary Metabolites from } E \text {. herbariorum filtrate extract }}$}

\subsubsection{Strain screening for major metabolites}

E. herbariorum strains (CBS 47-F3, CBS 47-F8, CBS 47-F9) produced metabolites detected in both E. amstelodami and E. rubrum strains. However, the metabolites of $E$. herbariorum strain CBS 47-G1 showed no similarities to these species. 
The filtrate extract chromatogram of strain CBS 47-F9 is presented in Figure 20 and revealed major peaks at $13.2,14.6,15.8$, and 20.4 min which were identical with regards to UV spectra retention time to E. amstelodami metabolites. Other major peaks at 8.8, 10.8 and 11.5 min were not present in E. amstelodami strain profiles. The TLC run filtrate extract of strain CBS 47-F9 contained most spots present in E. amstelodami extracts as well as three other spots between $R_{f} 0.25-0.37$ appearing blue and green at 254 nm (Figure 21). Compounds of interest are assigned 5-11.

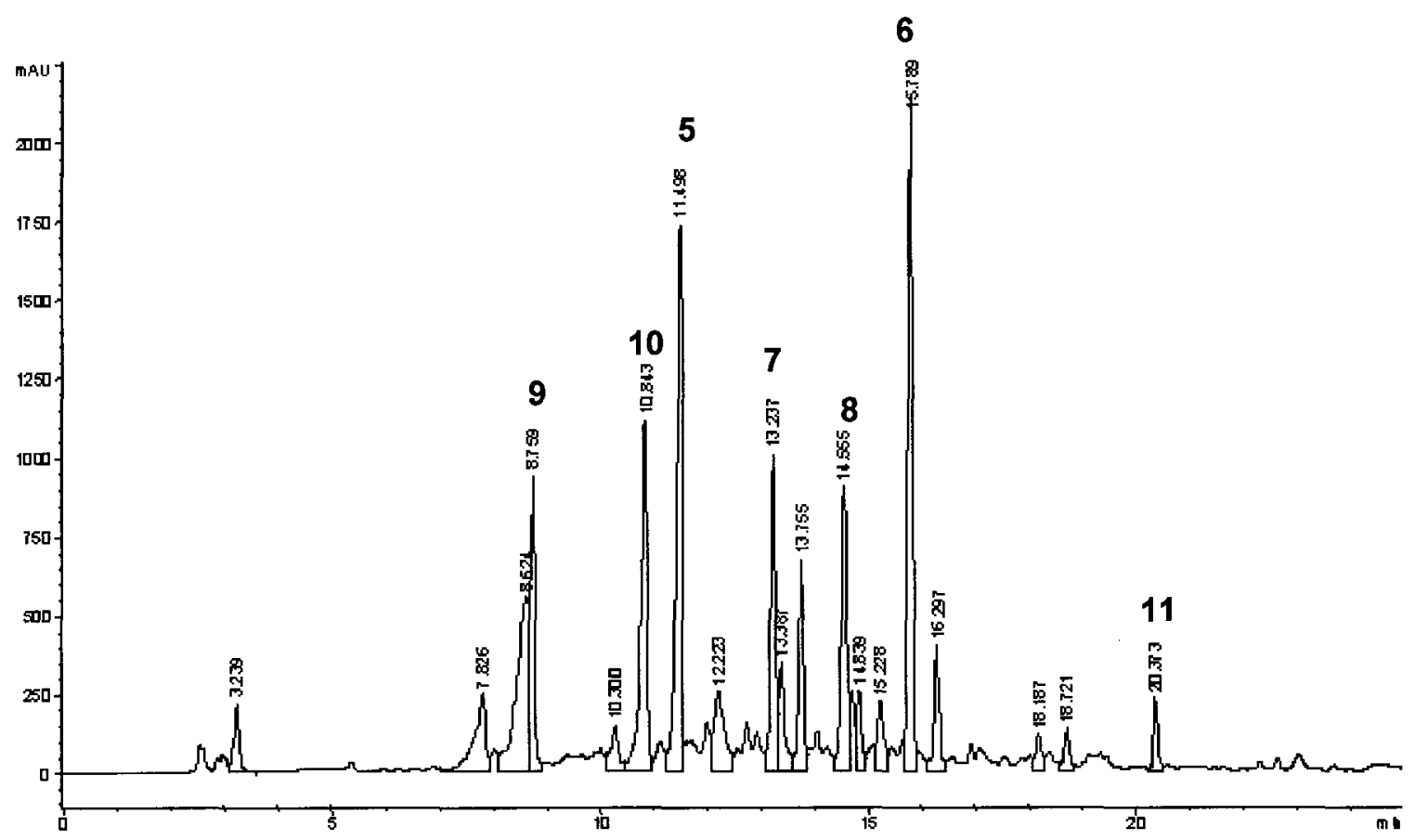

Figure 20: HPLC-DAD chromatogram of the filtrate extract of $E$. herbariorum strain 47F9 with assigned peak numbers $(254 \mathrm{~nm})$ 


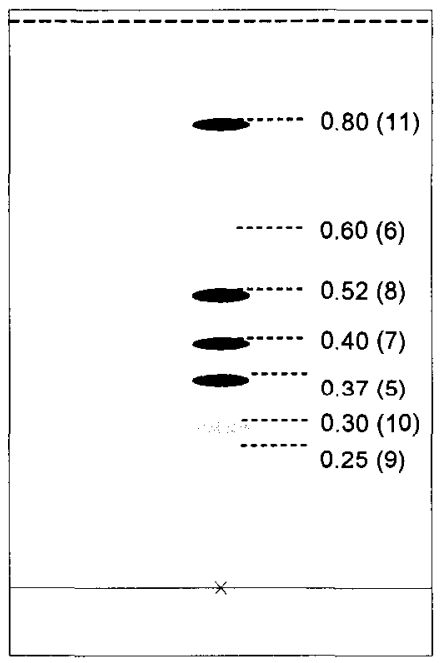

Figure 21: TLC plate drawing of major metabolites of $E$. herbariorum strain CBS 47-F9 filtrate extract with $\mathrm{R}_{\mathrm{f}}$ values and peak numbers indicated $\left(9: 1 \mathrm{CHCl}_{3} / \mathrm{MeOH}, 254 \mathrm{~nm}\right)$

\subsubsection{Major metabolite determination}

Large scale fermentation of strain CBS 47-F8 and CBS 47-F9 allowed for the isolation of major metabolites (5-11) by prep-TLC followed by prep-HPLC. Metabolites were then identified through HRMS and NMR experiments when required. They are presented in the order of which they were determined

\section{Compound 5}

Compound $\mathbf{5}$ was crystallized from methanol as pale yellow crystals with a melting point of $193-194^{\circ} \mathrm{C}$ and an optical rotation of $[\alpha]_{D}^{22}-14.8^{\circ}(c=1, \mathrm{MeOH})$. Analysis by TLC revealed one purple spot under UV light $(366 \mathrm{~nm})$ in $10 \% \mathrm{MeOH} / \mathrm{CHCl}_{3}$. The HPLCDAD chromatogram had UV maxima at: $218(100), 269(62)$ and 302 (24). The ESI mass spectrum displayed the $[\mathrm{M}+1]^{+}$at $\mathrm{m} / \mathrm{z} 293$ and HRMS found 292.1305 which provided the formula of $\mathrm{C}_{16} \mathrm{H}_{20} \mathrm{O}_{5}$ (calculated at 292.1305). The fragmentation pattern was: MS (EI) m/z (rel. int.): 292 (14), 193 (7), 99 (100). Strong IR bands [IRv $v_{\max }$ 
$\left.\left(\mathrm{CHCl}_{3}, \mathrm{~cm}^{-1}\right)\right]$ at 3190 and 2935 are indicative of hydroxyl groups, 1730 was attributed to an ester group while the absorption at 1464 was probably due to $\mathrm{CH}_{2}$ groups. Other strong bands at 1300-755 are in the range of the ether and $\mathrm{C}-\mathrm{C}$ regions. A mass search of the HRMS generated cladosporin as one possibility. However, isocladosporin, an isomer of cladosporin has been reported to have nearly identical UV, MS and IR data but contained differences in ${ }^{13} \mathrm{C}$ chemical shifts at position C-10 and C-14 (Jacyno et al., 1993).

The diagnostic signals in the ${ }^{1} \mathrm{H}$ NMR spectrum of $\mathbf{5}$ consisted of a downfield H-bonded phenolic proton at $\delta 11.27(\mathrm{C}-8-\mathrm{OH})$, demonstrating its proximity to the carbonyl group (C-1) in cladosporin (Table 8). Three oxygenated proton signals at $\delta 4.73(\mathrm{~m}, 1 \mathrm{H}, \mathrm{H}-3)$, $4.13(\mathrm{~m}, 1 \mathrm{H}, \mathrm{H}-10)$ and $4.02(\mathrm{~m}, 1 \mathrm{H}, \mathrm{H}-14)$, two aromatic protons at $\delta 6.2-6.3$ and benzylic protons at $\delta 2.87(\mathrm{~m}, 2 \mathrm{H})$ were observed. Two unique proton signals at $\delta 1.99$ (ddd, $\mathrm{J}_{9 \mathrm{R}-9 \mathrm{~S}} 14.6, \mathrm{~J}_{9 \mathrm{~S}-10} 10.1, \mathrm{~J}_{9 \mathrm{~S}-3} 3.6 \mathrm{~Hz}$, Pro-S H-9) and $\delta 1.87$ (ddd, Hz, J $\mathrm{J}_{9 \mathrm{R}-9 \mathrm{~S}} 14.7, \mathrm{~J}_{9 \mathrm{R}-3}$ 8.7, $\mathrm{J}_{9 \mathrm{R}-10}$ 3.0 Pro- $\mathrm{R} \mathrm{H}-9$ ) revealed a splitting pattern that is typical of geminal, trans, cis couplings. An aliphatic methyl doublet at $\delta 1.25(\mathrm{~d}, 6.5 \mathrm{~Hz}, \mathrm{H}-15)$ and two aliphatic proton multiplets at $1.73(\mathrm{~m}, 4 \mathrm{H})$ and $\delta 1.37(\mathrm{~m}, 2 \mathrm{H})$ are also characteristic of cladosporin. The second phenolic proton was not observed but was evident from the resonance at $\delta 162.0$ assignable to $\mathrm{C}-6$ in the ${ }^{13} \mathrm{C}$ NMR spectrum of 5 . In addition, the resonance at $\delta 171.4$ was consistent with the C-1 lactone carbonyl. The HSQC spectrum of 5 revealed three oxygenated methines at $\delta 76.3(\mathrm{C}-3), 66.3(\mathrm{C}-10)$ and $66.5(\mathrm{C}-14)$; two $\mathrm{CH}$ aromatic carbons at $\delta 106.5(\mathrm{C}-5)$ and $\delta 100.9(\mathrm{C}-7)$ as well as a benzylic carbon at $\delta 32.9(\mathrm{C}-4)$. Methylene and methyl carbons were seen at $\delta 37.7(\mathrm{C}-9)$ and $\delta 19.2$ (C- 
15) respectively. The remaining carbon signals were almost identical to those reported for cladosporin (Figure 22); (Jacyno et al., 1993). The absolute stereochemistry has been determined to be 3-R, 10-R and 14-S by x-ray analysis (John et al., 1999).<smiles>[2H][C@H]([C@H]1Cc2cc(O)cc(O)c2C(=O)O1)[C@H]1CCC[C@@H](C)O1</smiles>

Figure 22: Structure of cladosporin (5)

Table 8: ${ }^{1} \mathrm{H}$ and ${ }^{13} \mathrm{C}$ NMR data for $5\left(400 \mathrm{MHz}, \mathrm{CDCl}_{3}\right)$

\begin{tabular}{ccc}
\hline position & $\delta_{\mathrm{H}}(\mathrm{J}, \mathrm{Hz})$ & $\delta \mathrm{c}$ \\
\hline 1 & & 171.4 \\
3 & $4.73(\mathrm{~m}, 1 \mathrm{H})$ & 76.3 \\
4 & $2.87(\mathrm{~m}, 2 \mathrm{H})$ & 32.9 \\
$4 \mathrm{a}$ & & 143.5 \\
5 & $6.20(\mathrm{br} \mathrm{s}, 1 \mathrm{H})$ & 106.5 \\
6 & & 162.0 \\
7 & $6.32(\mathrm{~d}, 2.2,1 \mathrm{H})$ & 100.9 \\
8 & $11.27(\mathrm{~s}, \mathrm{OH})$ & 164.2 \\
$8 \mathrm{a}$ & & 102.2 \\
9 & $1.99(\mathrm{ddd}, 14.6,10.1,3.6,1 \mathrm{H})$ & 37.7 \\
10 & $1.87(\mathrm{ddd}, 14.7,8.7,3.0,1 \mathrm{H})$ & 66.3 \\
11 & $4.13(\mathrm{~m}, 1 \mathrm{H})$ & 30.0 \\
12 & $1.73(\mathrm{~m}, 2 \mathrm{H})$ & 18.1 \\
13 & $1.37(\mathrm{~m}, 2 \mathrm{H})$ & 31.5 \\
14 & $1.73(\mathrm{~m}, 2 \mathrm{H})$ & 66.5 \\
15 & $4.02(\mathrm{~m}, 1 \mathrm{H})$ & 19.2 \\
\hline
\end{tabular}




\section{Compounds 6, 7,8 and 11}

These compounds were determined to be neoechinulin B (6), a possible neoechinulin B isomer (7), neoechinulin A (8) and epiheveadride (11) based on HRMS, UV spectra and previously determined retention time of $E$. amstelodami metabolites. Neoechinulin E was also present, eluting at $15.2 \mathrm{~min}$.

\section{Compounds 9 and 10}

These compounds were cladosporin-like derivatives based ${ }^{1} \mathrm{H}$ NMR and UV spectra similarities to cladosporin. Unlike cladosporin, they were not consistently produced by other cladosporin producing strains. Their structures remain unknown and higher quantities of pure metabolite are needed for their identification.

\subsubsection{Minor metabolite determination}

A minor metabolite was isolated by prep-HPLC and is seen in Figure 20 eluting at 16.3 min. It was a yellow solid and produced an orange spot by TLC $(366 \mathrm{~nm})$ with an $\mathrm{R}_{\mathrm{f}}$ of 0.82 when developed in a 9:1 mixture of $\mathrm{MeOH} / \mathrm{CHCl}_{3}$. UV maxima were determined by HPLC-DAD at: 224 (100), 268 (55), 288 (55) and 435 (33).

The ESI mass spectrum displayed the $[\mathrm{M}+1]^{+}$at $\mathrm{m} / \mathrm{z} 285$. HRMS found 284.0670 , which was in conformity to $\mathrm{C}_{16} \mathrm{H}_{12} \mathrm{O}_{5}$ (calculated for 284.0679). The MS (EI) $\mathrm{m} / \mathrm{z}$ (rel. int.) was: $284(76), 255(29), 238(18), 162(20), 85(67)$. Literature searches of this mass provided two matches: physcion and questin, both anthraquinones produced by Eurotium 
(Anke et al., 1980; Nielsen \& Smedsgaard, 2003). The hydroxyl and methoxy groups at positions $\mathrm{C}-6$ and $\mathrm{C}-8$ on the ring system of these compounds are reversed and were diagnostic to their identification (Figure 23). NMR studies were needed to elucidate the correct structure. Insufficient material was isolated for ${ }^{13} \mathrm{C}$ studies but ${ }^{1} \mathrm{H}$ data proved invaluable.

These two possible structures were differentiated on the basis of the chemical shifts observed for the $\mathrm{H}-$ bonded $\mathrm{OH}$ at $\mathrm{C}-1$ and $\mathrm{C}-8$. One highly shifting $\mathrm{OH}$ at $\delta 13.23$ (s, 1H) was characteristic of questin and was pivotal in distinguishing it from physcion (Choi et. al., 2007). The corresponding signals in physcion were observed at $\delta 12.31$ and $\delta 12.1$ (Danielsen et. al., 1992). The second OH group was not seen in questin but the remaining protons were observed at $\delta 3.96(\mathrm{~s}, \mathrm{OMe}), \delta 2.43(\mathrm{~s}, \mathrm{Me})$ and four metacoupled aromatic protons [ $87.53(\mathrm{~d}, \mathrm{~J}=1.2 \mathrm{~Hz}, 1 \mathrm{H}, \mathrm{H}-4), \delta 7.30(\mathrm{~d}, \mathrm{~J}=2.4 \mathrm{~Hz}, 1 \mathrm{H}, \mathrm{H}-5)$, $\delta 7.12(\mathrm{~d}, \mathrm{~J}=0.78 \mathrm{~Hz}, 1 \mathrm{H}, \mathrm{H}-2), \delta 6.87(\mathrm{~d}, \mathrm{~J}=2.3 \mathrm{~Hz}, 1 \mathrm{H}, \mathrm{H}-7)]$. Although it could be isolated by preparatory methods in this strain, questin is presented as a minor metabolite because of its relatively smaller peak area counts in other strains of this species.



Figure 23: Differentiation of questin and physcion 


\subsubsection{Metabolite assignments and quantities}

Figure 24 assigns the metabolites to their corresponding HPLC-DAD peaks. Quantities of major metabolites isolated in the filtrate extract are compared to that of the mycelial extract in Table 9.

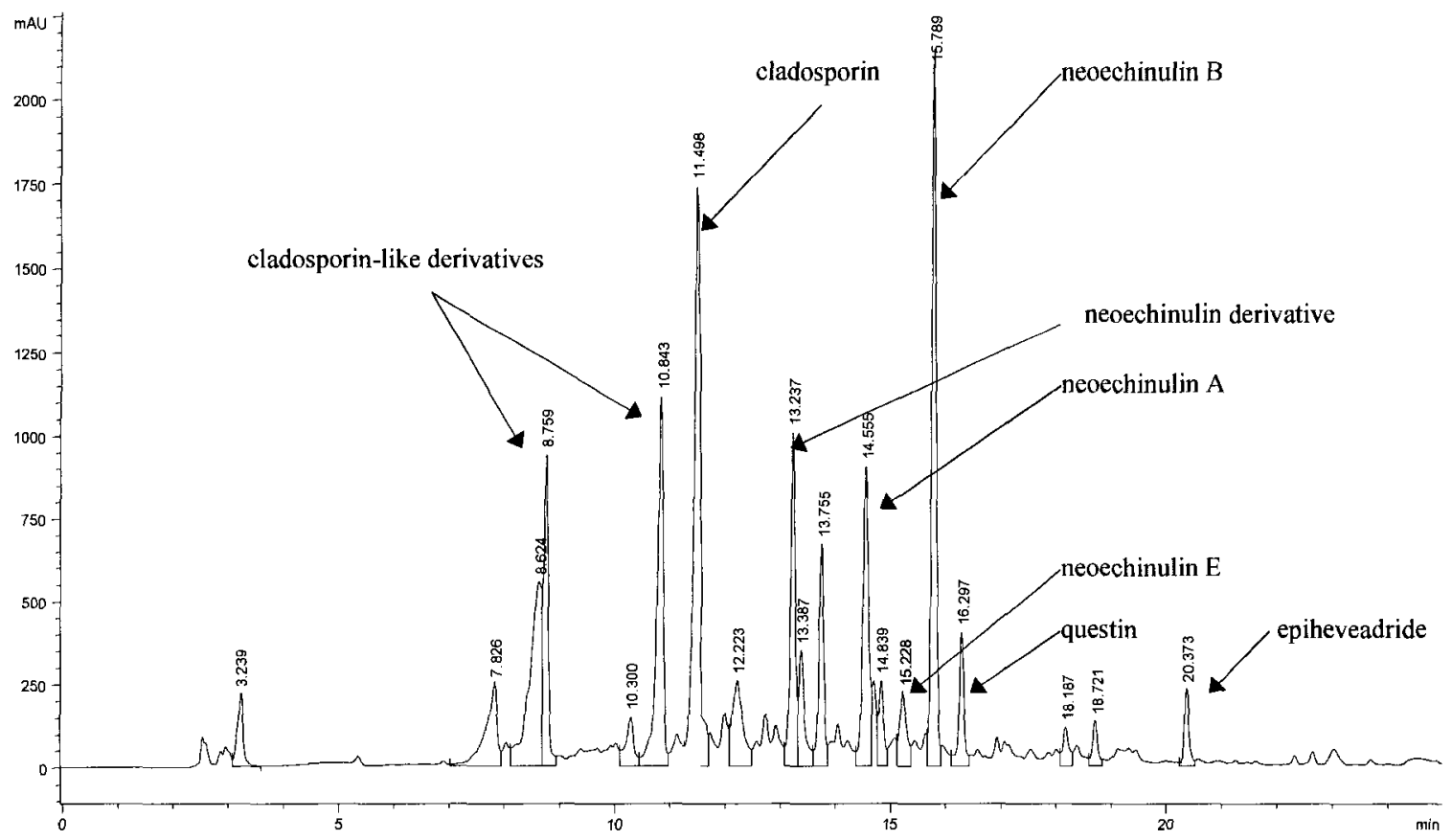

Figure 24: HPLC-DAD chromatogram of the filtrate extract of $E$. herbariorum strain CBS 47-F9 with metabolites indicated (254 nm)

Table 9: Major secondary metabolites isolated from filtrate extracts of $E$. herbariorum

\begin{tabular}{ccc}
\hline & CBS 47-F9 $(\mu \mathrm{g} / \mathrm{g}) \mathrm{L}$ & CBS 47-F8 $(\mu \mathrm{g} / \mathrm{g}) \mathrm{L}$ \\
\hline neoechinulin A (1) & 1848 & 651 \\
neoechinulin B (2) & 1750 & 1795 \\
neoechinulin deriv. (3) & 1858 & 601 \\
epiheveadride (4) & 408 & 230 \\
cladosporin (5) & 2613 & 894 \\
\hline
\end{tabular}




\section{$\underline{\text { 3.4 Secondary Metabolites of } E \text {. amstelodami and } E \text {. herbariorum Cellular Extract }}$}

E. amstelodami, E. rubrum and E. herbariorum cellular extract data are presented together because of the similarity in HPLC-DAD and TLC profiles. Relatively large peaks were eluted much later in the run compared to the filtrate extract (Figure 25). A dark orange TLC spot was found at $R_{f} 0.52$, while two dark blue spots appeared at $R_{f}$ 0.46 and 0.38 (Figure 26). The compounds were isolated from both E. amstelodami and E. herbariorum by prep-TLC using 19:1 hexane/ethyl acetate.

\section{2}



Figure 25: HPLC-DAD chromatogram of mycelial extract of a typical E. amstelodami or $E$. herbariorum strain with assigned peaks numbers $(254 \mathrm{~nm})$ 


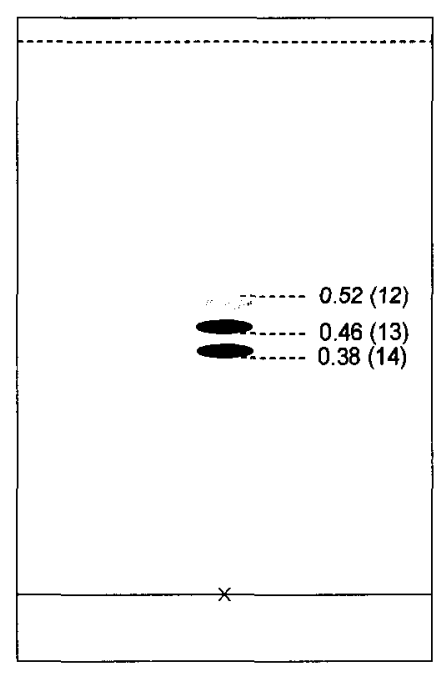

Figure 26: TLC plate drawing of major metabolites from $\boldsymbol{E}$. herbariorum strain CBS 47F9 cellular extract with $R_{f}$ values and compound numbers indicated (19:1 hexane/ethyl acetate, $254 \mathrm{~nm}$ )

\subsubsection{Major metabolite determination}

The cell mass extracts of E. herbariorum strain CBS 47-F9 and E. amstelodami strain J9589-1 were run on separate prep-TLC plates and major metabolites were isolated. They were identified by HRMS and NMR spectroscopy.

\section{Compounds 12-14}

An orange powder was isolated from the dried mycelia of both E. amstelodami and $E$. herbariorum. It appeared as a dark orange band under UV light (366 nm). HPLC-DAD chromatogram had UV maxima at: 241(36), 276(36) and 87(16). HRMS analysis gave 304.2012 and corresponded to the molecular formula of $\mathrm{C}_{19} \mathrm{H}_{28} \mathrm{O}_{3}$ (calculated at 304.2039). The major ion fragments were: MS (EI) m/z (rel. int.): 304 (100), 249 (49). These data were in accordance with flavoglaucin and were verified by NMR spectral data (Table 10). 
The most significant signals in the ${ }^{1} \mathrm{H}$ NMR spectrum of flavoglaucin (12) were observed for the chelated $\mathrm{OH}$ singlet at $\delta 11.87(\mathrm{C}-2)$, the aldehyde singlet at $\delta 10.23$, the $5-\mathrm{OH}$ broad singlet at $\delta 6.64$, the dimethyl allyl moiety $[\delta 5.26(\mathrm{dt}, \mathrm{J}=7.4 \mathrm{~Hz}, 1.4 \mathrm{~Hz}, 1 \mathrm{H}, \mathrm{H}-$ 15), $\delta 3.23(\mathrm{~d}, 7.5,2 \mathrm{H}, \mathrm{H}-14), 1.72(\mathrm{~s}, 3 \mathrm{H}, \mathrm{H}-17), 1.68(\mathrm{~s}, 3 \mathrm{H}, \mathrm{H}-18)]$, the benzylic protons at $\delta 2.86(\mathrm{t}, \mathrm{J}=7.9 \mathrm{~Hz}, \mathrm{H}-7)$ and the methyl triplet at $\delta 0.86(\mathrm{t}, \mathrm{J}=6.9 \mathrm{~Hz}, \mathrm{H}-13)$. The remaining methylene protons $(\mathrm{H}-8$ to $\mathrm{H}-12)$ were observed as overlapping multiplets at $\delta 1.2-1.5$. In the ${ }^{13} \mathrm{C}$ NMR spectrum of 12 , the resonances at $\delta 196.8(\mathrm{C}-19), 154.6(\mathrm{C}-$ 2) and 146.3 (C-5) confirmed the presence of the aldehyde carbon and two oxygenated aromatic carbons respectively. Four aromatic carbons were observed at $\delta$ 117.3-129.4 while the olefinic carbons resonated at $\delta 121.6(\mathrm{C}-15)$ and $\delta 133(\mathrm{C}-16)$. The ${ }^{13} \mathrm{C}$ NMR data of 12 matched literature data for flavoglaucin (Allen et al., 1978) and is a metabolite produced in the mycelia of many Eurotium species (Hamasaki et al., 1980; Nielsen \& Smedsgaard, 2003).

Compound 13 was isolated as a red powder and appeared as a dark orange band under UV light (366 nm). The HPLC-DAD chromatogram had UV maxima at: 225(38), 270 (100), 315 (75) and 414 (30). HRMS found 298.1564, corresponding to the molecular formula of $\mathrm{C}_{19} \mathrm{H}_{22} \mathrm{O}_{3}$ (calculated at 298.1564). The fragmentation pattern was: MS (EI) m/z (rel. int.): 298 (100), 243 (43), 162 (47), 143 (30). This metabolite was hypothesized to be auroglaucin, based on HRMS data and related to flavoglaucin previously described. ${ }^{1} \mathrm{H}$ NMR was performed in hopes to make this distinction at positions $7-13$ of the carbon chain. 
The ${ }^{1} \mathrm{H}$ NMR spectrum of 13 resembled that of 12 , where the substituted aromatic ring remained intact along with the dimethyl allyl system (Table 10), but the broad benzylic triplet at $\delta 2.86(\mathrm{~J}=7.9 \mathrm{~Hz}, \mathrm{H}-7)$, and the methyl triplet at $\delta 0.86(\mathrm{~J}=6.9 \mathrm{~Hz}, \mathrm{H}-13)$ previously observed for 12 have now disappeared. The new signals at $\delta 5.82-6.78$ were characteristic of olefinic protons $(\mathrm{H}-7$ to $\mathrm{H}-12)$, while the new doublet of doublets at $\delta$ 1.77 (dd, J=6.9 Hz, J=1.5 Hz, 3H, H-13) accounted for the methyl substituent on the unsaturated system. The large coupling constants for $\mathrm{H}-7$ at $\delta 6.78(\mathrm{~d}, \mathrm{~J}=15.6 \mathrm{~Hz})$ and $\mathrm{H}-$ 12 at $\delta 5.82(\mathrm{dq}, \mathrm{J}=14.2 \mathrm{~Hz}, \mathrm{~J}=6.8 \mathrm{~Hz})$ supported trans configuration of the double bond at these locations. Although the ${ }^{13} \mathrm{C}$ NMR signals were weak due to insufficient amount of material, the above evidences are in alignment with those for auroglaucin (Figure 27) (Hamasaki et al., 1981).

A third compound (14) was isolated as a yellowish/orange powder and appeared as a blue band under UV light $(366 \mathrm{~nm})$. The HPLC-DAD chromatogram contained UV maxima at: $212(80), 233$ (100), 278 (31) and 388 (18). HRMS found 302.1883, which corresponded to $\mathrm{C}_{19} \mathrm{H}_{26} \mathrm{O}_{3}$ (calculated at 302.1876), and was hypothesized to be isotetrahydroauroglaucin. As with auroglaucin, ${ }^{1} \mathrm{H}$ NMR data was used as confirmation.

The ${ }^{1} \mathrm{H}$ NMR data of 14 (Table 10) revealed two diagnostic signals at $\delta 5.41(\mathrm{~m}, 2 \mathrm{H})$ and at $\delta 1.60(\mathrm{~d}, \mathrm{~J}=4.6 \mathrm{~Hz}, 3 \mathrm{H}, \mathrm{Me})$ assignable to the olefinic protons $(\mathrm{H}-11$ and $\mathrm{H}-12)$ and the C-13 methyl group respectively, when compared to 12 . The five methylene overlapping multiplets at $\delta 1.2-1.5$ found in $\mathbf{1 2}$ were reduced to three at $\delta 1.3-1.6$ in $\mathbf{1 4}$ 
and were designated to $\mathrm{H}-8$ to $\mathrm{H}-10$. These data are comparable with referenced NMR, HRMS and UV data for isotetrahydroauroglaucin (Hamasaki et al., 1981) (Figure 27).

Table 10: ${ }^{13} \mathrm{C}$ and ${ }^{1} \mathrm{H}$ NMR data of 12 and the ${ }^{1} \mathrm{H}$ NMR data for 13 and $14(400 \mathrm{MHz}$, $\mathrm{CD}_{3} \mathrm{CN}$ )

\begin{tabular}{ccccc}
\hline & & 12 & 13 & 14 \\
position & $\delta_{\mathrm{C}}$ & $\delta_{\mathrm{H}}(\mathrm{J}, \mathrm{Hz})$ & $\delta_{\mathrm{H}}(\mathrm{J}, \mathrm{Hz})$ & $\delta_{\mathrm{H}}(\mathrm{J}, \mathrm{Hz})$ \\
\hline & & & & \\
1 & 117.3 & & & \\
2 & 154.6 & & & \\
3 & 127.7 & & & \\
4 & 125.4 & $6.93(\mathrm{~s}, 1 \mathrm{H})$ & & \\
5 & 146.3 & & & \\
6 & 129.4 & & & \\
7 & 23.4 & $2.86(\mathrm{br} \mathrm{t}, 7.9,2 \mathrm{H})$ & $6.78(\mathrm{~d}, 15.6,1 \mathrm{H})$ & $2.86(\mathrm{~s}, 7.8,2 \mathrm{H})$ \\
8 & 28.9 & $1.49(\mathrm{~m}, 2 \mathrm{H})$ & $6.55(\mathrm{~m}, 1 \mathrm{H})$ & $1.59(\mathrm{~m}, 2 \mathrm{H})$ \\
9 & 29.2 & $1.33(\mathrm{~m}, 2 \mathrm{H})$ & $6.36(\mathrm{~m}, 1 \mathrm{H})$ & $1.59(\mathrm{~m}, 2 \mathrm{H})$ \\
10 & 31.7 & $1.33(\mathrm{~m}, 2 \mathrm{H})$ & $6.36(\mathrm{~m}, 1 \mathrm{H})$ & $1.59(\mathrm{~m}, 2 \mathrm{H})$ \\
11 & 31.6 & $1.28(\mathrm{~m}, 2 \mathrm{H})$ & $6.17(\mathrm{~m}, 1 \mathrm{H})$ & $5.41(\mathrm{~m}, 1 \mathrm{H})$ \\
12 & 22.2 & $1.28(\mathrm{~m}, 2 \mathrm{H})$ & $5.82(\mathrm{dq}, 14.2,6.8)$, & $5.41(\mathrm{~m}, 1 \mathrm{H})$ \\
13 & 13.4 & $0.86(\mathrm{t}, 6.9,3 \mathrm{H})$ & $1.77(\mathrm{dd}, 6.9,1.5,3 \mathrm{H})$ & $1.60(\mathrm{~d}, 4.6,3 \mathrm{H})$ \\
14 & 26.8 & $3.23(\mathrm{br} \mathrm{d}, 7.5,2 \mathrm{H})$ & $3.26(\mathrm{br} \mathrm{d}, 7.4,2 \mathrm{H})$ & $3.23(\mathrm{br} \mathrm{d}, 7.6,2 \mathrm{H})$ \\
15 & 121.6 & $5.26(\mathrm{dt}, 7.4,1.4,1 \mathrm{H})$ & $5.27(\mathrm{dt}, 7.4,1.4,1 \mathrm{H})$ & $5.26(\mathrm{~m}, 1 \mathrm{H})$ \\
16 & 133.3 & & & \\
17 & 16.9 & $1.72(\mathrm{~s}, 3 \mathrm{H})$ & $1.72(\mathrm{~d}, 0.96,3 \mathrm{H})$ & $1.72(\mathrm{~s}, 3 \mathrm{H})$ \\
18 & 24.8 & $1.68(\mathrm{~s}, 3 \mathrm{H})$ & $1.69(\mathrm{~s}, 3 \mathrm{H})$ & $1.68(\mathrm{~s}, 3 \mathrm{H})$ \\
$19-\mathrm{CHO}$ & 196.8 & $10.23(\mathrm{~s}, 1 \mathrm{H})$ & $10.08(\mathrm{~s}, 1 \mathrm{H})$ & $10.22(\mathrm{~s}, 1 \mathrm{H})$ \\
$2-\mathrm{OH}$ & & $11.87(\mathrm{~s}, 1 \mathrm{H})$ & $11.85(\mathrm{~s}, 1 \mathrm{H})$ & $11.87(\mathrm{~s}, 1 \mathrm{H})$ \\
$5-\mathrm{OH}$ & & $6.64(\mathrm{br} \mathrm{s}, 1 \mathrm{H})$ & $6.89(\mathrm{br} \mathrm{s}, 1 \mathrm{H})$ & $6.66(\mathrm{br} \mathrm{s}, 1 \mathrm{H})$ \\
\hline & & &
\end{tabular}




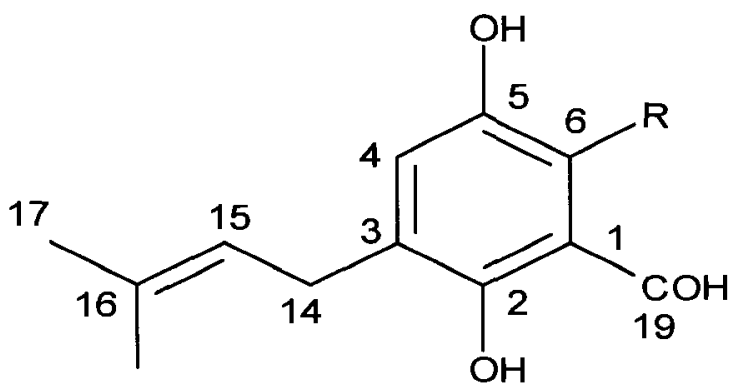

18
$12 \mathrm{R}=$<smiles>C[C]CCCCCC</smiles>

$13 \mathrm{R}=$<smiles>CC=CC=CC=CC</smiles>

$14 \mathrm{R}=$<smiles>CC=CCCCCC</smiles>

Figure 27: Structures of flavoglaucin (12), auroglaucin (13) and isotetrahydroauroglaucin (14)

\subsubsection{Metabolite assignments and quantities}

Figure 28 assigns the determined metabolites to their corresponding HPLC-DAD peaks. There were no apparent differences in metabolites profiles between these two species. However, metabolite quantities were greater in E. herbariorum strains as evident after quantification (Table 11). 


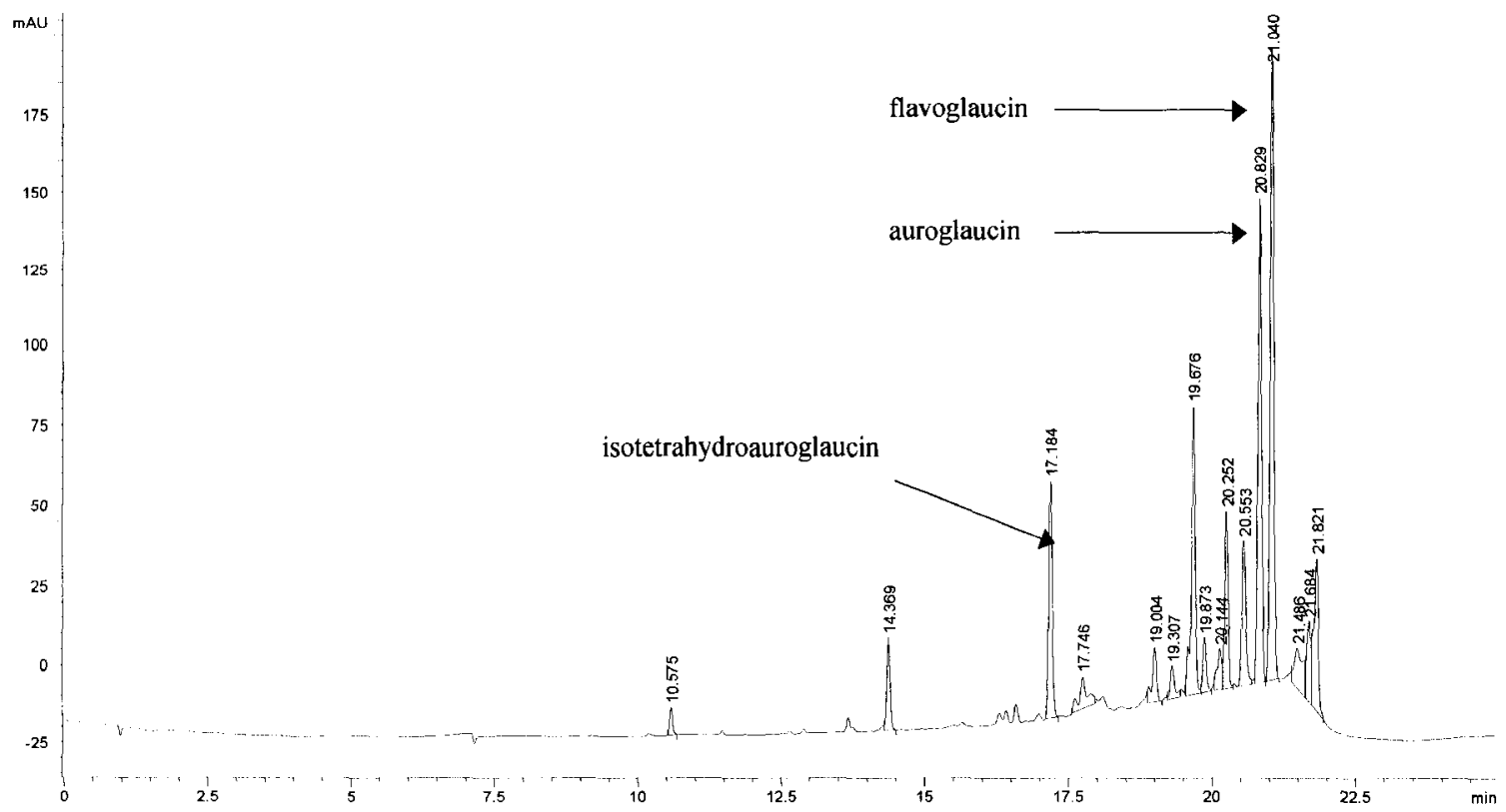

Figure 28: HPLC-DAD chromatogram of mycelial extract of a typical E. amstelodami or $E$. herbariorum strain with major metabolites indicated (254 nm)

Table 11: Major secondary metabolites isolated from cellular extracts of E.amstelodami and $E$. herbariorum

\begin{tabular}{ccccc}
\hline & \multicolumn{2}{c}{ E. amstelodami } & \multicolumn{2}{c}{ E. herbariorum } \\
\hline & $\begin{array}{c}\text { IBT 28307 } \\
(\mu \mathrm{g} / \mathrm{g}) / \mathrm{L}\end{array}$ & $\begin{array}{c}\mathrm{J} 9589-1 \\
(\mu \mathrm{g} / \mathrm{g}) / \mathrm{L}\end{array}$ & $\begin{array}{c}\text { CBS 47-F9 } \\
(\mu \mathrm{g} / \mathrm{g}) / \mathrm{L}\end{array}$ & $\begin{array}{c}\text { CBS 47-F8 } \\
(\mu \mathrm{g} / \mathrm{g}) / \mathrm{L}\end{array}$ \\
\hline & & & & \\
flavoglaucin (12) & 6318 & 6992 & 20112 & 12067 \\
auroglaucin (13) & 5813 & 5554 & 20253 & 9045 \\
isotetrahydroauroglaucin (14) & 3098 & 2865 & 17557 & 7146 \\
\hline
\end{tabular}




\subsection{Secondary Metabolites of $A$. ustus s.l. Filtrate Extracts}

A. ustus s.l. chromatograms for the filtrate extracts of all strains were compared. Although cell masses of $15.12 \pm 2.80 \mathrm{~g} / \mathrm{L}$ were obtained, it did not result in significant metabolite production. There were clear chemotype differences since five of the fourteen strains produced a few but similar metabolites while the remaining nine were more productive.

The HPLC-DAD chromatogram of a productive strain, IBT 28269 seen in Figure 29 revealed five major peaks at $9.9,10.1,10.6,11.1,12.4 \mathrm{~min}$ that were also detected in other strains and are assigned compounds 15-19. Approximately twelve minor metabolites are evident between 10.3-15.2 min. Figure 30 illustrates a TLC plate run of the filtrate extract and had five dominant spots appearing dark purple $\left(R_{f} 0.72\right)$ and $\left(R_{f}\right.$ $0.55)$, dark blue $\left(R_{f} 0.48\right)$ yellow $\left(R_{f} 0.45\right)$ and fluorescent blue $\left(R_{f} 0.22\right)$ which corresponded to the major peaks in the HPLC-DAD chromatogram. Many less intense spots were observed in the range of $R_{f} 0.72-0.20$. 


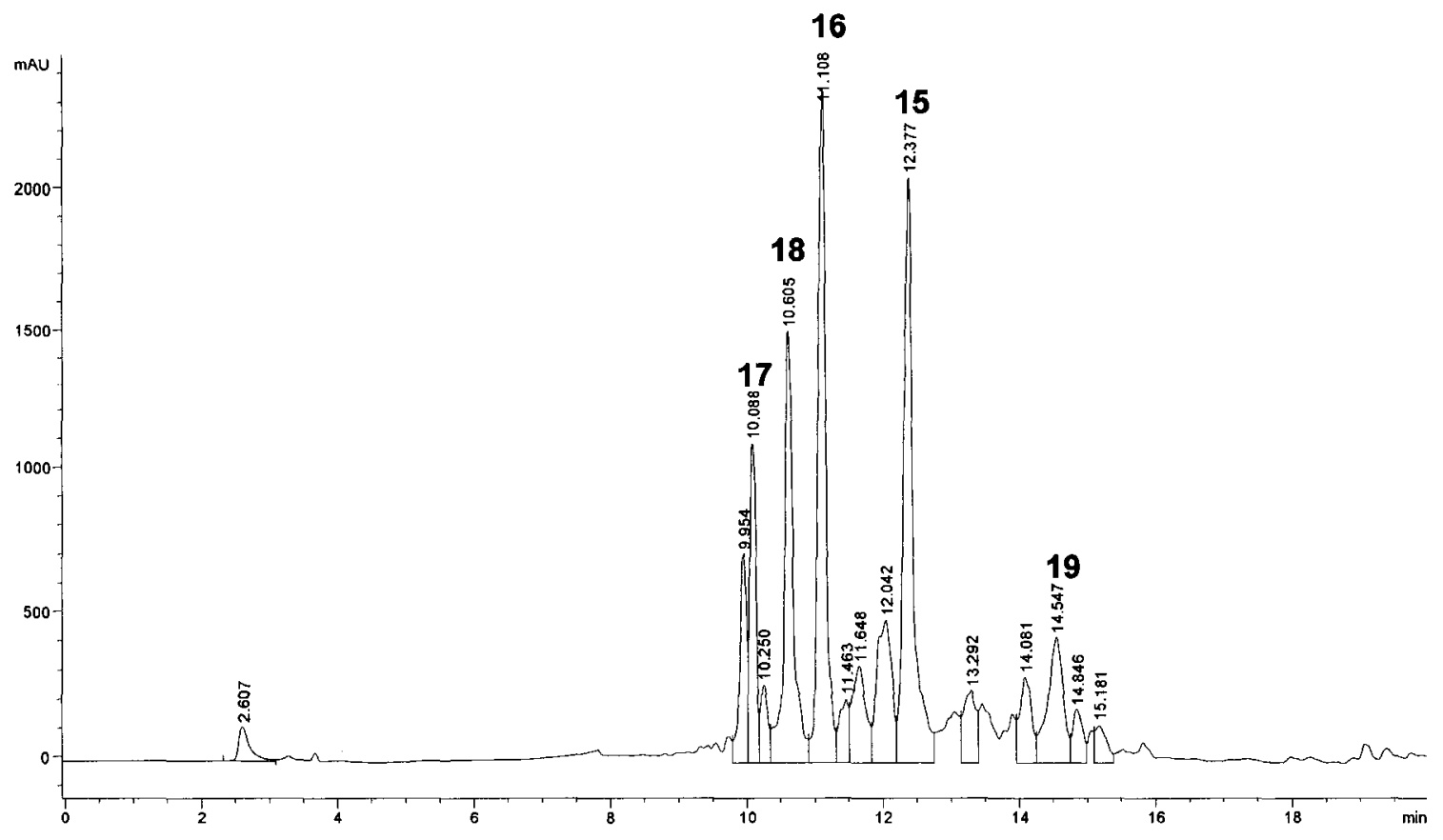

Figure 29: HPLC-DAD chromatogram of the filtrate extract of $A$. ustus s.l. strain IBT 28269 with assigned peak numbers $(254 \mathrm{~nm})$

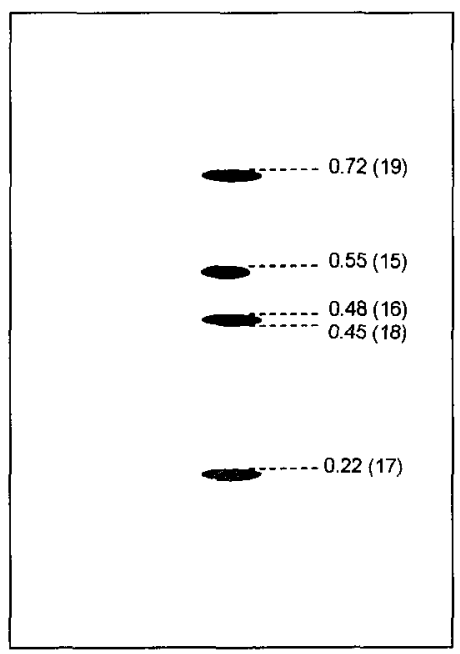

Figure 30: TLC plate drawing of major metabolites from $A$. ustus s.l. strain IBT 28269 filtrate extract with $\mathrm{R}_{\mathrm{f}}$ values and compound numbers indicated (2:1 hexane/ethyl acetate, followed by $9: 1 \mathrm{CHCl}_{3} / \mathrm{MeOH}, 254 \mathrm{~nm}$ ) 


\subsubsection{Major metabolite determination of compounds 15-19}

Compounds produced by $A$. ustus such as the austamides, austdiol, austocystins kotanin, TMC-120s, ophiobolins and drimanes have been reported but were not available as reference standards for strain screening. Sterigmatocystin had been reported (Schroeder \& Kelton, 1975) and was purchased as a standard (SIGMA) but was not detected in any of the strains. Large scale fermentation of strains IBT 28269 and IBT 28272 allowed for major metabolite isolation by initial SPE fractionation followed by prep-HPLC. NMR experiments were then acquired to determine unknown compounds 15 through 19.

\section{Compound 15}

Compound 15 eluted at $40 \%\left(\mathrm{CH}_{3} \mathrm{CN} / \mathrm{H}_{2} \mathrm{O}\right)$ by SPE and was purified by prep-HPLC. The resulting compound was a pale yellow solid with a melting point of $117-118^{\circ} \mathrm{C}$. The TLC plate revealed one purple spot under UV light $(366 \mathrm{~nm})$ when developed 2:1 hexane/ethyl acetate, followed by 9:1 $\mathrm{CHCl}_{3} / \mathrm{MeOH}$. The HPLC-DAD chromatogram had one peak with UV maxima at 218 (100), 240 (83), 365 (32). The ESI mass spectrum displayed the $[\mathrm{M}+1]^{+}$at $\mathrm{m} / \mathrm{z} 242$ and HRMS found 241.1101, establishing the molecular formula $\mathrm{C}_{15} \mathrm{H}_{15} \mathrm{NO}_{2}$ (calculated at 241.1097). The MS fragmentation pattern revealed: MS (EI) m/z (rel. int.): 226 (98), 199 (100), 185 (99). Infrared spectroscopy gave major absorptions for a cyclic ketone at 1707, aromatic $\mathrm{C}=\mathrm{C}$ absorptions between 1574-1504 and a large absorption characteristic of an ether at $1289 \mathrm{~cm}^{-1}$. From this data alone, the compound's identity remained unknown and NMR study was pursued. The distinguishing features in the ${ }^{1} \mathrm{H}$ NMR spectrum of $\mathbf{1 5}$ were observed for the methyl isoquinoline chromophore $[\delta 9.55(\mathrm{~s}, \mathrm{H}-9)$, two ortho-coupled aromatic doublets at $\delta 7.70$ 
$(\mathrm{J}=8.5 \mathrm{~Hz}, \mathrm{H}-4)$ and at $\delta 7.44(\mathrm{~J}=8.6 \mathrm{~Hz}, \mathrm{H}-5)$, one aromatic singlet at $\delta 7.69(\mathrm{H}-6)$ and an aromatic methyl singlet at $\delta 2.71(\mathrm{H}-10)]$. The oxygenated methine doublet at $\delta 4.78$ $(\mathrm{J}=4.0 \mathrm{~Hz}, \mathrm{H}-2$ ) coupled to $\mathrm{H}-11$ one-proton multiplet at $\delta 2.42$ (visible in the COSY spectrum) which in turn coupled to the two methyl doublets at $\delta 1.23(\mathrm{~d}, \mathrm{~J}=6.9 \mathrm{~Hz}, \mathrm{H}-13)$ and at $\delta 0.93(\mathrm{~d}, \mathrm{~J}=6.8 \mathrm{~Hz}, \mathrm{H}-12)$ (Table $12 \mathrm{~A})$. The ${ }^{13} \mathrm{C}$ NMR spectrum of 15 exhibited fifteen carbon signals attributable to one ketone carbon ( $\delta$ 198.7, C-3), the methyl isoquinoline chromophore $[\delta 174.0, \mathrm{C}-9 \mathrm{~b} ; 157.6, \mathrm{C}-7 ; 146.2, \mathrm{C}-9 ; 142.5, \mathrm{C}-5 \mathrm{a} ; 123.3, \mathrm{C}-$ 4; 120.2, C-5; 119.2, C-6; 117.3, C-3a; 115.0, C-9a, 23.8, C-10], two methines of which one is oxygenated $(\delta 91.1, \mathrm{C}-2 ; 30.9, \mathrm{C}-11)$, and two methyls $(\delta 15.0, \mathrm{C}-12 ; 17.8, \mathrm{C}-13)$ (Table 12B). The HSQC and HMBC spectra acquired for 15 facilitated these carbon assignments and their connectivities, which also matched well with previously reported data for TMC-120 A (Kohno, 1999a) (Figure 31). Preliminary chemical investigation revealed the absolute configuration to be $2-\mathrm{R}$ (Kohno et al., 1999b). The optical rotation was $[\alpha]_{D}^{22}-15^{\circ}\left(c=1, \mathrm{CHCl}_{3}\right)$ compared to the literature value of $[\alpha]_{D}^{22}-18^{\circ}(c=0.5$, $\mathrm{MeOH})$ (Kohno et al., 1999a).

\section{Compound 16}

Purification was performed by SPE elution $\left(30 \% \mathrm{CH}_{3} \mathrm{CN} / \mathrm{H}_{2} \mathrm{O}\right)$ followed by prep-HPLC. The resulting compound was a pale yellow solid with a melting point of $178-179^{\circ} \mathrm{C}$. The TLC plate revealed one purple spot under UV light $(366 \mathrm{~nm})$ when developed in 2:1 hexane/ethyl acetate and 9:1 $\mathrm{CHCl}_{3} / \mathrm{MeOH}$. The HPLC-DAD chromatogram had UV maxima at: $213(100), 252$ (86), 356 (34) and 370 (36). The ESI mass spectrum displayed the $[\mathrm{M}+1]^{+}$at $\mathrm{m} / \mathrm{z} 258$ and HRMS found 257.1026, corresponding to 
$\mathrm{C}_{15} \mathrm{H}_{15} \mathrm{NO}_{3}$ (calculated at 257.1046). The MS fragmentation pattern was: MS (EI) $\mathrm{m} / \mathrm{z}$ (rel. int.): 257 (8), 226 (4), 186 (100). Infrared spectroscopy indicated an $\mathrm{OH}$ absorption at 3100 , a cyclic ketone at 1719 and aromatic $\mathrm{C}=\mathrm{C}$ at 1634 and 1572, methyl groups at 1459 and 1423 as well as an ether at $1270 \mathrm{~cm}^{-1}$.

Compound 16 appeared to be a derivative of 15 . In fact, the ${ }^{1} \mathrm{H}$ NMR spectrum of 16 was almost identical to 15 except for the disappearance of the methine doublet at $\delta 4.78$ (d, $\mathrm{J}=4.0 \mathrm{~Hz}$ ) and the appearance of a broad singlet at $\delta 5.10$ integrating to one proton assigned to the $\mathrm{OH}$ at $\mathrm{C} 2$ (Table $12 \mathrm{~A}$ ). The ${ }^{13} \mathrm{C}$ NMR spectrum of $\mathbf{1 6}$ was comparable with that of $\mathbf{1 5}$ except for C-2 shifting from $\delta 91.1$ in $\mathbf{1 5}$ to $\delta 110.3$ in $\mathbf{1 6}$ (Table 12B). Compound 16 was identified as TMC-120 C (Figure 31) after comparing with referenced data (Kohno et al., 1999a).

\section{Compound 17}

Compound 17 was isolated from the SPE elutant $\left(20 \% \mathrm{CH}_{3} \mathrm{CN} / \mathrm{H}_{2} \mathrm{O}\right)$ and purified by prep-HPLC. The resulting compound was a fluorescent blue/green amorphous solid with an optical rotation of $[\alpha]_{D}^{22}-25^{\circ}(c=1, \mathrm{MeOH})$. The TLC plate revealed one bright blue fluorescent spot under UV light (366 nm) when developed in 2:1 hexane/ethyl acetate and 9:1 $\mathrm{CHCl}_{3} / \mathrm{MeOH}$. HPLC-DAD chromatogram had UV maxima at: 210 (100), 247 (75), 313 (8) and 464 (12). The ESI mass spectrum displayed the $[M+1]^{+}$at $\mathrm{m} / \mathrm{z} 244$ and was confirmed by HRMS which revealed 243.1267, corresponding to $\mathrm{C}_{15} \mathrm{H}_{17} \mathrm{NO}_{2}$ (calculated for 243.1254) and did not match any known fungal compounds. The major ion fragments were: MS (EI) m/z (rel. int.): 243 (61), 184 (100), 172, (48). The base peak 
at $\mathrm{m} / \mathrm{z} 184$ could be due to $\mathrm{C}-2 / \mathrm{C}-11$ bond cleavage leading to the loss of $\left(\mathrm{CH}_{3}\right)_{2} \mathrm{COH}$. Infrared spectroscopy [IR $\left.v_{\max }\left(\mathrm{CHCl}_{3}, \mathrm{~cm}^{-1}\right)\right]$ exhibited major bands for hydroxyl (3197), NH $(2976,2927)$, carboxyl (1641), aromatic (1594, 1571), methyl $(1427,1376)$ and an ether (1273).

Inspection of the ${ }^{1} \mathrm{H}$ and ${ }^{13} \mathrm{C}$ NMR spectra of 17 revealed the presence of the methyl isoquinoline skeleton observed in 15 and 16 (Table 12A-B). However, new resonances in the ${ }^{1} \mathrm{H}$ NMR spectrum of 17 include an oxygenated methine triplet at $\delta 4.89(\mathrm{~J}=9.0 \mathrm{~Hz}$, H-2) coupling to a benzylic methylene doublet at $\delta 3.35(\mathrm{~J}=9.0 \mathrm{~Hz}, \mathrm{H}-3)$, also visible in the COSY experiment as well as two methyl singlets at $\delta 1.35(\mathrm{H}-13)$ and $\delta 1.23(\mathrm{H}-12)$ [instead of the two methyl doublets at $\delta$ 0.9-1.2 $(\mathrm{J}=6.8-6.9)$ in 15 and 16] (Table 13). The $\mathrm{H}-11$ methine multiplet at $\delta 2.3-2.4(\mathrm{~m}, 1 \mathrm{H}, \mathrm{H}-11)$ previously observed in $\mathbf{1 5}$ and $\mathbf{1 6}$ have also disappeared.

The ${ }^{13} \mathrm{C}$ NMR and HSQC data acquired for 17 established the methyl isoquinoline part of the molecule, while the new oxygenated quarternary carbon at $\delta 71.2(\mathrm{C}-11)$ indicated the presence of a hydroxyl group and the new resonances at $\delta 90.8(\mathrm{C}-2), 30.4(\mathrm{C}-3), 24.1$ (C-12), and 23.3 (C-13) accounted for the proposed structure. This was verified by strong HMBC correlations from the methylene protons $\mathrm{H}-3$ to $\mathrm{C}-2, \mathrm{C}-4, \mathrm{C}-9 \mathrm{~b}$ and $\mathrm{C}-11$, as well as from $\mathrm{H}-12$ and $\mathrm{H}-13$ (the two methyl singlets) to $\mathrm{C}-2$ and $\mathrm{C}-11$ (Table 13). This was largely in agreement with similar structures found in the literature (Kinoshita et. al., 2003) and 17 represents a novel TMC-120 derivative (Figure 31). 


\section{Compound 18}

The SPE elutant $\left(25 \% \mathrm{CH}_{3} \mathrm{CN} / \mathrm{H}_{2} \mathrm{O}\right)$ primarily contained $\mathbf{1 8}$ and was purified as a yellow amorphous solid with an optical rotation $[\alpha]_{D}^{22}+32^{\circ}(c=1, \mathrm{MeOH})$. The TLC plate revealed one yellow spot under UV light (366 nm) when developed in 2:1 hexane/ethyl acetate and 9:1 $\mathrm{CHCl}_{3} / \mathrm{MeOH}$. The HPLC-DAD chromatogram had UV maxima at: 202 (100), 218 (93), 245 (86), 260 (82) and 360 (39). The ESI mass spectrum showed the $[\mathrm{M}+1]^{+}$at $\mathrm{m} / \mathrm{z} 260$ and the HRMS of 259.1180 established the molecular composition $\mathrm{C}_{15} \mathrm{H}_{17} \mathrm{NO}_{3}$ (calculated at 259.1203). The major ion fragments were: $\mathrm{MS}$ (EI) $\mathrm{m} / \mathrm{z}$ (rel. int.): 259 (17), $186(100)$. The base peak indicated the loss of $\mathrm{C}_{4} \mathrm{H}_{9} \mathrm{O}$ from a cleavage of the $\mathrm{C}-2 / \mathrm{C}-3$ bonds. Infrared spectroscopy values were similar to the related TMC-120 compounds at IRv $v_{\max }\left(\mathrm{CHCl}_{3}, \mathrm{~cm}^{-1}\right): 3195(\mathrm{OH}), 2927(\mathrm{NH}), 1629,\left(\mathrm{CH}_{2}\right), 1260$ (ether).

Detailed analysis of the one and two-dimensional NMR spectral data of $\mathbf{1 8}$ showed that it contained the methyl isoquinoline nucleus previously found in 15,16 and 17 . However, two principal differences were observed in the ${ }^{1} \mathrm{H}$ NMR spectra of 18 (Table 12A). Firstly, two deuterium oxide $\left(\mathrm{D}_{2} \mathrm{O}\right)$ exchangeable singlets at $\delta 13.56(\mathrm{~s}, 1-\mathrm{H})$, and 3.46 (br s, 1-H) ascribed to the chelated $\mathrm{OH}$ at $\mathrm{C}-9 \mathrm{~b}$, and the free $\mathrm{OH}$ at $\mathrm{C}-2$ respectively were evident. Secondly, a broad one-proton singlet at $\delta 5.01$, which was resolved into a doublet $(\mathrm{d}, \mathrm{J}=2.6 \mathrm{~Hz}, 1 \mathrm{H})$ upon $\mathrm{D}_{2} \mathrm{O}$ exchange experiment was assignable to $\mathrm{H}-2$. This methine proton showed clear coupling to $\mathrm{H}-11$ at $\delta 2.21$ (dqq, J=6.8 Hz, $2.6 \mathrm{~Hz}, \mathrm{H}-11$ ), which in turn couples to the methyl protons $\mathrm{H}-12$ and H-13 in the COSY spectrum. The coupling constants between these protons and the two methyl doublets at $\delta 1.22(\mathrm{~J}=6.9$ $\mathrm{Hz}, \mathrm{H}-12)$ and $\delta 0.7(\mathrm{~J}=6.8 \mathrm{~Hz}, \mathrm{H}-13)$ confirmed this deduction. The ${ }^{13} \mathrm{C} \mathrm{NMR}$ and 
HSQC data of 18 revealed a ketone carbonyl at 205.6 (C-3), and an oxygenated methine at $\delta 76.5(\mathrm{C}-2)$. Further proof for this proposed structure was obtained from the HMBC spectrum of 18 disclosing strong correlations between $\mathrm{H}-2$ and the two methyl groups at $\delta 20.3(\mathrm{C}-12)$ and at $\delta 14.6(\mathrm{C}-13)$, between $\mathrm{H}-4$ and the ketonic carbon at $\delta 205.6(\mathrm{C}-3)$, $\mathrm{C}-3 \mathrm{a}, \mathrm{C}-5 \mathrm{a}$ and $\mathrm{C}-9 \mathrm{~b}$, as well as $\mathrm{H}-11$ with the two methyl groups $\mathrm{C}-12$ and $\mathrm{C}-13$ (Table 13). It was concluded that $\mathbf{1 8}$ is a novel TMC-120 derivative (Figure 31) and perhaps a product from ring opening of $\mathbf{1 6}$ between $\mathrm{C}-2$ and the oxygen at position 1 . The absolute stereochemistry of $\mathbf{1 8}$ was assumed to be 2-R based on previous investigations by Kohno and coworkers (Kohno et al., 1999a).
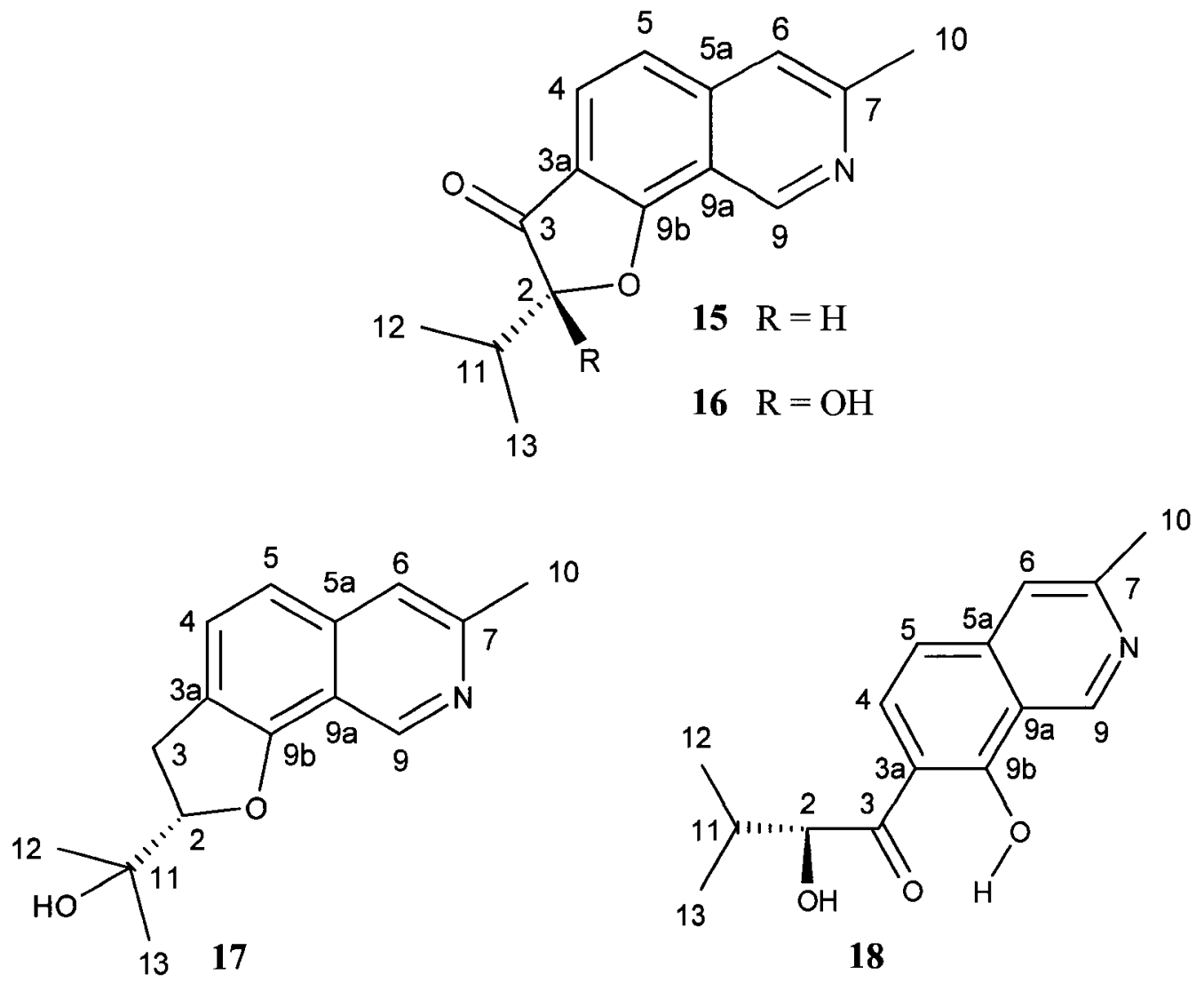

Figure 31: Structures of TMC-120 A (15), TMC-120 C (16) and two novel TMC-120 derivatives $(\mathbf{1 7}, \mathbf{1 8})$ 
Table 12A: Comparative ${ }^{1} \mathrm{H}$ NMR data for $\mathbf{1 5}$ and $\mathbf{1 6}$ and the novel metabolites $\mathbf{1 7}$ and $18\left(300 \mathrm{MHz}, \mathrm{CD}_{3} \mathrm{CN}\right)$

\begin{tabular}{ccccc}
\hline & $\mathbf{1 5}$ & $\mathbf{1 6}$ & $\mathbf{1 7}$ & $\mathbf{1 8}$ \\
position & $\delta_{\mathrm{H}}(\mathrm{J}, \mathrm{Hz})$ & $\delta_{\mathrm{H}}(\mathrm{J}, \mathrm{Hz})$ & $\delta_{\mathrm{H}}(\mathrm{J}, \mathrm{Hz})$ & $\delta_{\mathrm{H}}(\mathrm{J}, \mathrm{Hz})$ \\
\hline & & & $4.89(\mathrm{t}, 9.0,1 \mathrm{H})$ & $5.01(\mathrm{br} \mathrm{s}, 1 \mathrm{H})$ \\
2 & $4.78(\mathrm{~d}, 4.0,1 \mathrm{H})$ & & $3.35(\mathrm{~d}, 9.0,2 \mathrm{H})$ & \\
4 & & & $7.55(\mathrm{~d}, 8.2,1 \mathrm{H})$ & $7.69(\mathrm{~d}, 8.9,1 \mathrm{H})$ \\
5 & $7.70(\mathrm{~d}, 8.5,1 \mathrm{H})$ & $7.64(\mathrm{~d}, 8.6,1 \mathrm{H})$ & $7.27(\mathrm{~d}, 8.2,1 \mathrm{H})$ & $7.16(\mathrm{~d}, 8.9,1 \mathrm{H})$ \\
6 & $7.44(\mathrm{~d}, 8.6,1 \mathrm{H})$ & $7.30(\mathrm{~d}, 8.6,1 \mathrm{H})$ & $7.50(\mathrm{~s}, 1 \mathrm{H})$ & $7.42(\mathrm{~s}, 1 \mathrm{H})$ \\
9 & $7.69(\mathrm{~s}, 1 \mathrm{H})$ & $7.57(\mathrm{~s}, 1 \mathrm{H})$ & $9.25(\mathrm{~s}, 1 \mathrm{H})$ & $9.70(\mathrm{~s}, 1 \mathrm{H})$ \\
10 & $2.55(\mathrm{~s}, 1 \mathrm{H})$ & $9.45(\mathrm{~s}, 1 \mathrm{H})$ & & $2.72(\mathrm{~s}, 3 \mathrm{H})$ \\
11 & $2.42(\mathrm{~s}, 3 \mathrm{H})$ & $2.65(\mathrm{~s}, 3 \mathrm{H})$ & $2.60(\mathrm{~s}, 3 \mathrm{H})$ & $2.21(\mathrm{dqq}, 6.8$, \\
& & $2.34(\mathrm{~m}, 1 \mathrm{H})$ & & $2.6,1 \mathrm{H})$ \\
12 & $0.93(\mathrm{~d}, 6.8,3 \mathrm{H})$ & $1.05(\mathrm{~d}, 6.8,3 \mathrm{H})$ & $1.23(\mathrm{~s}, 3 \mathrm{H})$ & $1.22(\mathrm{~d}, 6.9,3 \mathrm{H})$ \\
13 & $1.23(\mathrm{~d}, 6.9,3 \mathrm{H})$ & $1.05(\mathrm{~d}, 6.8,3 \mathrm{H})$ & $1.35(\mathrm{~s}, 3 \mathrm{H})$ & $0.75(\mathrm{~d}, 6.8,3 \mathrm{H})$ \\
$2-\mathrm{OH}$ & & $5.10(\mathrm{br} \mathrm{s}, 1 \mathrm{H})$ & & $3.46(\mathrm{br} \mathrm{s}, 1 \mathrm{H})$ \\
$9 \mathrm{~b}-\mathrm{OH}$ & & & & $13.56(\mathrm{~s}, 1 \mathrm{H})$ \\
$11-\mathrm{OH}$ & & & & \\
\hline
\end{tabular}

Table 12B: Comparative ${ }^{13} \mathrm{C}$ NMR data for 15 and 16 and the novel metabolites 17 and $18\left(300 \mathrm{MHz}, \mathrm{CD}_{3} \mathrm{CN}\right)$

\begin{tabular}{ccccc}
\hline position & $\mathbf{1 5}$ & $\mathbf{1 6}$ & $\mathbf{1 7}$ & $\mathbf{1 8}$ \\
& $\delta_{\mathrm{C}}$ & $\delta_{\mathrm{C}}$ & $\delta_{\mathrm{C}}$ & $\delta_{\mathrm{C}}$ \\
\hline & & & & \\
\hline 3 & 91.1 & 110.3 & 90.8 & 76.5 \\
$3 \mathrm{a}$ & 198.7 & 197.4 & 30.4 & 205.6 \\
4 & 117.3 & 115.4 & 122.0 & 110.9 \\
5 & 123.3 & 124.2 & 128.0 & 128.2 \\
$5 \mathrm{a}$ & 120.2 & 119.2 & 117.0 & 116.7 \\
6 & 142.5 & 142.6 & 136.6 & 141.1 \\
7 & 119.2 & 119.2 & 118.0 & 118.3 \\
9 & 157.6 & 157.7 & 157.0 & 149.3 \\
$9 \mathrm{a}$ & 146.2 & 146.5 & 146.2 & 118.6 \\
$9 \mathrm{~b}$ & 115.0 & 116.6 & 113.9 & 164.4 \\
10 & 174.0 & 171.8 & 151.1 & 24.6 \\
11 & 23.8 & 23.7 & 24.9 & 33.5 \\
12 & 30.9 & 34.1 & 71.2 & 20.3 \\
13 & 15.0 & 15.2 & 24.1 & 14.6 \\
\hline
\end{tabular}


Table 13: Key COSY and HMBC correlations for novel metabolites 17 and 18

\begin{tabular}{|c|c|c|c|c|}
\hline \multirow[b]{2}{*}{ position } & \multicolumn{2}{|r|}{17} & \multicolumn{2}{|c|}{18} \\
\hline & COSY & $\mathrm{HMBC}$ & COSY & $\mathrm{HMBC}$ \\
\hline 2 & $\mathrm{H}-3$ & & 2-OH, H-11 & $\mathrm{C}-12, \mathrm{C}-13$ \\
\hline 3 & $\mathrm{H}-2$ & $\mathrm{C}-2, \mathrm{C}-4, \mathrm{C}-9 \mathrm{~b}, \mathrm{C}-11$ & & \\
\hline \multicolumn{5}{|c|}{ 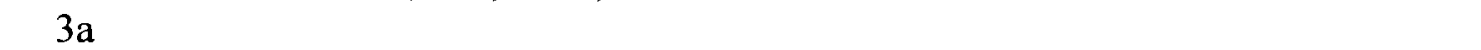 } \\
\hline 4 & $\mathrm{H}-5$ & & $\mathrm{H}-5$ & $C-3, C-3 a, C-5 a, C-9 b$ \\
\hline 5 & $\mathrm{H}-4$ & & $\mathrm{H}-4$ & $C-3 a, C-5 a, C-6, C-9 a$ \\
\hline \multicolumn{5}{|r|}{ 然 } \\
\hline 6 & & & & $\mathrm{C}-5, \mathrm{C}-9$ \\
\hline \multicolumn{5}{|l|}{7} \\
\hline 9 & & & & $\begin{array}{c}\text { C-5a, C-6, C-7 C-9a, } \\
\text { C-9b }\end{array}$ \\
\hline \multicolumn{5}{|r|}{ 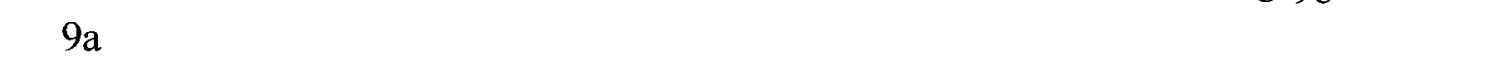 } \\
\hline $9 b$ & & & & \\
\hline 10 & & $\mathrm{C}-6, \mathrm{C}-9$ & & $\mathrm{C}-7, \mathrm{C}-9$ \\
\hline 11 & & & $\mathrm{H}-2, \mathrm{H}-12, \mathrm{H}-13$ & C-12, C-13 \\
\hline 12 & & $\mathrm{C}-2, \mathrm{C}-11$ & & $\mathrm{C}-13$ \\
\hline 13 & & $\mathrm{C}-2, \mathrm{C}-11$ & & $\mathrm{C}-12$ \\
\hline
\end{tabular}

\section{Compound 19}

Compound 19 was isolated from the SPE elution $\left(50 \% \mathrm{CH}_{3} \mathrm{CN} / \mathrm{H}_{2} \mathrm{O}\right)$ and purified by prep-HPLC. It was a pale white amorphous solid and the TLC plate revealed one dark purple spot under UV light $\left(366 \mathrm{~nm}\right.$ ) in 2:1 hexane/ethyl acetate and 9:1 $\mathrm{CHCl}_{3} / \mathrm{MeOH}$. The HPLC-DAD chromatogram had a UV maximum at 235. The ESI mass spectrum displayed the $[\mathrm{M}+1]^{+}$at $\mathrm{m} / \mathrm{z} 267$. HRMS gave 266.1531 corresponding to $\mathrm{C}_{15} \mathrm{H}_{22} \mathrm{O}_{4}$ (calculated at 266.1513). The fragmentation pattern was: MS (EI) $\mathrm{m} / \mathrm{z}$ (rel. int): 266 (8), $142(49), 124(32), 109(100)$. 
The ${ }^{1} \mathrm{H}$ NMR spectrum of 19 (Table 14) disclosed diagnostic signals for one olefinic proton $[\delta 5.97(\mathrm{~m}, 1 \mathrm{H})]$, at least three protons bearing carbons next to an oxygen $[\delta 4.95$ $(\mathrm{dt}, \mathrm{J}=12.2,2.5 \mathrm{~Hz}, 1 \mathrm{H}), \delta 4.77(\mathrm{dt}, \mathrm{J}=12.2,1.3 \mathrm{~Hz}, 1 \mathrm{H}), \delta 4.56(\mathrm{~m}, 1 \mathrm{H})]$, three methyl singlets $(\delta 1.32,1.14,1.12)$, a methine doublet $(\delta 1.79, \mathrm{~J}=4.9 \mathrm{~Hz})$, and aliphatic proton multiplets $[\delta 1.2-1.8(\mathrm{~m}, 6 \mathrm{H})]$. The ${ }^{13} \mathrm{C}$ NMR spectra exhibited 15 carbon resonances assignable to a lactone carbonyl at $\delta 175.1$, three oxygenated carbon at $\delta 74.6$ (C-9), 69.0 $(\mathrm{C}-12)$ and $65.5(\mathrm{C}-6)$, one double bond at $\delta 132.8(\mathrm{C}-8)$ and $127.9(\mathrm{C}-7)$, and nine aliphatic carbons at $\delta 17.8-45.7$. Careful analyses of the COSY, HSQC and DEPT-135 spectra and comparison with a similar drimane fragment isolated from fermentations of A. ustus var. pseudodeflectus (Hayes et al., 1995) led to the identification of drim-7-en11,12-oide (Figure 32). These authors reported the absolute configuration of 19 to be 5S, 6-R, 9-R and 10-S.

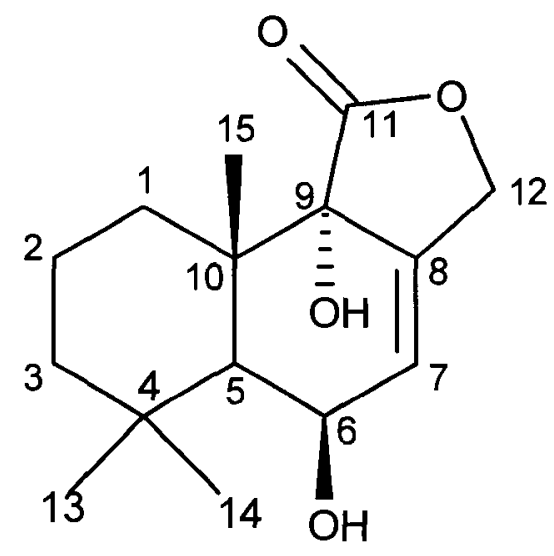

Figure 32: Structure of drim-7-en-11,12-oide fragment (drimane) (19) 
Table 14: ${ }^{1} \mathrm{H}$ and ${ }^{13} \mathrm{C}$ NMR data for $19\left(400 \mathrm{MHz}, \mathrm{CD}_{3} \mathrm{CN}\right)$

\begin{tabular}{cccc}
\hline position & $\delta_{\mathrm{H}}(\mathrm{J}, \mathrm{Hz})$ & $\delta_{\mathrm{C}}(\mathrm{DEPT} 135)$ & $\mathrm{COSY}$ \\
& & & \\
1 & $1.75(\mathrm{~m}, 1 \mathrm{H}), 2.04(\mathrm{~m}, 1 \mathrm{H})$ & $30.6\left(\mathrm{CH}_{2}\right)$ & $\mathrm{H}-2$ \\
2 & $1.60(\mathrm{~m}, 1 \mathrm{H}), 1.40(\mathrm{~m}, 1 \mathrm{H})$ & $17.8\left(\mathrm{CH}_{2}\right)$ & $\mathrm{H}-1, \mathrm{H}-3$ \\
3 & $1.29(\mathrm{~m}, 1 \mathrm{H}), 1.25(\mathrm{~m}, 1 \mathrm{H})$ & $44.7\left(\mathrm{CH}_{2}\right)$ & $\mathrm{H}-2$ \\
4 & & $34.2(\mathrm{C})$ & \\
5 & $1.79(\mathrm{~d}, 4.9,1 \mathrm{H})$ & $45.7(\mathrm{CH})$ & $\mathrm{H}-6$ \\
6 & $4.56(\mathrm{~m}, 1 \mathrm{H})$ & $65.5(\mathrm{CH})$ & $\mathrm{H}-5, \mathrm{H}-7$ \\
7 & $5.97(\mathrm{~m}, 1 \mathrm{H})$ & $127.9(\mathrm{CH})$ & $\mathrm{H}-6, \mathrm{H}-12$ \\
8 & & $132.8(\mathrm{CH})$ & \\
9 & & $74.6(\mathrm{C})$ & $\mathrm{H}-7, \mathrm{H}-12$ \\
10 & & $37.5(\mathrm{C})$ & \\
11 & & $175.1(\mathrm{C})$ & \\
12 & $4.77(\mathrm{dt}, 12.2,1.3,1 \mathrm{H})$, & $69.1\left(\mathrm{CH}_{2}\right)$ & \\
13 & $4.95(\mathrm{dt}, 12.2,2.5,1 \mathrm{H})$ & $32.6\left(\mathrm{CH}_{3}\right)$ & \\
14 & $1.32(\mathrm{~s}, 3 \mathrm{H})$ & $25.0\left(\mathrm{CH}_{3}\right)$ & \\
15 & $1.14(\mathrm{~s}, 3 \mathrm{H})$ & $18.9\left(\mathrm{CH}_{3}\right)$ & \\
\hline
\end{tabular}

\subsubsection{Minor metabolite determination}

A fluorescent blue amorphous solid was isolated by SPE elution $\left(40 \% \mathrm{CH}_{3} \mathrm{CN} / \mathrm{H}_{2} \mathrm{O}\right)$ and purified by prep-HPLC. The TLC plate revealed one bright blue fluorescent spot under UV light $(366 \mathrm{~nm})$ when developed in 2:1 hexane/ethyl acetate and 9:1 $\mathrm{CHCl}_{3} / \mathrm{MeOH}$. The HPLC-DAD chromatogram displayed UV maxima at: 210 (100), 247 (75), 313 (8) and 464 (12). The ESI mass spectrum displayed the $[\mathrm{M}+1]^{+}$at $\mathrm{m} / \mathrm{z} 240$ and HRMS found 239.0904 corresponding to $\mathrm{C}_{15} \mathrm{H}_{13} \mathrm{NO}_{3}$ (calculated at 239.0868). The MS fragmentation pattern gave: MS (EI) m/z (rel. int.): 239 (100), 192 (20), 161 (31). Insufficient material was available for NMR studies but UV and HRMS data [comparable to Kohno et al (1999a)] was sufficient to identify this compound as TMC-120 B. 
<smiles>CC(C)=C1Oc2c(ccc3cc(C)ncc23)C1=O</smiles>

Figure 33: Structure of TMC-120B

\subsubsection{Metabolite assignments and quantities}

Figure 34 assigns the major and minor metabolites identified to their corresponding HPLC-DAD peaks. After characterization of these metabolites by retention time and UV spectra of this strain, their presence in other $A$. ustus s.l. strains was determined. Cellular extracts contained few detectable peaks and quantities are compared to filtrate extracts in Table 15.

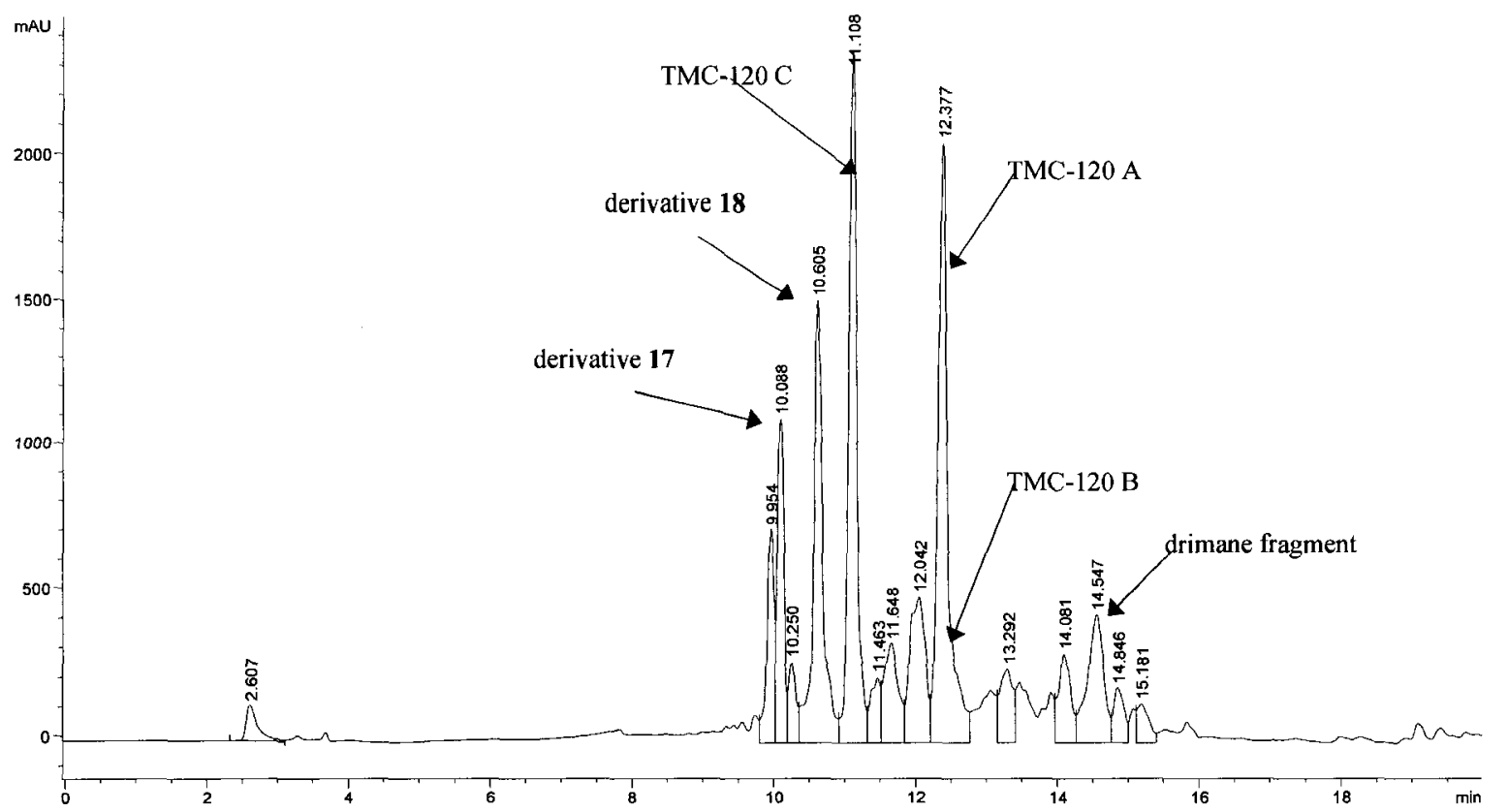

Figure 34: HPLC-DAD chromatogram of the filtrate extract of $A$. ustus s.l. strain IBT 28269 with metabolites indicated $(254 \mathrm{~nm})$ 
Table 15: Secondary metabolites isolated from extracts of A. ustus s.l.

\begin{tabular}{ccccc}
\hline & \multicolumn{2}{c}{ IBT 28269 $(\mu \mathrm{g} / \mathrm{g}) \mathrm{L}$} & \multicolumn{2}{c}{ IBT 28272 $(\mu \mathrm{g} / \mathrm{g}) / \mathrm{L}$} \\
& filtrate & mycelium & filtrate & mycelium \\
\hline & & & & \\
TMC-120 A (15) & 1115 & - & 324 & - \\
TMC-120 C (16) & 2958 & 197 & 3955 & 60 \\
novel derivative 17 & 2423 & - & 2145 & 29 \\
novel derivative 18 & 3140 & - & 359 & - \\
drimane (19) & 853 & 357 & 1005 & 750 \\
\hline
\end{tabular}

\subsection{Secondary Metabolite Production}

\subsubsection{Extraction method}

The neoechinulin A (1) standard curve showed a linear relationship with an $R^{2}$ value of 1.00 over the full concentration range. The same was true for neoechinulin B (2); $\left(\mathrm{R}^{2}=1.00\right)$, the neoechinulin isomer $(3) ;\left(\mathrm{R}^{2}=0.98\right)$, epiheveadride $(4) ;\left(\mathrm{R}^{2}=0.99\right)$ and cladosporin $(5) ;\left(\mathrm{R}^{2}=0.99\right)$. The percent recovery of these compounds from the spiked media was then calculated using the respective equation of the line from the calibration curve. Percent recoveries of the major metabolites 1-5 are summarized in Table 16A. The standard curves of $A$. ustus s.l. metabolites also showed linear relationships of TMC120 A (15); $\left(\mathrm{R}^{2}=1.00\right)$, TMC-120 C (16); $\left(\mathrm{R}^{2}=0.98\right)$, novel TMC-120 derivatives 17 $\left(\mathrm{R}^{2}=1.00\right), 18\left(\mathrm{R}^{2}=0.99\right)$ and the drimane $(19) ;\left(\mathrm{R}^{2}=0.99\right)$. Recoveries are summarized in Table 16B. The recovery calculations indicated that the extraction method was suitable for the analysis of the compounds. The quantity of each metabolite produced in culture was calculated by correcting for extraction loss. 
Table 16A: Compound recoveries from Eurotium extractions

\begin{tabular}{cccccc}
\hline & $\mathbf{1}$ & $\mathbf{2}$ & $\mathbf{3}$ & $\mathbf{4}$ & $\mathbf{5}$ \\
\hline \% recovery & $82.65 \pm 2.45$ & $83.95 \pm 3.74$ & $74.43 \pm 5.12$ & $85.43 \pm 2.46$ & $87.64 \pm 2.03$ \\
\hline
\end{tabular}

Table 16B: Compound recoveries from A. ustus s.l. extractions

\begin{tabular}{cccccc}
\hline & $\mathbf{1 5}$ & $\mathbf{1 6}$ & $\mathbf{1 7}$ & $\mathbf{1 8}$ & $\mathbf{1 9}$ \\
\hline \% recovery & $79.43 \pm 2.56$ & $79.65 \pm 3.49$ & $83.39 \pm 2.38$ & $77.46 \pm 4.56$ & $75.29 \pm 3.72$ \\
\hline
\end{tabular}

\subsubsection{Major metabolite production in Eurotium}

Secondary metabolite production was calculated using the standard curves constructed for each major metabolite and corrected for recovery levels for each extraction procedure. Calculations were made on each strain of the species screened and presented in $(\mu \mathrm{g} / \mathrm{g}) / \mathrm{L}$. From Table 17A, major secondary metabolites were consistently produced by all of the E. amstelodami strains studied with the exception of strain IBT 28437, with 1 not detected. Compound 2 had the largest average metabolite production followed by 4,3 and 1. All E. herbariorum strains produced compounds 1-5 with the exception of strain CBS 47-G1, from which 1-4 were not detected by these methods (Table 17B). E. rubrum strains produced 1-4 and were not distinguishable by chemical profiles from $E$. amstelodami (Table 17C). Calculated metabolite quantities were greatest in $E$. amstelodami followed by E. rubrum and E. herbariorum with regards to 1-4. 
Table 17A: E. amstelodami filtrate metabolite production

\begin{tabular}{ccccc}
\hline strain & $\begin{array}{c}\text { neoechinulin A } \\
(\mathbf{1}) \\
(\mu \mathrm{g} / \mathrm{g}) / \mathrm{L}\end{array}$ & $\begin{array}{c}\text { neoechinulin B } \\
(\mathbf{2}) \\
(\mu \mathrm{g} / \mathrm{g}) / \mathrm{L}\end{array}$ & $\begin{array}{c}\text { neoechinulin } \\
\text { derivative }(\mathbf{3}) \\
(\mu \mathrm{g} / \mathrm{g}) / \mathrm{L}\end{array}$ & $\begin{array}{c}\text { epiheveadride } \\
(\mathbf{4}) \\
(\mu \mathrm{g} / \mathrm{g}) / \mathrm{L}\end{array}$ \\
\hline & & & & 76 \\
J9968-5 & 173 & 139 & 76 & 740 \\
IBT 28252 & 292 & 1182 & 648 & 2128 \\
IBT 28305 & 281 & 1828 & 354 & 410 \\
J9843-11 & 332 & 1213 & 539 & 1113 \\
IBT 28247 & 637 & 1692 & 1263 & 848 \\
J9688-3 & 1000 & 2120 & 404 & 848 \\
IBT 28251 & 828 & 2262 & 1085 & 413 \\
J9589-1 & 363 & 1958 & 873 & 2422 \\
J9571-1 & - & 2090 & 322 & 143 \\
IBT 28250 & 717 & 2233 & 1079 & 584 \\
IBT 28307 & 820 & 970 & 339 & 1251 \\
J1726-4 & 663 & 4283 & 654 & 468 \\
IBT 28253 & 493 & 2050 & 377 & 30 \\
IBT 28308 & 132 & 538 & 147 & 462 \\
J1005-19 & 57 & 76 & 148 & 227 \\
IBT 28249 & 363 & 1558 & 752 & 172 \\
J0837-8 & 762 & 2883 & 2163 & 268 \\
IBT 28246 & 586 & 1212 & 881 & 282 \\
IBT 28254 & 1261 & 4490 & 2367 & 670 \\
IBT 28248 & 146 & 372 & 795 & $1268 \pm 2902$ \\
J0653-1 & 208 & 1507 & $660 \pm 523$ & \\
\hline mean & $500 \pm 277$ & $1710 \pm 1021$ & &
\end{tabular}

Table 17B: E. herbariorum filtrate metabolite production

\begin{tabular}{|c|c|c|c|c|c|}
\hline strain & $\begin{array}{c}\text { neo. A } \\
(\mathbf{1}) \\
(\mu \mathrm{g} / \mathrm{g}) / \mathrm{L}\end{array}$ & $\begin{array}{c}\text { neo. B } \\
(\mathbf{2}) \\
(\mu \mathrm{g} / \mathrm{g}) / \mathrm{L}\end{array}$ & $\begin{array}{c}\text { neo. isomer } \\
(\mathbf{3}) \\
(\mu \mathrm{g} / \mathrm{g}) / \mathrm{L}\end{array}$ & $\begin{array}{c}\text { epiheveadride } \\
(\mathbf{4}) \\
(\mu \mathrm{g} / \mathrm{g}) / \mathrm{L} \\
\end{array}$ & $\begin{array}{c}\text { cladosporin } \\
(\mathbf{5}) \\
(\mu \mathrm{g} / \mathrm{g}) / \mathrm{L} \\
\end{array}$ \\
\hline CBS 47-F9 & 473 & 449 & 475 & 104 & 670 \\
\hline CBS 47-F8 & 587 & 1375 & 327 & 228 & 557 \\
\hline CBS 47-F3 & 651 & 1795 & 601 & 230 & 894 \\
\hline CBS 47-G1 & - & - & - & - & 1481 \\
\hline mean & $428 \pm 295$ & $905 \pm 824$ & $351 \pm 259$ & $141 \pm 111$ & $911 \pm 412$ \\
\hline
\end{tabular}


Table 17C: E. rubrum filtrate metabolite production

\begin{tabular}{lcccc}
\hline strain & $\begin{array}{c}\text { neo. A } \\
(\mathbf{1}) \\
(\mu \mathrm{g} / \mathrm{g}) / \mathrm{L}\end{array}$ & $\begin{array}{c}\text { neo. B } \\
(\mathbf{2})\end{array}$ & $\begin{array}{c}\text { neo. isomer } \\
(\mathbf{3}) \\
(\mu \mathrm{g} / \mathrm{g}) / \mathrm{L}) / \mathrm{L}\end{array}$ & $\begin{array}{c}\text { epiheavedride } \\
(\mathbf{4}) \\
(\mu \mathrm{g} / \mathrm{g}) / \mathrm{L}\end{array}$ \\
\hline & & & & \\
CBS 47-F4 & 778 & 2559 & 641 & 48 \\
CBS 47-F5 & 1963 & 7963 & 150 & $<1$ \\
CBS 47-F6 & 680 & 637 & 353 & 37 \\
\hline mean & $1140 \pm 714$ & $3720 \pm 3798$ & $381 \pm 247$ & $27 \pm 26$ \\
\hline
\end{tabular}

Metabolite quantities calculated from the cellular extracts of the three Eurotium species are summarized in Tables 18A-C. Compound 12 had the highest production followed by 13 and 14 in all species. E. amstelodami produced noticeably fewer of these metabolites compared to E. herbariorum and E. rubrum. 
Table 18A: E. amstelodami cellular extract metabolite production

\begin{tabular}{cccc}
\hline strain & $\begin{array}{c}\text { flavoglaucin }(\mathbf{1 2}) \\
(\mu \mathrm{g} / \mathrm{g}) / \mathrm{L}\end{array}$ & $\begin{array}{c}\text { auroglaucin }(\mathbf{1 3}) \\
(\mu \mathrm{g} / \mathrm{g}) / \mathrm{L}\end{array}$ & $\begin{array}{c}\text { isotetrahydroauroglaucin }(\mathbf{1 4}) \\
(\mu \mathrm{g} / \mathrm{g}) / \mathrm{L}\end{array}$ \\
\hline & & & \\
J9968-5 & 12541 & 10548 & 5042 \\
IBT 28252 & 6318 & 5814 & 1874 \\
IBT 28305 & 13051 & 8450 & 2998 \\
J9843-11 & 11341 & 2047 & 980 \\
IBT 28247 & 13002 & 6257 & 4018 \\
J9688-3 & 6992 & 5554 & 1066 \\
IBT 28251 & 4686 & 5107 & 957 \\
J9589-1 & 8410 & 3509 & 1984 \\
J9571-1 & 8461 & 5177 & 2145 \\
IBT 28250 & 5065 & 6498 & 1084 \\
IBT 28307 & 8614 & 4841 & 1547 \\
J1726-4 & 12487 & 12048 & 2501 \\
IBT 28253 & 8410 & 7147 & 3232 \\
IBT 28308 & 12054 & 10815 & 1102 \\
J1005-19 & 13058 & 7501 & 3101 \\
IBT 28249 & 14505 & 9189 & 4017 \\
J0837-8 & 12051 & 6501 & 3054 \\
IBT 28246 & 5146 & 5188 & 1087 \\
IBT 28254 & 4858 & 5141 & 981 \\
IBT 28248 & 9501 & 6832 & 2098 \\
J0653-1 & 11205 & 9821 & 1320 \\
\hline mean & $9607 \pm 3192$ & $6856 \pm 2519$ & $2199 \pm 1202$ \\
\hline
\end{tabular}

Table 18B: E. herbariorum cellular extract metabolite production

\begin{tabular}{cccc}
\hline strain & $\begin{array}{c}\text { flavoglaucin }(\mathbf{1 2}) \\
(\mu \mathrm{g} / \mathrm{g}) / \mathrm{L}\end{array}$ & $\begin{array}{c}\text { auroglaucin }(\mathbf{1 3}) \\
(\mu \mathrm{g} / \mathrm{g}) / \mathrm{L}\end{array}$ & $\begin{array}{c}\text { isotetrahydroauroglaucin }(\mathbf{1 4}) \\
(\mu \mathrm{g} / \mathrm{g}) / \mathrm{L}\end{array}$ \\
\hline & & & \\
$47-\mathrm{F} 9$ & 14066 & 14904 & 5419 \\
$47-\mathrm{F} 8$ & 22547 & 15487 & 5060 \\
$47-\mathrm{F} 3$ & 17654 & 14821 & 11547 \\
$47-\mathrm{G} 1$ & 21987 & 15478 & 11042 \\
\hline mean & $19064 \pm 3985$ & $15173 \pm 360$ & $8267 \pm 3505$ \\
\hline
\end{tabular}


Table 18C: E. rubrum cellular extract metabolite production

\begin{tabular}{cccc}
\hline strain & $\begin{array}{c}\text { flavoglaucin }(12) \\
(\mu \mathrm{g} / \mathrm{g}) / \mathrm{L}\end{array}$ & $\begin{array}{c}\text { auroglaucin }(13) \\
(\mu \mathrm{g} / \mathrm{g}) / \mathrm{L}\end{array}$ & $\begin{array}{c}\text { isotetrahydroauroglaucin (14) } \\
(\mu \mathrm{g} / \mathrm{g}) / \mathrm{L}\end{array}$ \\
\hline & & & \\
$47-\mathrm{F} 4$ & 17841 & 15005 & 9065 \\
$47-\mathrm{F} 5$ & 22594 & 18711 & 15000 \\
$47-\mathrm{F} 6$ & 15412 & 12400 & 12021 \\
\hline mean & $18616 \pm 3653$ & $15372 \pm 3172$ & $12029 \pm 2968$ \\
\hline
\end{tabular}

CYA supplemented with $20 \%$ sucrose

Klich \& Pitt (1988) reported that 20\% sucrose supplementation in CYA media increased colony diameter of many Eurotium species. The two most productive strains of $E$. herbariorum and E. amstelodami were tested in triplicate for metabolite production on this medium. Results presented in Table 19A show increased dry cellular mass, however, the data in Table 19B indicated a large decrease in secondary metabolite production per gram of cell compared to the standardized CYA media. Cellular metabolite production was also decreased in this fermentation (Table 19C).

Table 19A: E. amstelodami and E. herbariorum mycelial dry weight on CYA (20\% sucrose)

\begin{tabular}{cccc}
\hline \multicolumn{2}{c}{ E. amstelodami $(\mathrm{g} / \mathrm{L})$} & \multicolumn{2}{c}{ E. herbarorium $(\mathrm{g} / \mathrm{L})$} \\
IBT 28307 & J9589-1 & CBS 47-F9 & CBS 47-F8 \\
\hline & & & \\
$15.2 \pm 2.0$ & $25.0 \pm 3.3$ & $27.3 \pm 4.1$ & $19.6 \pm 17.8$ \\
\hline
\end{tabular}


Table 19B: E. amstelodami and E. herbariorum filtrate metabolite production on CYA (20\% sucrose)

\begin{tabular}{ccccc}
\hline & \multicolumn{2}{c}{ E. amstelodami $(\mu \mathrm{g} / \mathrm{g}) \mathrm{L}$} & \multicolumn{2}{c}{ E. herbarorium $(\mu \mathrm{g} / \mathrm{g}) \mathrm{L}$} \\
& IBT 28307 & J9589-1 & CBS 47-F9 & CBS 47-F8 \\
\hline & & & & \\
neoechinulin A (1) & $122 \pm 54$ & $68 \pm 30$ & $45 \pm 11$ & $321 \pm 89$ \\
neoechinulin B (2) & $336 \pm 80$ & $79 \pm 15$ & $33 \pm 10$ & $123 \pm 47$ \\
neoechinulin isomer (3) & $264 \pm 102$ & $59 \pm 63$ & $34 \pm 18$ & $95 \pm 24$ \\
epiheveadride (4) & $696 \pm 79$ & $367 \pm 150$ & $11 \pm 5$ & $410 \pm 132$ \\
cladosporin (5) & - & - & $47 \pm 20$ & $163 \pm 87$ \\
\hline
\end{tabular}

Table 19C: E. amstelodami and E. herbarorium mycelial metabolite production on CYA (20\% sucrose)

\begin{tabular}{ccccc}
\hline & \multicolumn{2}{c}{ E. amstelodami $(\mu \mathrm{g} / \mathrm{g}) \mathrm{L}$} & \multicolumn{2}{c}{ E. herbarorium $(\mu \mathrm{g} / \mathrm{g}) \mathrm{L}$} \\
& IBT 28307 & J9589-1 & CBS 47-F9 & CBS 47-F8 \\
\hline & & & & \\
flavoglaucin (12) & $4404 \pm 290$ & $4216 \pm 21$ & $5755 \pm 409$ & $1213 \pm 251$ \\
auroglaucin (13) & $3510 \pm 150$ & $5420 \pm 73$ & $2792 \pm 2314$ & $1410 \pm 181$ \\
isotetrahydrouroglaucin (14) & $4672 \pm 16$ & $4895 \pm 232$ & $1803 \pm 1411$ & $1227 \pm 78$ \\
\hline
\end{tabular}

\subsubsection{Metabolite production in A. ustus s.l.}

The TMC-120 family of metabolites was identified in $10 \mathrm{~A}$. ustus s.l. strains while the drimane fragment was detected in all but 4 of the studies strains (Table 20). Metabolite production was an order of magnitude lower compared to the Eurotium fermentations and made for difficult isolations. 
Table 20: A. ustus s.l. filtrate metabolite production

\begin{tabular}{|c|c|c|c|c|c|}
\hline strain & $\begin{array}{c}\text { TMC-120 A } \\
(\mathbf{1 5}) \\
(\mu \mathrm{g} / \mathrm{g}) \mathrm{L} \\
\end{array}$ & $\begin{array}{c}\text { TMC-120 C } \\
(\mathbf{1 6}) \\
(\mu \mathrm{g} / \mathrm{g}) \mathrm{L} \\
\end{array}$ & $\begin{array}{c}\text { TMC-120 } \\
\text { novel }(17) \\
(\mu \mathrm{g} / \mathrm{g}) / \mathrm{L} \\
\end{array}$ & $\begin{array}{c}\text { TMC-120 } \\
\text { novel }(\mathbf{1 8}) \\
(\mu \mathrm{g} / \mathrm{g}) \mathrm{L}\end{array}$ & $\begin{array}{c}\text { Drimane } \\
(\mathbf{1 9}) \\
(\mu \mathrm{g} / \mathrm{g}) \mathrm{L}\end{array}$ \\
\hline $\begin{array}{l}\text { A. insuetus } \\
\text { IBT } 28265 \\
\text { IBT } 28266 \\
\text { IBT } 28267 \\
\text { K9197-10 }\end{array}$ & & 186 & 75 & & $\begin{array}{c}11 \\
163\end{array}$ \\
\hline $\begin{array}{l}\text { A. calidoustus } \\
\text { IBT } 28268 \\
\text { IBT } 28269 \\
\text { IBT } 28270 \\
\text { IBT } 28271 \\
\text { IBT } 28272 \\
\text { IBT } 28273 \\
\text { IBT } 28274 \\
\text { IBT } 28275\end{array}$ & 218 & $\begin{array}{c}322 \\
150 \\
65 \\
20 \\
153 \\
\\
172\end{array}$ & $\begin{array}{c}14 \\
28 \\
10 \\
2 \\
10 \\
\\
15\end{array}$ & $\begin{array}{l}86 \\
66 \\
\\
18 \\
66 \\
64\end{array}$ & $\begin{array}{l}84 \\
52 \\
65 \\
\\
22 \\
65 \\
24 \\
72\end{array}$ \\
\hline $\begin{array}{c}\text { A. ustus s.l. } \\
\text { L3852-1 } \\
\text { K0954-4 } \\
\text { L3945-1 } \\
\text { K3796-2 } \\
\text { K3752-3 } \\
\text { K3629-2 } \\
\text { K3576-3 } \\
\text { L3931-10 } \\
\end{array}$ & 128 & $\begin{array}{c}240 \\
17\end{array}$ & $\begin{array}{l}14 \\
68\end{array}$ & $\begin{array}{l}14 \\
74\end{array}$ & $\begin{array}{c}49 \\
16 \\
91 \\
124 \\
124 \\
6 \\
4\end{array}$ \\
\hline mean & $173 \pm 64$ & $147 \pm 108$ & $26 \pm 28$ & $55 \pm 30$ & $61 \pm 48$ \\
\hline
\end{tabular}

\subsection{Purity of Compounds Used for Toxicity Studies}

Neoechinulin A (1), neoechinulin B (2), cladosporin (5) and TMC-120 A (15) were identified, isolated and purified by means of several chromatographic methods described. Neoechinulin A was isolated as a yellow crystals (m.p. $262-264^{\circ} \mathrm{C}$; lit. $264-265^{\circ} \mathrm{C}$, Cole \& Schweikert, 2003 ). Neoechinulin B was isolated as white crystals (m.p. $235-237^{\circ} \mathrm{C}$; 
lit. $234-236^{\circ} \mathrm{C}$, Cole \& Schweikert, 2003). Cladosporin was obtained as white crystals (m.p. $193-194^{\circ} \mathrm{C}$; lit. $189-190^{\circ} \mathrm{C}$, Scott et al., 1971). TMC-120 A was isolated as pale white powder (m.p. $117-118^{\circ} \mathrm{C}$; lit. $115-116^{\circ} \mathrm{C}$, Kohno et al., 1999a). For all four compounds, other spectral data such as ${ }^{13} \mathrm{C}$ and ${ }^{1} \mathrm{H}$ NMR spectra, optical rotations and the IR maxima were similar to the literature values (see Results). For toxicology studies, the purity of these compounds is of outmost importance. The purity based on ${ }^{1} \mathrm{H}$ NMR, HPLC-DAD, TLC, optical rotation and melting point was assessed at $\geq 98 \%$ and acceptable for toxicity studies. 


\section{DISCUSSION}

Cultural variability, morphology and chemotypic profiles of a single strain may be expressed uniquely on different growth media. It was important to choose culture media that would provide the necessary nutrients for cellular growth and not inhibit secondary metabolite production. Early studies on Eurotium indicated that this fungus grew well on beet sugar molasses (Quilico \& Panizzi, 1943). Yabuki (1963) found that several synthetic media including Czapek-Dox could replace molasses as a nutrient source. The Czapek-Dox formula was first used by Thom in 1930 and is a synthetic medium that provides sucrose and sodium nitrate as the sources of carbon and nitrogen. It may however, lack the trace elements considered necessary for fungal growth. In this study it was supplemented with yeast extract to provide amino acids, vitamins and minerals. Czapek-Dox and CYA are commonly used media for screening fungal metabolites (Frisvad et al., 2006). Ingredient consistency was important as batch to batch differences may exist that can lead to different results. For this reason, the same batch of yeast extract was used for all fermentations.

Roux bottles were chosen for strain screening and may help increase metabolite production by providing low but changing oxygen tension (Sumarah, 2002). Adequate levels of dissolved $\mathrm{O}_{2}$ can be critical in the success of the fermentation (Bai, 2003). It was also important to keep the fermenting cultures in the dark as some fungal metabolites are light sensitive. 
Secondary metabolites produced by particular strains of fungi may depend on geographical location (Miller et al., 1991; Kozlovskii et al., 2002). It was important to obtain strains of indoor and outdoor origin to determine if chemotypic differences exist between strains of the two environments. Results clearly indicated that there were no differences in Eurotium metabolite profiles of strains isolated outdoors when compared to indoors (data not shown) or between European (Nielsen, 2003a) and Canadian strains.

All Eurotium strains fermented on CYA produced secondary metabolites that were detected in both the filtrate and mycelia extracts while strains of $A$. ustus s.l. produced metabolites exclusively in the filtrate. Excretion of secondary metabolites is consistent with the current view on fungal secondary metabolism. Although a species will be somewhat tolerant to its secondary metabolites, they do not usually accumulate intracellulary and are excreted as a defense mechanism during times of stress (Vanek et al., 1981). Only small amounts of neoechinulin A, B and epiheavadride were detected in the cell masses and most were excreted into the culture media. In contrast, flavoglaucin, auroglaucin and isotetrahydroauroglaucin were found exclusively in extracted mycelia. These amongst other hydroquinones pigments are known to occur in the mycelial mats of many Eurotium species (Gould \& Raistrick, 1934).

Reports showed that $20 \%$ sucrose supplementation in Czapek-Dox media increase culture growth in Eurotium (Allen, 1972; Klich \& Pitt, 1988) proved to be true in these studies. However, secondary metabolite production was less per gram of dry cell mass in all Eurotium studied strains. Sugar exhaustion may not have occurred and may explain the 
increased growth but lack of secondary metabolites in this fermentation. Allen (1972) reports no fungal growth and hence no flavoglaucin, or echinulin production when $E$. amstelodami (ATCC 10065) was fermented on standard (3\% sucrose) Czapek-Dox. Allen found that between $30-40 \%$ sucrose was required for adequate mycelial and metabolite production. In this thesis, neoechinulins, echinulins and hydroquinones were consistently produced in both tested CYA media. Eurotium species are known to be consistent producers of these metabolites, even in hypersaline waters with up to $17 \%$ salinity (Butinar et al., 2005). As with other metabolite studies on Eurotium, the culture media influenced quantitative not qualitative results. Standard CYA provided the nutrients needed for sufficient metabolite production.

Butinar et al. (2005) isolated many Eurotium species for metabolite profiling in hypersaline waters. The secondary metabolite profiles produced by Eurotium from salterns were not different from those of Eurotium species from foods and other habitats. HPLC analysis revealed all species to produce echinulin, neoechinulin A, flavoglaucin, physcion, auroglaucin, dihydroauroglaucin, and tetrahydroauroglaucin, while only $E$. repens produced cladosporin. In this study, E. herbariorum was a consistent cladosporin producer and this discrepancy may be due to differences in distinguishing these closely related species. The E. herbariorum and E. rubrum strains used in this study were identified by ITS sequencing. Cladosporin and the undetermined cladosporin-like metabolites may represent a chemotypic variation between $E$. herbariorum and the noncladosporin producers, E. amstelodami and E. rubrum. 
E. amstelodami strains isolated from moulding buildings in Denmark have been reported to produce echinulin, neoechinulins as well as many benzoquinones and anthraquiones (Nielsen et al., 2004a) Most of the building material-associated strains of $E$. amstelodami isolated from Canadian homes in this study produced: neoechinulin A, B, and E, preechinulin, echinulin, the anthraquionone: questin, the benoquinones: flavoglaucin, auroglaucin, isotetrahydroauroglaucin and the nonadride epiheavidride, which has not been reported from Eurotium as a natural product (Figure 35). There appears to be little worldwide variation in Eurotium metabolite profiles. 
<smiles>C=CC(C)(C)c1[nH]c2ccccc2c1/C=C1\NC(=O)[C@@H](C)NC1=O</smiles>

neoechinulin A (1)<smiles>CCC[C@H]1C2=C(CCC3=C(C[C@H]1CC)C(=O)OC3=O)C(=O)OC2=O</smiles>

epiheveadride (4)<smiles>C=CC(C)(C)c1[nH]c2ccccc2c1C[C@@H]1NC(=O)[C@H](C)NC1=O</smiles>
preechinulin<smiles>COc1cc(O)cc2c1C(=O)c1c(O)cc(C)cc1C2=O</smiles>

questin<smiles>C=CC(C)(C)c1[nH]c2ccccc2c1/C=c1\[nH]c(=O)c(=C)[nH]c1=O</smiles>

neoechinulin B (2)<smiles>C[C@H]1CCC[C@@H](C[C@@H]2Cc3cc(O)cc(O)c3C(=O)O2)O1</smiles>

cladosporin (5)<smiles>C=CC(C)(C)c1[nH]c2ccccc2c1/C=C1\NC(=O)C(=O)NC1=O</smiles>

neoechinulin $\mathbf{E}$

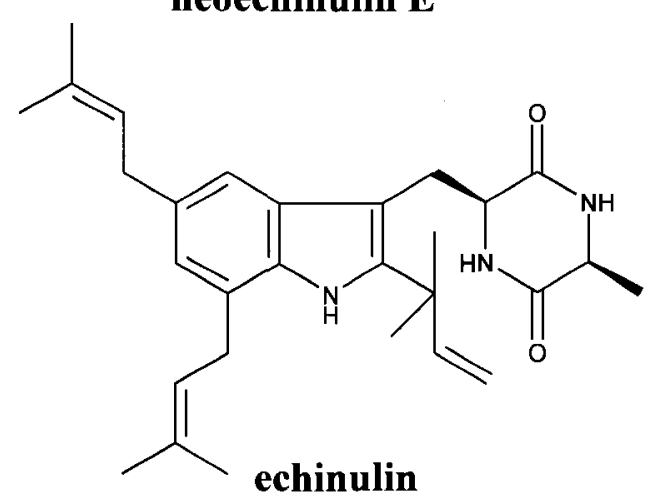

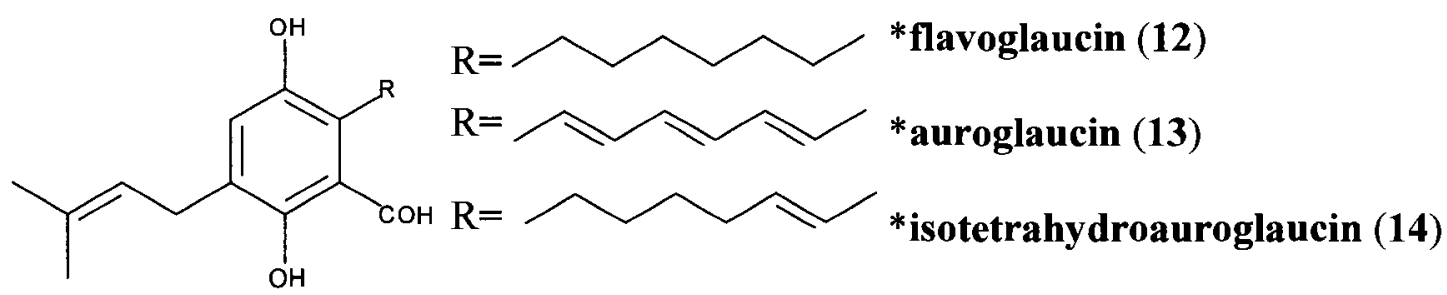

Figure 35: Summary of determined Eurotium metabolites

* detected in the mycelium 
Echinulin has mixed biosynthetic origin, being derived from tryptophan, alanine and one or more isoprenoid units derived from mevalonic acid (MacDonald \& Slater, 1966). Radio-tracer experiments have determined L-alanyl-L-tryptophan anhydride is incorporated intact into echinulin and neoechinulins A, B, C and D, so that it is an early biosynthetic intermediate for both echinulins and the neoechinulins. A cell free preparation of E. amstelodami catalyzes the isoprenylation of the indole nucleus to give preechinulin which acts as a precursor to either neoechinulin A or echinulin (Allen, 1972). These early biosynthetic pathways are not defined in detail but formation of echinulin from preechinulin may occur by alkylation of the benzene ring with the loss of a hydrogen via electrophilic attack of dimethyl allyl pyrophosphate (DMAPP). Preechinulin may also be oxidized to yield neoechinulin A and further oxidized and converted into neoechinulin B (Plate et al., 1987). The biosynthetic relationship of neoechinulin $\mathrm{A} \rightarrow \mathrm{B} \rightarrow$ neoechinulin by an oxidation mechanism (CH-Me $\rightarrow \mathrm{C}=\mathrm{CH}_{2} \rightarrow$ $\mathrm{CO}$ ) at the C-14 position has been proposed (Dossena et al., 1975).

A total synthesis of neoechinulin A was first accomplished by Nakatsuka et al. (1980) and the stereochemistry at $\mathrm{C}-12$ position is in the $S$-configuration on the assumption that the diketopiperazine will be derived from L-tryptophan and L-alanine (Aoki et al., 2005). In this thesis, no neoechinulin was detected and biosynthesis may not have occurred. Relatively small amounts of echinulin and neoechinulin $\mathrm{E}$ were detected in many strains and are probably a result of conversion of neoechinulin B to these products. The neoechinulin B derivative could not be fully characterized due to instability of the compound. 
Flavoglaucin, auroglaucin and isotetrahydroauroglaucin are commonly occurring metabolites in many Eurotium species found over a wide range of habitat. These pigments may act as important scavengers of reactive oxygen species and protect conidia against oxidative damage (Jahn et al., 2000). Recently, they have been isolated from $E$. repens on the marine sponge Suberites domuncula (Smetanina et al., 2007) supporting the evidence their biosynthesis may serve an important biological role in Eurotium. In this report, all studied Eurotium strains produced these three compounds with flavoglaucin calculated as having the largest amount followed by auroglaucin.

The biosynthetic pathway of flavoglaucin is poorly defined. Acetate is a precursor of the hydroquinone nucleus, the aldehyde moiety and the aliphatic side chain, whereas the dimethyl allyl side chain is derived from mevalonic acid (Allen, 1972). Incorporation studies with $\left[1,2-13 \mathrm{C}_{2}\right]$ acetate in E. amstelodami have established that flavoglaucin is a regular polyketide modified by isoprenylation which occurs with retention of the labeling pattern in the dimethyl allyl moiety (Allen et al., 1978). It has been suggested that flavoglaucin and isotetrahydroauroglaucin are formed by the reduction of auroglaucin. The production of these pigments and echinulin-like metabolites is often found in Eurotium and reflects a common pathway of biosynthesis from the isoprenoid subunit (Podojil et al., 1979). Auroglaucin is a component of cryptoechinulins B and D isolated from E. amstelodami which is formed by Diels-Alder addition to the co-occuring neoechinulin $\mathrm{C}$ and $\mathrm{B}$ respectively. These compounds are now known to be artifacts of extraction procedures and not natural products as reported (Cardillo et al., 1975). 
Questin is a commonly reported metabolite of Eurotium. Positional isomerism, similarities in chemical reactivity and physical properties in questin and related anthraquinones lead to difficulties in their identification (Knut et al., 1992). Isolation of individual anthraquinones in pure form has been reported as rather difficult, and artifacts may occur with extensive extraction and isolation (Piattelli \& Nicola, 1968). Questin was detected in only one strain of E. herbariorum but its presence in other Eurotium strains cannot be ruled out.

The biosynthesis of questin and related compounds such as physcion is via the acetate/malonate pathway (Mann, 1987). The folding of eight $C_{2}$ units form the polyketides that make up the periphery of the carbon skeleton. Three aldol-type condensations and an addition of a carbonyl in the center of the ring along with enolizations can form endocrocin, a metabolic precursor to emodin. Final O-methylation of emodin results in questin (Dewick, 1987).

Cladosporin was a major metabolite detected exclusively in E. herbariorum. The production of echinulins, neoechinulins, flavoglaucin and cladosporin was first reported by Podojil et al. (1979) in strains of E. repens isolated from contaminated candy. Cladosporin is a polyketide derived from eight acetate units via the acetate-polymalonate pathway (Cattel et al., 1973) and was first synthesized by Rawlings et al. (1989). In this thesis, the unknown cladosporin-like metabolites were crudely isolated and may represent C-8 and C-6 O-methyl ethers which are commonly reported cladosporin derivatives (Grove et al., 1972). However, insufficient data was collected to make this conclusion. 
Epiheveadride is described here as a new member of a group of natural products which contain a nine membered carbocylic with two affixed cyclic anhydrides and are termed nonadrides. Epiheveadride has been characterized as an oxidized derivative of dihydroepiheveadride and a diastereomer of the fungal metabolite heveadride (Hosoe et al., 2004b). Heveadride was originally isolated from the mycelium of Helminthosporium heveae and related nonadrides have been isolated from an unidentified mangrove fungus (k38) from the South China Sea (Li et al., 2007). Biosynthesis of epiheavadride-related nonadrides such as glauconic acid occurs by the condensation of hexanoic acid and oxaloacetic acid, resulting in an unsaturated anhydride from which head to head dimerization forms the C-9 unit characteristic of nonadrides (Chen et al, 2007). Few studies exist on the toxicity of epiheveadride. In a study by Hosoe et al. (2004a), epiheveadride exhibited strong antifungal activity against A. fumigatus, $P$. marneffei, $T$. rubrum and T. mentagrophytes at $5 \mu \mathrm{g} / \mathrm{disc}$. This thesis is the first report of a nonadride being isolated from Eurotium and the first report of epiheveadride occurring as a natural product.

Eurotium is not recognized as an agriculturally important mycotoxin producing genus. There is no known toxicity data on the major metabolites, neoechinulin A and B. These compounds may be important as they were detected as major metabolites in most of the studied strains. Preliminary data for inhalation toxicity reveal that they affected transcription of inflammatory genes at approximately $10^{-7} \mathrm{M}$. (Rand \& Miller, unpublished). 
Houbraken et al. (2007) have separated A. insuetus and A. calidoustus from A. ustus based on chemical, molecular and morphological data. Here, there was no overwhelming evidence of chemotypic variation between $A$. calidoustus and $A$. insuetus and supports their work that these species are chemically similar. Houbraken et al. detected ophiobolins and austins based on HPLC-DAD data from largely pathogenic strains. In this thesis, these compounds were not detected and may be due to continental differences between strains or that the studied indoor strains are different from the pathogenic strains studied by Houbraken et al.

A. calidoustus appeared to accumulate the TMC-120's to a greater extent when compared to A. insuetus (Table 20). However, upon closer examination of the data, it is clear that overall metabolite yield was low and A. insuetus was represented by a small sample size (4 strains) and poor geographical distribution. Consistencies with drimane production within all $A$. ustus s.l. strains were apparent and in agreement with Houbraken et al.

In a study by Nielsen et al. (1999), A. ustus s.l. (now clarified as $A$. calidoustus strains) were isolated from building materials and inoculated on gypsum and chipboard with and without wallpaper. Secondary metabolite production was investigated. Many unknown metabolites were detected and $A$. ustus s.l. was chemically different from the isolates found on cereals. Nielsen hypothesized that TMC-120 A, B and C were produced in many of the isolates along with numerous sesquiterpene drimanes. Unfortunately this work could not be verified due to lack of reference standards. This thesis has given 
support to Nielsens's view that the TMC-120 isoquinoline alkaloids and at least one drimane sesquiterpene are produced by indoor $A$. calidoustus. strains. TMC-120 A, B and $\mathrm{C}$ are reported with certainty for the first time from indoor $A$. insuetus and $A$. calidoustus strains. Reference standards can now be used in conjunction with Nielsen's and Houbraken's isolates. The discovery of two novel TMC-120 derivatives $(\mathbf{1 7}, \mathbf{1 8})$ may aid in chemically characterizing $A$. insuetus and $A$. calidoustus. Their production may be favoured by $A$. calidoustus but supporting evidence is needed. These novel metabolites may also be used as reference standards to clarify some of the unknown metabolites of these species

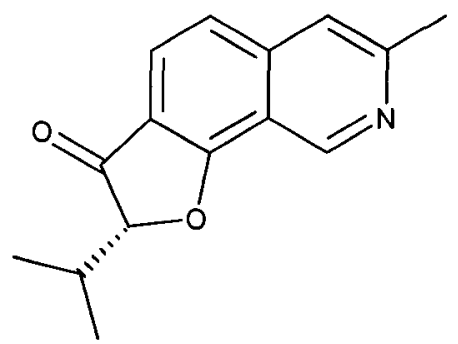

TMC-120 A (15)



TMC-120 B

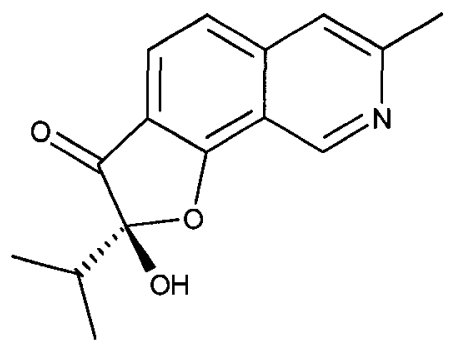

TMC-120 C (16)

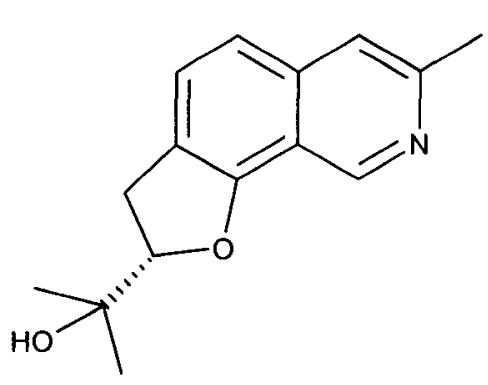

novel $1(17)$

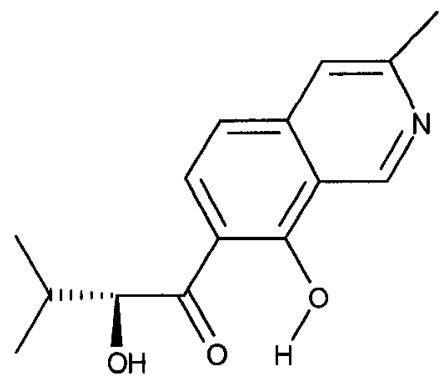

novel $2(18)$



drimane (19)

Figure 36: Summary of determined $A$. insuetus and $A$. calidoustus metabolites 
Isoquinoline alkaloids are one of the largest groups of natural products and possess interesting antifungal and antimicrobial activities (Erada et al., 1996). However, most have been discovered in plants and only a limited number are reported from lichens (Kinoshita et al., 2003) and fungi (Kohno et al., 1999). Most isoquinoline alkaloids discovered in plants exhibit complicated structures and are mainly synthesized from tyrosine while those of lichens and fungi contain simple skeletons and are probably synthesized via mixed pathways (Li et al., 2007).

The two novel isoquinoline TMC-120 derivatives $(17,18)$ possessed fluorescent characteristics. They also exhibited structural similarities to the fluorescent isoquinoline pigments: panaeflourines A-C (Kinoshita et al., 2003) and D-H (Kinoshita et al., 2005), which were discovered in the cultured mycobiont of the lichen: Amygdalaria panaeola. The panaeflourines differ from the TMC-120's and 17 and $\mathbf{1 8}$ by an N-linked side chain at the N-8 position of the isoquinoline chromophore. The absolute stereochemistry of $\mathbf{1 7}$ and 18 was deduced based on NOESY experiments on the sodium borohydride reduced TMC-120 B (Kohno et al., 1999b) and by X-ray crystallography on panaefluoroline D (Kinoshita et al., 2005). Novel derivative 18 presents the same structural formula to TMC-120 $\mathrm{C}$ but there is a ring opening at the oxygen between positions $\mathrm{O}-1$ and $\mathrm{C}-2$. This compound was determined after extensive COSY, HSQC, HMBC, ${ }^{1} \mathrm{H}$, and ${ }^{13} \mathrm{C}$ NMR analysis. To our knowledge, no such compound has ever been reported.

The biosynthesis of sesquiterpene $\left(\mathrm{C}_{15}\right)$ drimanes is via the mevalonate pathway which utilizes farnesyl pyrophosphate as the main precursor (Jansen \& Groot, 1990). The 
resulting terpenes may cyclize to form saturated hydrocarbons. Seemingly endless possibilities may result and more than fifty basic skeletons have been recognized (Mann, 1987). However, the modes of biogenesis are generally unknown for the sesquiterpene lactones. These drimanes are not closely related to the $S$. chartarum drimanes, which are biosynthesized from polyketides (Dewick, 1997).

In this study, a sesquiterpene drimane was detected consistently in strains of both $A$. insuetus and A. calidoustus. Drimanes generally have little conjugation and UV spectra contain single UV absorbances close to $235 \mathrm{~nm}$. Unidentified peaks in other strains of these species may represent unknown drimanes. The drimane presented has been previously isolated from A. ustus s.l. found in Egyptian desert soil by Hayes et al. (1995), who also reported many drimanes containing an ester-linked side chain at the C-6 position. Drimane detection in both $A$. insuetus and $A$. calidoustus is evidence that these species share a similar pathway of secondary metabolite biosynthesis.

Although most of the major and some minor chromatogram peaks of $A$. insuetus, $A$. calidoustus and Eurotium were assigned, additional peaks still remain unknown. LCMS analysis of these compounds gave accurate masses that did not match any known compound. Structural elucidation was difficult due to relatively small amounts of compound contained in the extract. Unknown Eurotium compounds are likely echinulin or neoechinulin related based on similar UV spectrums to that of the assigned compounds. Metabolites 9 and $\mathbf{1 0}$ are likely cladosporin-related based on initial NMR 
studies. Unknown metabolites from $A$. insuetus and $A$. calidoustus were low in abundance and culture media studies to increase metabolite production may be needed. 


\section{SUMMARY}

A chemotypic investigation of Eurotium, A. insuetus and A. calidoustus isolated from Canadian homes has provided a greater understanding of the metabolites produced by these species. Little variation existed between E. amstelodami, E. herbariorum and E. rubrum. All three produced the major metabolites: neoechinulin A and B, epiheveadride, flavoglaucin, auroglaucin and isotetrahyroauroglaucin, as well as the minor metabolites: neoechinulin $\mathrm{E}$, echinulin and preechinulin. The metabolites profiles of these morphologically similar species have not been well documented in the literature. In this thesis, E. herbariorum strains were cladosporin producers and therefore, chemically different from E. amstelodami and E. rubrum.

Metabolite studies on A. insuetus and A. calidoustus have demonstrated that these isolates are chemically distinct from $A$. ustus found on cereals and supports division of the species. TMC-120 A, B, C and a sesquiterpene drimane are reported with certainty for the first time from indoor isolates and two novel TMC-120 derivatives were also discovered. These compounds may aid to characterize A. insuetus and A. calidoustus, as chemotypic variation between them is possible.

The major metabolites: neoechinulin A, neoechinulin B, cladosporin and TMC-120 A were purified and characterized. Studies of their effects on primary cultures of murine alveolar macrophage cells are underway and preliminary data reveal that all affect inflammatory genes. 


\section{REFERENCES}

Abellana, M., Magri, X., Sanchis, V., Ramos, A. Water activity and temperature effects on growth of Eurotium amstelodami, E. chevalieri and E. herbariorum on a sponge cake analogue. 1999. International Journal of Food Microbiology. Vol. 52. 97-103.

Ali, M., Mohammed, N., Alnaqeeb, M., Hassan, R., Ahmad, H. Toxicity of echinulin from Aspergillus chevalieri in rabbits. 1989. Toxicology Letters. Vol. 48. 235-241.

Allen, C. Isoprene-containing metabolites of Aspergillus amstelodami. 1972. Canadian Journal of Microbiology. Vol. 18. 1275-1282.

Allen, M., Jr. Monoisoprenylated cyclo-L-alanyl-L-tryptophanyl. Biosynthetic precursor of echinulin. The Journal of the Chemical Society. 1973. Vol. 95. No. 7 2386-7.

Allen, J., Barrow, A., Jones, A., Hanisch, P. Biosynthesis of flavoglaucin. Stereochemistry of aromatic isoprenylation. 1978. Journal of the Chemical Society, Perkin Transaction I. Vol. 2. 152-154.

Anke, $\mathrm{H}$. Metabolic products of microorganisms. 184 . On the mode of action of cladosporin. 1979. The Journal of Antibiotics. Vol. 32. No. 9. 952-958.

Anke, H., Kolthoum, I., Zahner, H., Laatsch, H. Metabolic Products of Microorganisms. 185.* The Anthraquinones of the Aspergillus glaucus Group. I. Occurrence, Isolation, Identification and Antimicrobial Activity. 1980. Archives of Microbiology. Vol. 126. 223-230.

Anke, H., Zaehner, H., Koenig, W. Metabolic products of microorganisms. 170. 1978. On the antibiotic activity of cladosporin. Archives of Microbiology. Vol. 116. No. 3. 253-257.

Aoki, T., Kamisuki, S., Kimoto, M., Ohnishi, K., Takakusagi, Y., Kuramochi, K., Takeda, Y., Nakazaki, A., Kuroiwa, K., Ohuchi, T., Sugawara, F., Arai, T., Kobayashi, S. Total synthesis of (-) neoechinulin A. 2006. SYNLETT. No. 5. 667-670.

Ashley, J., Raistrick, H., Richards, T. The cristalline colouring matters of species in the Aspergillus glaucus series II. 1939. Biochemical. Journal. Vol. 33. 1291-1303.

Ayerst, G. The effects of moisture and temperature on growth and spore germination of some fungi. 1969. Journal of Stored Product Research. Vol. 5. 127-141.

Bachmann, M., Blaser, P., Luethy, J., Schlatter, C. Toxicity and mutagenicity of anthraquinones from Aspergillus chevalieri. 1992. Journal of Environmental Pathology, Toxicology and Oncology. Vol. 11. No. 2. 113-16. 
Bachmann, M., Luthy, J., Schlatter, C. Toxicity and mutagenicity of molds of the Aspergillus glaucus group, identification of physcion and three chelated anthraquinones as main toxic constituents from Aspergillus chevalieri. 1979. The Journal of Agricultural and Food Chemistry. Vol. 27. No. 6. 1342-47.

Bai, Z, Harvey, L., McNeil, B. Oxidative stress in submerged cultures of fungi. 2003. Critical Reviews Biotechnology. Vol. 23. No. 4. 267-302.

Becker, R. Condensation and mould growth in dwellings-Parametric field study. 1984. Building and Environment. Vol. 19. No. 4. 243-250.

Betina, V. Thin layer chromatography of mycotoxins. 1985. Journal of Chromotography. Vol. 334. No. 3. 211-76.

Birch, A., Farrar, K. 1961. Studies in relation to biosynthesis. XXIV. Some remarks on the structure of echinulin. 1961. Journal of the Chemical Society. 3128-3131.

Blackley, D. Experimental research on the cause and nature of Catarrhus aestivus. 1873. Bailliere Tindall and Cox, London.

Brunekreef, B., Dockery, D., Speizer, F., Ware, F., Spengler, J., Ferris, B. Home dampness and respiratory morbidity in children. 1989. The American Review of Respiratory Disease. Vol. 140. 1363-1367.

Bu'Lock, J. Secondary metabolism in fungi and its relationship to growth and development. 1975. The Filamentous Fungi. Volume 1. Industrial Mycology. Edward Arnold Ltd.

Bunger, J., Westphal, G., Monnich, A., Hinnendahl, B., Hallier, E., Muller., M. Cytotoxicity of occupationally and environmentally relevant mycotoxins. 2004. Toxicology. Vol. 202. 199-211.

Burnett, J. Fungal populations and species. 2003. Oxford, UK, Oxford University Press.

Butinar, L., Polona, P., Frisvad, J., Gunde-Cimerman, N. The genus Eurotium - members of indigenous fungal community in hypersaline waters of salterns. 2005. FEMS Microbiology Ecology. Vol. 51. 155-166.

Cabrera, H., Taniwaki, M., Menezes, H., Iamanaka, B. The production of ochratoxin A by Aspergillus ochraceus in raw coffee at different equilibrium relative humidity and under alternating temperatures. 2004. Food Control. Vol. 15. No. 7. 531-535.

Casnati, G., Pochini, A., Ungaro, R.. Neoechinulin. A new isoprenyl-indole metabolite from Aspergillus amstelodami. 1973. Gazzetta Chimica Italiana. Vol. 103. No 1-2. 141151. 
Chen, X., Zheng, Y., Shen, Y. Natural products with maleic anhydride structure: nonadrides, tautomycin, chaetomellic anhydride, and other compounds. 2007. Chemical Reviews. Vol. 107. No. 5. 1777-1830.

Cole, R., Schweikert, M. Handbook of secondary fungal metabolites. 2003. Vol. 1. Academic Press. Elsevier Science. USA.

Cole, E., Foarde, K., Leese, K., Green, D., Franke, D., Berry, M. Assessment of fungi in carpeted environments. In Health Implications of Fungi in Indoor Environments. Elsevier, Amsterdam. 103-128.

Crane, R., Hedden, P., MacMillan, J. Fungal Products. Part 1V. The structure of heveadride, a new nonadride from Helminthosporium heveae. 1973. J.C.S. Perkins I. Vol. 1911. No. 2. 194-200.

Cutler, H., Crumley, F., Cox, R., Springer, S., Arrendale, R., Cole, R., Cole, P. Ophiobolins $\mathrm{G}$ and $\mathrm{H}$ : new fungal metabolites from a novel source, Aspergillus ustus. 1984. The Journal of Agriculture and Food Chemistry. Vol. 32. 778-782.

Dales R., Burnett, R., Zwanenburg, H. Adverse health effects among adults exposed to home dampness and molds. 1991b. The American review of respiratory disease. Vol. 143 No. 3. 505-509.

Dales R., Zwanenburg, H., Burnett, R., Franklin, A. Respiratory health effects of home dampness and molds among Canadian children. 1991a. American journal of epidemiology. Vol. 134. No. 2. 196-203.

De Jesus, A., Horak, R., Steyn, P., Vleggaar, R. Metabolites of Aspergillus ustus. Part 4. Stable-isotope labelling studies on the biosynthesis of the austalides. 1987. The Journal of the Chemical Society. Perkins Transaction I. 2253-2257.

Dearborn, D., Infield, M., Smith, P. Update: acute pulmonary hemorrhage/hemosiderosis among infants: Cleveland. 1997. MMWR. Vol. 46. 33-35.

Dearborn, D., Infield, M., Smith, P. Acute pulmonary hemorrhage/hemosiderosis among infants: Cleveland. 1994. MMWR. Vol. 43. 881-883.

Dewick, P. Medicinal Natural Products. A Biosynthetic Approach. 1997. John Wiley \& Sons. West Sussex, England.

Domsch, K., Gams, W., Anderson, T. Compendium of Soil Fungi. Vol. 1. 1980. Academic Press, London.

Dossena, A., Marchelli, R., Pochini, A. New metabolites of Aspergillus amstelodami related to the biogenesis of neoechinulin. 1975. Journal of the Chemical Society, Chemical Communications. Vol. 19. No. 771-2. 
Douwes, J., Pearce, N. Invited commentary: is indoor mold exposure a risk factor for asthma? 2003. American Journal of Epidemiology. Vol. 158. No. 3. 203-206.

Engvall., K., Norrby, C., Norback, D. Sick building syndrome in relation to building dampness in multi-family residential buildings in Stockholm. International Archives of Occupational and Environmental Health. 2001. Vol. 74. No. 4. 270-278.

Erada, A., Proksh, P., Wray, V., Christ, R., Witte, L., Vansoest, R. Bioactive isoquinoline quinone from an undescribed philippine marine sponge of the genus Xestospongia. 1996. The Journal of Natural Products. Vol. 59. 973-976.

Filtenborg, O., Frisvad, J., Svendsen, J. Simple screening methods for moulds producing intracellular mycotoxins in pure cultures. 1983. Applied and Environmental Microbiology. Vol. 45. No. 2. 581-585.

Fischer, G., Muller, T., Schwalbe, R., Ostrowski, R., Gott, W. Species-specific profiles of mycotoxins produced in cultures and associated with conidia of airborne fungi derived from biowaste. 2000. International Journal of Hygiene and Environmental Health. Vol. 203. 105-116.

Flannigan, B. Microorganisms in indoor air. 2001. Microorganisms in home and indoor work environments, diversity, health impacts, investigation and control. 2001. Taylor and Francis Inc. New York, NY.

Flannigan, B., McCabe E., McGarry F. Allergenic and toxigenic micro-organisms in houses. 1991. Journal of Applied Bacteriology. Vol. 70. 61-73.

Flannigan, B., Samson, R., Miller, J.D. Microorganisms in home and indoor work environments, diversity, health impacts, investigation and control. 2001. Taylor and Francis Inc. New York, NY.

Frisvad, J. The connection between the Penicillia and Aspergilli and mycotoxins with special emphasis on misidentified isolates. 1989. Archives of Environmental Contamination and Toxicology. Vol. 18. 452-467.

Frisvad, J. Nielsen, K., Samson, R. Recommendations concerning the chronic problem of misidentification of mycotoxigenic fungi associated with foods and feeds. 2006. Advances in Food Mycology. Advances in Experimental Medicine and Biology. Vol. 571. 33-46.

Gatti, G., Fuganti, C. ${ }^{13}$ NMR spectra of echinulin and related compounds. 1979. The Journal of Chemical Research (S). 366-367.

Gloer, J. The chemistry of fungal antagonism and defense. 1995. Canadian Journal of Botany. Vol. 73. S1265-S1274. 
Gock, M., Hocking, A., Pitt, J., Poulos, P. Influence of temperature, water activity and $\mathrm{pH}$ on growth of some xerophilic fungi. 2002. International Journal of Food Microbiology. Vol. 2481. 11-19.

Gould, A., Raistrick, H. The biochemistry of micro.ovrddot.organisms. XL. The crystalline pigments of species in the Aspergillus glaucus series. 1934. Biochemical Journal. Vol. 28. 1640.

Grant, C., Hunter, C., Flannigan, B., Bravery, A. Water activity requirements of moulds isolated from domestic dwellings. 1989. International Biodeterioration. Vol. 25. 259-284.

Gravesen, S., Nielsen. P., Nielsen, K. Microfungi in water damaged buildings. 1997. SBI Report No. 282. Danish Building Research Institute, Copenhagen, Denmark.

Grove, J. New metabolic products of Aspergillus flavus. Part 1. Asperentin, its methyl ethers, and $5{ }^{`}$-hydroxyasperentin. 1972. J.C.S. Perkin I. 2400-2406.

Grove, J., Pople, M. The insecticidal activity of some fungal dihydroisocoumarins. 1981. Mycopathologia. Vol. 76. No. 2 .65-67.

Guarro, J., Gené, J., Stchigel, A. Developments in Fungal Taxonomy. Clinical Microbiology Reviews. 1999. Vol. 12. No. 3. 454-500.

Gumowski, P. Hypersensitivity to airborne moulds: diagnostics and therapeutic approaches. 1997. Expressions. Vol. 5. 9-14.

Hamasaki, T., Fukunaga M., Kimura, Y., Hatsuda, Y. Isolation and structures of two new metabolites from Aspergillus ruber. 1980. Agricultrual and Biological Chemistry. Vol. 44. 1685.

Haruhiro, F., Toshiyuki, F., Emi, O., Mikio, Y. Immunomodulatory constituents from an ascomycete, Microascus tardifaciens. 1999. Chemical \& Pharmaceutical Bulletin. Vol. 47. No. 10. 1426-1432.

Hayes, M., Wrigley, S., Chetland, I., Renyolds, E., Ainsworth, A., Renno, D., Latif, M., Cheng, X., Hupe, D., Charlton, P., Doherty, A. Novel drimane sesquiterpene esters from Aspergillus ustus var. pseudodeflectus with endothelin receptor binding activity. 1995. The Journal of Antibiotics. Vol. 49. No. 6. 505-512.

Health Canada. Fungal contamination in public buildings: health effects and investigation methods. 2004. Ottawa. Health Canada.

Health Canada. Fungal contamination in public buildings; recognition and management. 1995. Ottawa. Health Canada. 
Horak, R., Steyn, P., Van Rooyen, P., Leggaar, R. Structures of the Austalides A-E, five novel toxic metabolites from Aspergillus ustus. 1981. The Journal of the Chemical Society. Chemical Communication. 1265.

Hosoe, T., Fukushima, K., Itabashi, T., Nozawa, K., Takizawa, K. A new nonadride derivative, dihydroepiheveadride, as characteristic antifungal agent against filamentous fungi, isolated from unidentified fungus IFM 52672. 2004a. The Journal of Antibiotics. Vol. 57. No. 9. 573-578.

Hosoe, T., Fukushima, K., Itabashi, T., Nozawa, K., Takizawa, K., Kawai, K. The absolute structures of dihydroepiheveadride, as characteristic antifungal agent agent against filamentous fungi, and its related compounds from unidentified fungus IFM 52672. 2004b. Heterocycles. Vol. 63. No. 11. 2581-2589.

Houbraken, J., Due, M., Varga, J., Meijer, M., Frisvad, J., Samson, R. Polyphasic taxonomy of Aspergillus section Usti. 2007. Studies in Mycology. Vol. 59. 107-128.

Hsieh, D., Singh, R., Yao, R., Bennett, J. Anthraquinones in the biosynthesis of sterigmatocystin by Aspergillus versicolor. 1978. Applied Environmental Microbiology. Vol. 35. 980-982.

Hunter, C., Bravery, A. Requirements for growth and control of surface moulds in dwellings. 1989. In Flannigan, B. (ed.), Airborne Deteriogens and Pathogens, The Biodeterioration Society. Kew, Surrey, UK. 174-182.

Institute of Medicine. Clearing the air: asthma and indoor air exposures. 2000. Washington DC: National Academy Press.

Jacyno, J., Harwood, J., Cutler, H., Lee, M. Isocladosporin, a biologically active isomer of cladosporin from Cladosporium cladosporioides. 1993. Journal of Natural Products. Vol. 56. No. 8. 1397-1401.

Jahn, B., Boukhallouk, F., Lotz, J., Langfelder, K., Wanner, G., Brakhage, A. Interaction of human phagocytes with pigmentless Aspergillus conidia. 2000. Infection and Immunity. Vol. 68. No. 6. 3736-3739.

Jansen B., Groot, A. The occurrence and biological activity of drimane sesquiterpenoids. 1991. Natural Product Reports. Vol 8. No. 3. 309-318.

Jarvis, B., Miller, J.D. Mycotoxins as harmful indoor air contaminants. 2005. Applied Microbiology and Biotechnology Vol. 4. 367-372.

John, M., Krohn, K., Florke, U., Aust, H., Draeger, S., Shulz, B. Biologically active secondary metabolites from fungi. 12.1 Oidiolactones A-F, labdane diterpene derivatives isolated from Oidiodendron truncate. 1999. Journal of Natural Products. Vol. 62. 12181221. 
Kawai, K., Hisada, K., Nakamaru, T., Nozawa, Y., Kitamura, J. Inhibition of mitochondrial electron transport system by flavoglaucin from Eurotium chevalieri. II. The interaction with complex III. 1986. Mycotoxins. Vol. 24. 13-18.

Kawai, K., Mori, H., Kitamura, J. The uncoupling effect of flavoglaucin, a quinol pigment from Aspergillus chevalieri (Mangin), on mitochondrial respiration. 1983. Toxicology Letters. Vol. 19. No. 3. 321-5.

Kildeso, J., Wurtz, H., Nielsen, K., Kruse, P., Wilkins, K., Thrane, U., Gravensen, P., Nielsen, P., Schneider, T. 2003. Determination of fungal spore release from wet building materials. Indoor Air. Vol. 13. 148-155.

Kinoshita, K., Yamamoto, Y., Koyama, K., Takahashi, K., Yoshimura, I. Novel fluorescent isoquinoline pigments, panaeflourolines A-C from the cultured mycobiont of a lichen, Amygdalaria panaeola. 2003. Tetrahedron Letters. Vol. 44. 8009-8011.

Kinoshita, K., Yamamoto, K., Takatori, K., Koyama, K., Takahashi, K., Kawai, K., Yoshimura I. Fluorescent compounds from the cultured mycobiont of Amygdalaria panaeola. 2005. The Journal of Natural Products. Vol. 68. 1723-1727.

Klich, M. Identification of common Aspergillus species. 2002. Centraalbureau voor Schimmelcultures. New Olreans, Louisiana, USA.

Klich, M, Pitt, J. A laboratory guide to common Aspergillus species and their teleomorphs. 1988. Commonwealth Scientific and Industrial Research Organisation, Division of Food Processing.

Knut, P., Aksnes, D., Francis, G. NMR study of some anthraquiones from rubarb. 1992. Magnetic Resonance Chemistry. Vol. 30. 359-363.

Kohno, J., Hiramastu, H., Nishio, M., Sakurai, M., Okuda, T., Komatsubara, S. Structures of TMC-120 A, B, C, novel isoquinoline alkaloids from Aspergillus ustus TC 1118. 1999a. Tetrahedron. Vol. 55. 11247-11252.

Kohno, J., Sakurai, M., Kameda, N., Nishio, M., Kawano, K., Kishi, N., Okuda, T., Komatsubara, S. Production, isolation and biological properties of TMC-120A, B, C, novel inhibitors of eosinophil survival from Aspergillus ustus TC 1118. 1999b. The Journal of Antibiotics. Vol. 52. No. 10. 913-916.

Kozak, P., Gallup, J., Cummins, L., Gillman, S. Currently available methods for home mold surveys. II. Examples of problem homes surveryed. 1980. Annual Allergy. Vol. 45. 167-176.

Kozakiewicz, Z. Aspergillus species on stored products. 1989. Mycological Papers. Vol. 161. 1-188. 
Kozlovskii A., Zhelifonova V., Adanin V., Antipova T., Shnyreva A., and Viktorov A., The biosynthesis of low-molecular-weight nitrogen-containing secondary metabolitealkaloids by the resident strains of Penicillium chrysogenum and Penicillium expansum isolated on the board of the Mir space station. 2002. Mikrobiologiia. No 71. Vol. 773777.

Kuo, Y., Tsai, W., Meng, H., Chen, W., Yang, L., Lin, C. Immune reponses in human mesangial cells regulated by emodin from Polygonum hypoleucum Ohwi. 2001. Life Sciences. Vol. 68. 1271-1286

Lacey, J., Hill, S., Edwards, M. Microorganisms in stored grains: their enumeration and significance. 1980. Trop. Stored Prod. Information. Vol. 39. 19-33.

Larsen, T., Smedsgaard, J., Nielsen, K., Hansen, M., Frisvad, J. Phenotypic taxonomy and metabolite profiling in microbial drug discovery. 2005. Natural Product Reports. Vol. 22. 672-695.

Li, Y., Li, X., Kim, S., Kang, J., Choi, H., Rho, J., Son, B. Golmaenone, a new diketopiperazine alkaloid from the marine-derived fungus Aspergillus sp. 2004. Chemical and Pharmaceutical Bulletin. Vol. 52. Vol. 3. 375-376.

Li, C., Yang, Y., Lin, R., She, Z., Zhou, S. A new nonadride derivative from mangrove fungus (strain No. k38). 2007. Journal of Asian Natural Products Research. Vol. 9. No. 3. 285-291.

MacDonald, J., Slater, G. The utilization of trytophan in the biosynthesis of echinulin. 1966. Canadian Journal of Microbiology. Vol. 12. 455-463.

Magan, N., Lacey, J. Effect of temperature and $\mathrm{pH}$ on the water relations of field and storage fungi. 1984. Applied and Environmental Microbiology. Vol. 47. No. 1113-17.

Malloch, D., Cain, R. The trichocomataceae: ascomycetes with Aspergillus, Paecilomyces, and Penicillium imperfect states. 1972. Canadian Journal of Botany. Vol. 50. 2613-2628.

Mann, J. Secondary Metabolism Second Addition. Oxford Science Publications. Clarendon Press Oxford. 1987.

Marchelli, R., Dossena, A., Casnati, G. Biosynthesis of Neoechinulin by Aspergillus amstelodami from cyclo-L-[U-1 4C]Alanyl-L-[5 ,7-3H,] tryptophyl. 1975. J.C.S. Journal of the Chemical Society, Chemical Communications. Vol. 19. 779-780.

Marchelli, R., Dossena, A., Pochini, A., Dradi, E. The structures of five new didehydropeptides related to neoechinulin, isolated from Aspergillus amstelodami. 1977. Journal of the Chemical Society. Perkin Transaction 1. Vol. 7. 713-7. 
Marzo, A., Lorenzo, D. Chromatography as an analytical tool for selected antibiotic classes: a reappraisal addressed to pharmacokinetic applications. 1998. Journal of Chromotography A. Vol. 812. 17-34.

McGinnis, M. Pathogenesis of indoor fungal disease. 2004. Medical Mycology. Vol. 42. 107-117.

Miller, J.D. Recognition, Evaluation \& Control of Indoor Mold. Section 1: Underlying principles and background for evaluation and control. Chapter 4. Mold Ecology: recovery of fungi from certain moldy building materials. $2008 \mathrm{a}$, in press.

Miller, J.D. Fungi as contaminants in indoor air. 1992. Atmospheric Environment. Vol. 26A. No. 12. 2163-2172.

Miller, J.D., Day, J. Indoor mold exposure: epidemiology, consequences, and immunotherapy. 1997. The Canadian Journal of Agriculture. Vol. 1. No. 5

Miller, J.D., Rand, T., McGregor, H., Solomon, J., Yang, J. Mold ecology: recovery of fungi from certain moldy building materials. In: Prezant B, Weekes D, Miller JD (eds) Recognition, Evaluation and Control of Indoor Mold. 2008b. American Industrial Hygiene Association, Fairfax, VA. (in press).

Miller, J.D., Gilbert, N., Dales, R. Fungal contamination in public buildings: health effects and investigation methods. 2004. Health Canada.

Miller, J.D., Laflamme, A., Sobol, Y., Lafontaine, P., Greenhalgh, R. Fungi and fungal products in some Canadian houses. International Biodeterioration. 1988. Vol. 24. 103120.

Miller, J.D., Rand, T., Jarvis, B. Stachybotrys chartarum: cause of human disease or media darling? 2003. Medical Mycology. Vol. 41. No. 4. 271-291.

Miller, J.D., Greenhalgh, R., Wang, Y., Lu, M. Mycotoxin chemotypes of three Fusarium species. 1991. Mycologia. Vol. 83. 121-130.

Mori, H., Kawai, K., Ohbayashi, F., Kuniyasu, T., Yamazaki, M., Hamasaki, T., Williams, G. Genotoxicity of a variety of mycotoxins in the hepatocyte primary culture/DNA repair test using rat and mouse hepatocytes. 1984. Cancer Research. Vol. 44. 2918-2923.

Mouchacca, J. Heat tolerant fungi and applied research: Addition to the previously treated group of strickly thermotolerant species. 2007. World Journal of Microbiology and Biotechnology. Vol. 23. 1755-1770. 
Mueller, S., Lutz, W., Stopper, H. Factors affecting the genotoxic potency ranking of natural anthraquinones in mammalian cell culture systems. 1998. Mutation Research, Genetic Toxicology and Environmental Mutagenesis. Vol. 414. No. 1-3. 125-129.

Nakatsuka, S., Miyazaki, H., Goto, T. Configuration of echinulin. III. Absolute configuration of echinulin. 1980. Tetrahedron Letters. Vol. 21. 2817.

National Academy of Science. Clearing the Air. 2000. National Academy press, Washington, D.C.

Nazar, M., Ali, M., Fatima, T., Gubler, C. Toxicity of flavoglaucin from Aspergillus chevalieri in rabbits. 1984. Toxicology Letters. Vol. 23. 233-237.

Nielsen, K. Mycotoxins production by indoor molds. 2003a. Fungal Genetics and Biology. Vol. 39. 103-117.

Nielsen, K. Mould growth on building materials. Secondary metabolites, mycotoxins and biomarkers. 2003b. Ph.D. thesis.

Nielsen, K., Gravesen, S., Nielsen, P., Andersen, B., Thrane, U., Frisvad, J. Ogawa, A., Murakami, C., Kamisuki, S., Kuriyama, I., Yoshida, H., Sugawara, F., Mizushina, Y. Pseudodeflectusin, a novel isochroman derivative from Aspergillus pseudodefletus a parasite of the sea weed, Sargassum fusiform, as a selective human cancer cytotoxin. 2004a. Bioorganic \& Medicinal Chemistry Letters. Vol. 14. 3539-3543.

Nielsen, K., Gravesen, S., Nielsen P., Andersen, B., Thrane, U., Frisvad, J.C. Production of mycotoxins on artificially and naturally infested building materials. 1999. Mycopathologia. Vol. 145. 43-56.

Nielsen, K., Holm, G. Uttrup, L., Nielsen, P. Mould growth on building materials under low water activities. Influence of humidity and temperature on fungal growth and secondary metabolism. 2004b. International Biodeterioration \& Biodegradation. Vol. 54. $325-336$.

Nielsen, K., Smedsgaard, J., Larsen, T., Lund, F. Chemical identification of fungi: metabolite profiling and metabolomics. 2003a. Marcel Dekker, Inc. New York, N.Y.

Nielsen, K., Smedsgaard, J. Fungal metabolite screening: database of 474 mycotoxins and fungal metabolites for dereplication by standardized liquid chromatography-UVmass spectrometry methodology. 2003b. Journal of Chromatography A. Vol. 1002. 111136.

Northolt, M. The effect of water activity and temperature on the production of some mycotoxins. 1979. PhD Thesis, University of Wageningen, Netherlands. 
Northolt, M., Frisvad, J., Samson, R. Occurrence of food-borne fungi and factors for growth. 1995. Introduction to Food-borne Fungi, $4^{\text {th }}$ Edition, Centraalbureau voor Schimmelcultures, Baarn, Netherlands. 243-250.

Ogawa, A., Murakami, C., Kamisuki, S., Kuriyama, I., Yoshida, H., Sugawari, F., Mizushira, Y. Pseudodeflectusin, a novel isochroman derivative from Aspergillus pseudodeflectus a parasite of the sea weed, Sargassum fusiform, as a selective human cancer cytotoxin. 2004. Bioorganic and Medicinal Letters. Vol. 14. No. 13. 3539-3543.

Piattelli, M., Nicola, M. Anthraquione pigments from Xanthoria parientina (L.)* 1968. Phytochemistry. Vol. 7. 1183-1187.

Pitt, J., Samson, R., Frisvad, J. List of accepted species and their synonyms in the Family Trichocomaceae. 2000. In: Samson, R., Pitt, J. (eds). Integration of modern taxonomic methods of Aspergillus and Penicillium classifications. Harwood Academic Publishers. $9-49$.

Plate, R., Nivard R., Ottenheijm, H. Conversion of N-hydroxytrptophans into $\alpha, \beta-$ dehydrotryptophan. An approach to the neoechinulin series. 1987. Journal of the Chemical Society. Perkin Transaction I. 2473-2480.

Podojil, M., Sedmera, P., Vokoun, J., Betina, V., Barathova, H., Durackova, Z., Horakova, K., Nemec, P. Eurotium (Aspergillus) repens metabolites and their biological activity. 1978. Folia Microbiologica. Vol. 23. 438-443.

Pohland, A. Studies concerning the metabolites produced by Stachybotrys atra, Penicillium islandicum, Penicillium viridicatum and Aspergillus versicolor. 1977. Annales de la Nutrition et de l'Alimentation. Vol. 31. 663-684.

Quilico, A. The constitution of echinulin. 1964. Res. Progr. Org. Biol. Med. Chem. Politecnico, Milan. Vol. 1. 225-56.

Quilico, A., Panizzi, L. Chemische Untersuchungen uber Aspergillus echinulatus. I. Mitterlung. 1943. Chem. Ber. Vol. 76. 348-358.

Raistrick, H. A region of biosynthesis. Proceedings of the Royal Society of London, B. 1950. Vol. 136. 481-508.

Raistrick, H., Robinson, R., Todd, A. The chemistry of Aspergillus chemistry matters. 1938. Part I. Journal of the Chemical Society. 80-86.

Raistrick, H., Robinson, R., Todd, A. The chemistry of Apsergillus colouring matters. Part II. 1938. Journal of the Chemical Society. 2056-64.

Rand, T., Flemming, J., Miller, J.D., Womiloju, T. Comparison of inflammaotry responses in mouse lungs exposed to atranones A and C from Stachybotrys chartarum. Journal of Toxicology and Environmental Health. 2006. Part A. Vol. 69. 1239-1251 
Rand, T., Giles, S., Flemming, J., Miller, J.D., Puniani, E. Inflammatory and cytotoxic responses in mouse lungs exposed to purified toxins from building isolated Penicillium brevicompactum Dierckx and $P$. chrysogenum Thom. 2005. Toxicological Sciences. Vol. 87. No. 1. 213-222.

Rawlings, B., Reese, P. Ramer, E. Vederas, J. Comparison of fatty acid and polyketide biosynthesis: stereochemistry of cladosporin and oleic acid Formation in Cladosporium cladosporioides. 1989. The Journal of the American Chemical Society. Vol. 111. 33823390.

Rodriguez, B., Zapata, N., Medina, P., Vinuela, E. A complete ${ }^{1} \mathrm{H}$ and ${ }^{13} \mathrm{C}$ NMR data assignment for four drimane sesquiterpenoids isolated from Drimys winterii. 2005. Magnetic Resonance in Chemistry. Vol. 43. 82-84.

Samson, R. Mycotoxins: a mycologist's perspective. 1992. Journal of Med. Vet. Mycology. Vol. 30. 9-18.

Samson, R., Mouchacca, J. Additional notes on species of Aspergillus, Eurotium and Emericella from Egyptian desert soil. 1975. Antonie van Leeuwenhoek. Vol. 41. 343351 .

Samson, R., Pitt, J. Integration of modern taxonomic methods for Penicillium and Aspergillus classification. 2000. Overseas Publishers Association. N.V.

Sandoval, I., Davis, R., Bugni, T., Concepcion, M., Harper, M., Ireland, C. Cytotoxic isoquinoline quinones from sponges of the genus Petrosia. 2004. Natural Product Research. Vol. 18 No. 1. 89-93.

Schroeder, H. Kelton, W. Production of sterigmatocystin by some species of the genus Aspergillus and its toxicity to chicken embryos. 1975. Applied Microbiology. Vol. 30. 589-591.

Scott, P., Van Walbeek, W., MacLean, W. Cladosporin, a new antifungal metabolite from cladosporium cladosporioides. 1971. The Journal of antibiotics. Vol. 24. No. 11. 747755.

Smedsgaard, J., Frisvad, J. Using direct electrospray mass spectrometry in taxonomy and secondary metabolite profiling to crude fungal extracts. 1996. Journal of Microbiological Methods. Vol. 25. 5-17.

Smedsgaard, J., Nielsen, K. Metabolite profiling of fungi and yeast: from phenotype to metabolome by MS and informatics. 2005. Vol. 56. No. 410. 273-286.

Smetanina, O., Kalinovskii, A., Khudyakova, Y., Slinkina, N., Pivkin, M., Kuznetsova, T. Metabolites from the marine fungus Eurotium repens. 2007. Chemistry of Natural Compounds. Vol. 43. No. 4. 395-398. 
Smith, J., Berry, D. The Filamentous Fungi. Volume 1. Industrial Mycology. Edward Arnold Ltd. 1975.

Sorenson, W. Occupational respiratory disease: organic dust toxic syndrome. 2001. Microorganisms in home and indoor work environments, diversity, health impacts, investigation and control. Taylor and Francis, New York, NY. 143-153.

Sorenson, W., Shanan, T., Lewis, D. Activation of alveolar macrophages by conidia of common fungi associated with organic dust toxic syndrome. 1995. In Samson, R.,

Springer, J., Cutler, H., Crumley, F., Cox, R., Davis, E., Thean, J. Plant growth regulatory effects and stereochemistry of cladosporin. 1981. Journal of Agricultural and Food Chemistry. Vol. 29. No. 4. 853-5.

Steyn, P. The biosynthesis of mycotoxins. 1998. Revue de Medecine Veterinaire. Vol. 149. No. 6. 469-478.

Steyn, P. The structures of five diketopiperazines from Aspergillus ustus. 1973. Tetrahedron. Vol. 29. 107-120.

Steyn, P., Vleggaar, R. Dihydrofuro[3',s': 4,5]furo,3,2-b-xanthenones: the structures of austocystins G, H and I. 1975. Journal of South Africa.Chem.Inst. Vol. 28. No. 1. 375377.

Steyn, P., Vleggaar, R. Austocystins. Six novel dihydrofuro[3',s': 4,5]furo,3,2-bxanthenones: from Aspergillus ustus. 1974. The Journal of the Chemical Society, Perkin I. Vol. 1. 2250-2256.

Stickings, C., Raistrick, H. Chemistry of fungi. 1956. Annual Reviews. Biochemistry. Vol. 25. 225-256.

Strauss, D. Anthracyclines-Modern tumour-inhibiting agents. 1978. Folia Microbiologica. Vol. 23. 152-161.

Su, H., Rotnitzky, A., Burge, H., Spengler, J. Examination of fungi in domestic interiors by using factor analysis: correlations and associations with home factors. 1992. Applied Environmental Microbiology. Vol. 58. No 1. 181-186.

Sumarah, M. Fermentation, biosynthesis and identification of secondary metabolites from Penicillium species. 2002. Master of Science Thesis. Ottawa, Carleton University.

Sweeney, M., Dobson, A. Mycotoxin production by Aspergillus, Fusarium and Penicillium species. 1998. International Journal of Food Microbiology. Vol. 43. 141-158. 
Tarlo, S., Franklin, A., Tobin, R. Skin testing with extracts of fungal species derived from the homes of allergy clinic patients in Toronto, Canada. 1988. Clinical Allergy. Vol. 18. 45-52.

Tobin, R., Baranowski, E., Gilman, A., Kuiper-Goodman, T., Miller, J.D., Giddings, M. Significance of fungi in indoor air: report of a working group. 1987. Canadian Journal of Public Health. Vol. 78. S1-S32.

Torssell, K. Natural product chemistry. 1983. New York, John Wiley and Sons Ltd. Turner, W., Aldrich, D. Fungal Metabolites II. 1983. Academic Press Inc. New York, NY.

Umeda, M., Yamashita, T., Saito, M., Skeita, S., Takahashi, C., Yoshihira, K., Natori, S., Kurata, H., Udagawa, S. Chemical and cytotoxicity survey on the metabolites of toxic fungi. 1974. Japanese Journal of Experimental Medicine. Vol. 44. 83-96.

Vanek, Z., Cudlin, J., Blumauerova, M., Hostalek, Z., Podojil, M., et al. Physiology and pathophysiology of the production of excessive metabolites. 1981. Prague: Institute of Microbiology, Czechoslovak Academy of Sciences. Vol. 135.

Vesonder, R., Lambert, R., Wicklow, D., Biehl, M. Eurotium spp. and echinulin in feed refused by swine. 1988. Applied and Environmental Microbiology. Vol. 54. No. 3. 830831.

Vidal, D., Mavet, S. In vitro and in vivo toxicity of T-2 toxin, a Fusarium mycotoxin, to mouse peritoneal macrophages. 1989. Infection and Immunity. Vol. 57. 2260-2264.

Vining, L. Function of secondary metabolites. Annual Reviews of Microbiology. 1990. Vol. 44. 395-427.

Wicklow, D. Interference competition and the organization of fungal communities. 1981. In: Wicklow, D., Carroll, G. The fungal community, its organization and role in the ecosystem. Marcel Dekker Inc.

Wei, H., Kinoshita, M., Nikai, Y., Kurotaki, M., Kobayayashi, M. Cytotoxic sesterterpenes, 6-epi-ophiobolin $\mathrm{G}$ and 6-epi-ophiobolin $\mathrm{N}$, from marine derived fungus Emericella variecolor GF10. 2004. Tetrahedron. Vol. 60. No. 28. 6015-6019.

Whiting, D. Natural phenolic compounds 1900-2000: a bird's eye view of a century's chemistry. 2001. Natural Product Reports. Vol. 18. 583-606.

Yabuki, M. Studies on Aspergillus amstelodami Part I. Selective formation of conidia and perithecia and oxidation of substrates by its conidia. 1963. Nippon Nogei Kaga Kaishi. Vol. 38. 407-412. 


\section{APPENDIX}

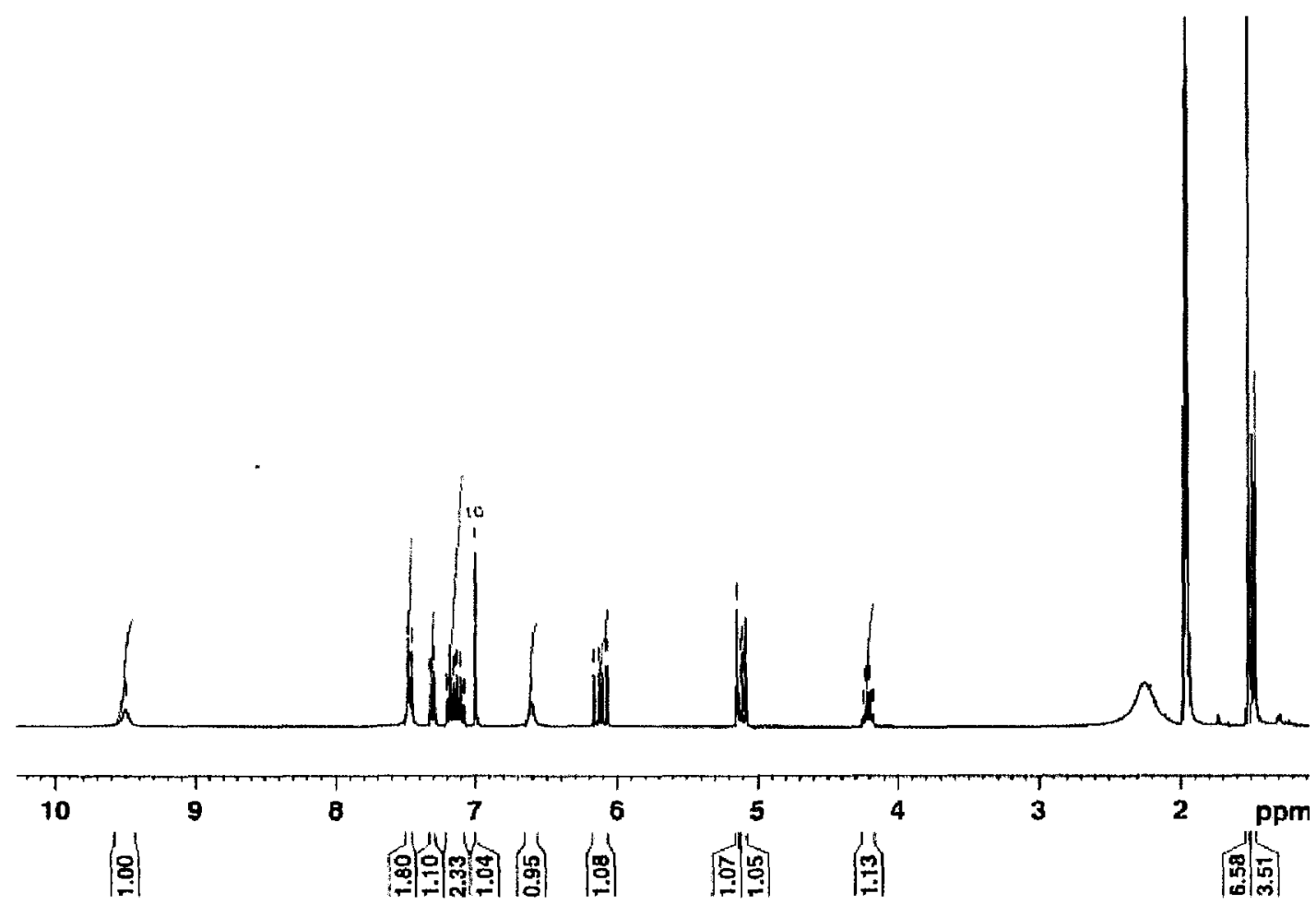

neoechinulin A (1)






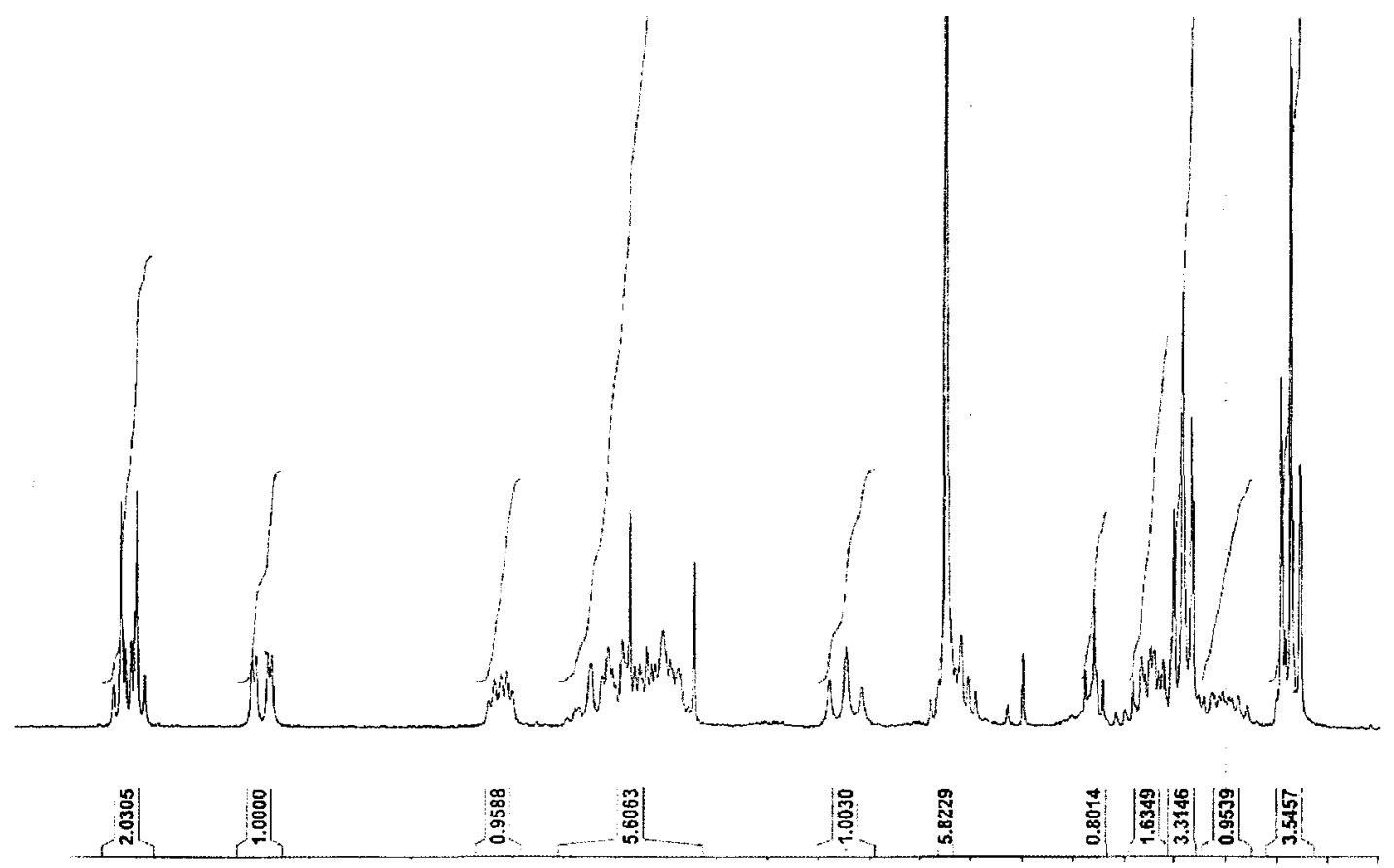

epiheveadride (4)

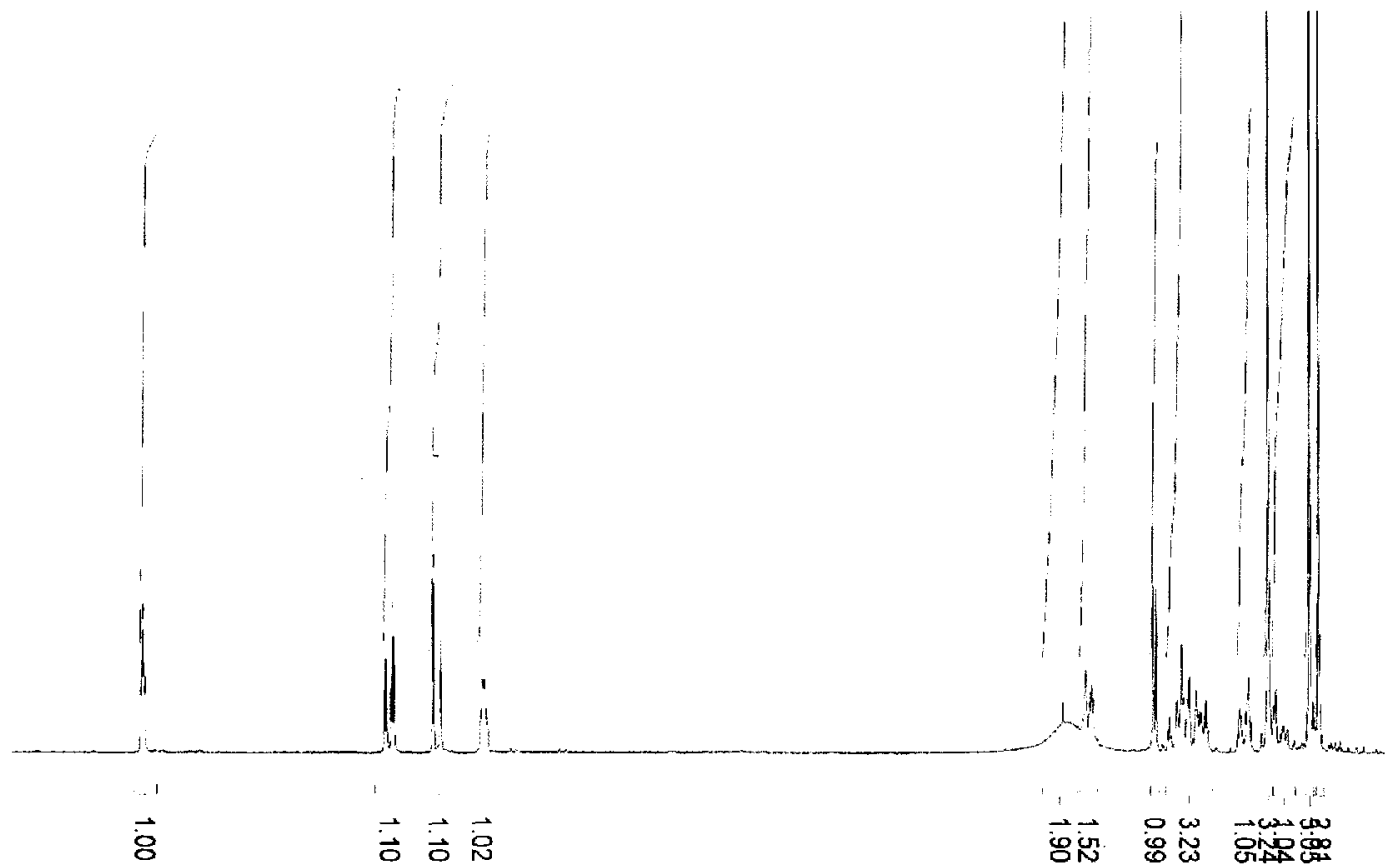

cladosporin (5) 


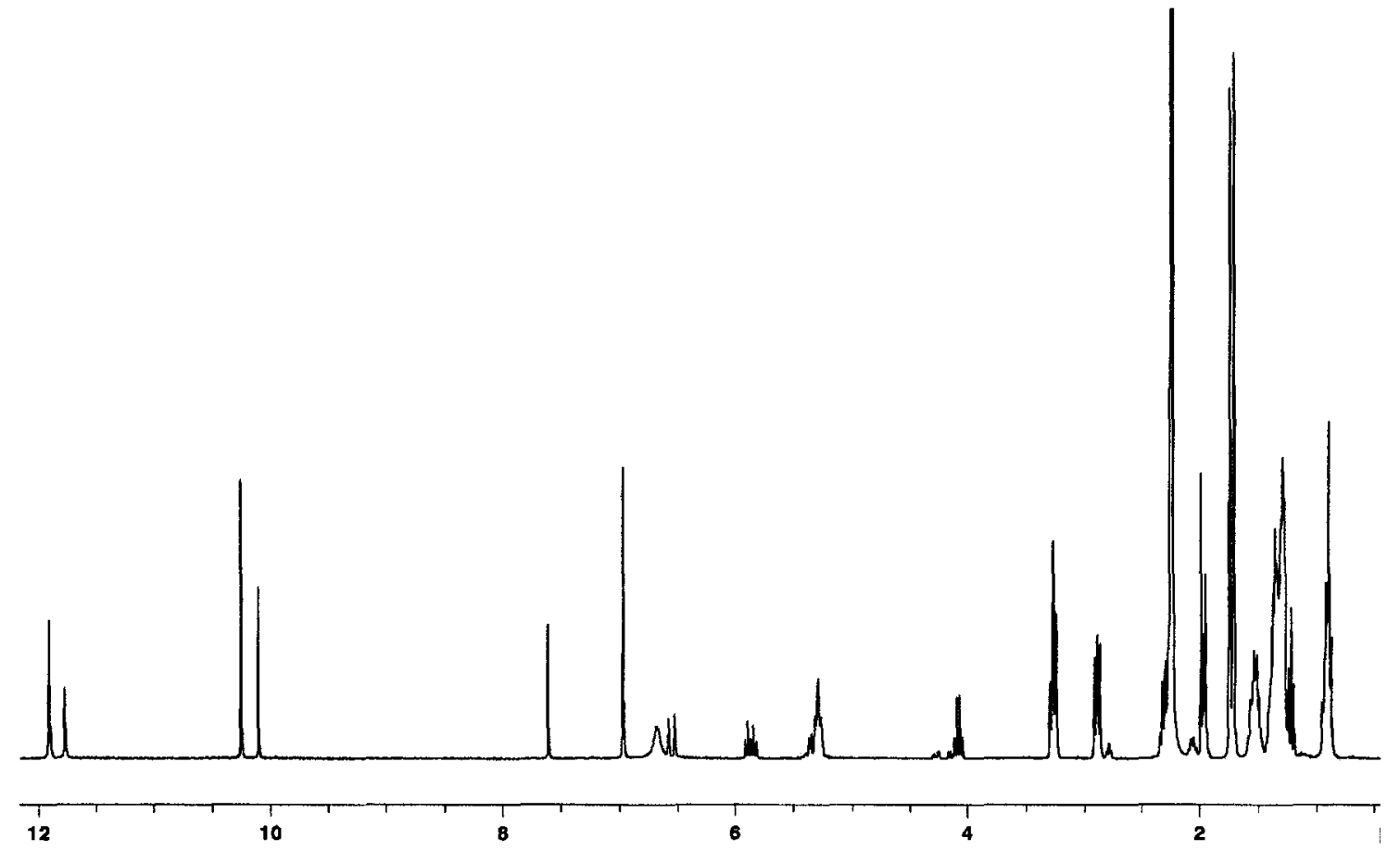

flavoglaucin (12)

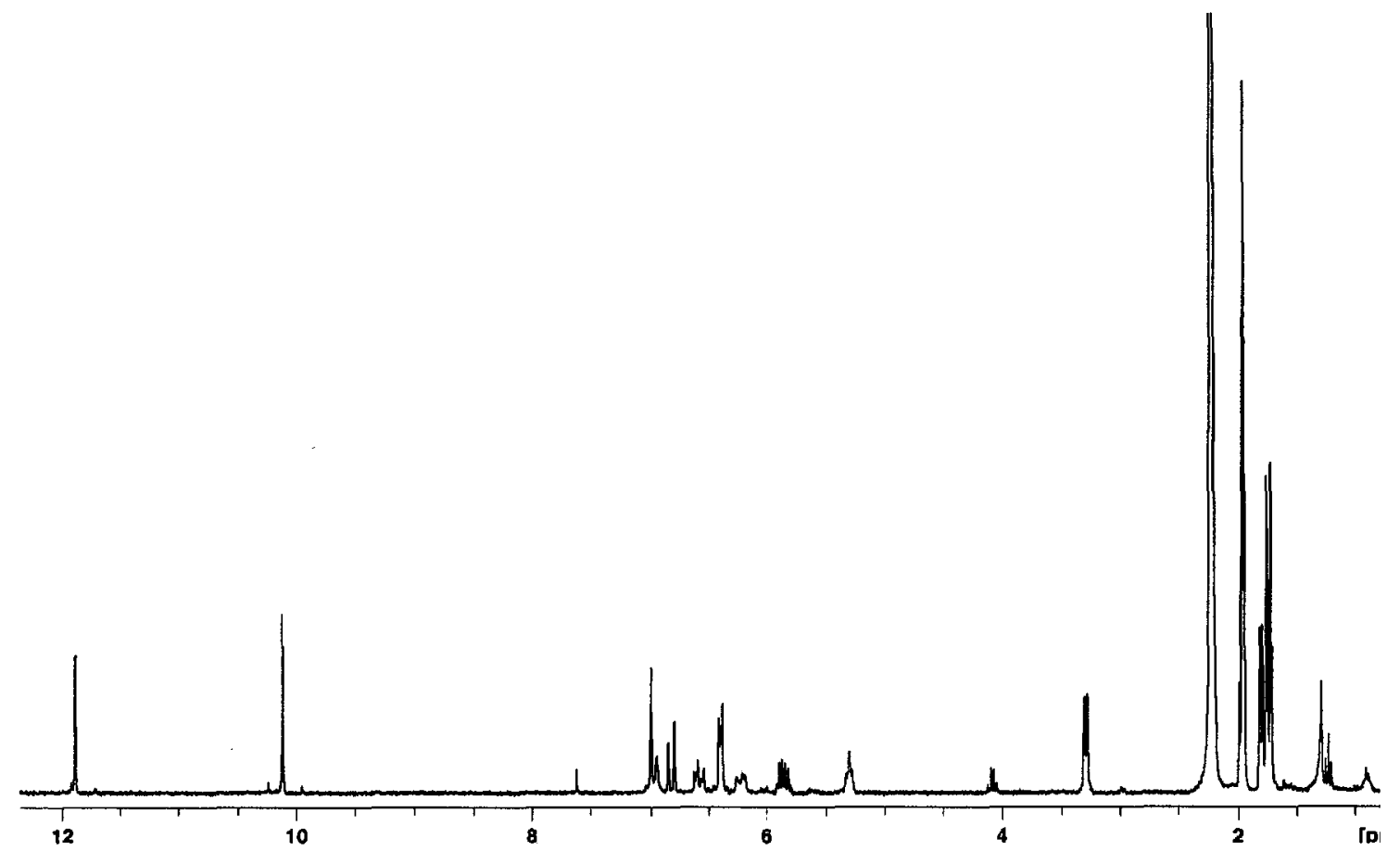

auroglaucin (13) 


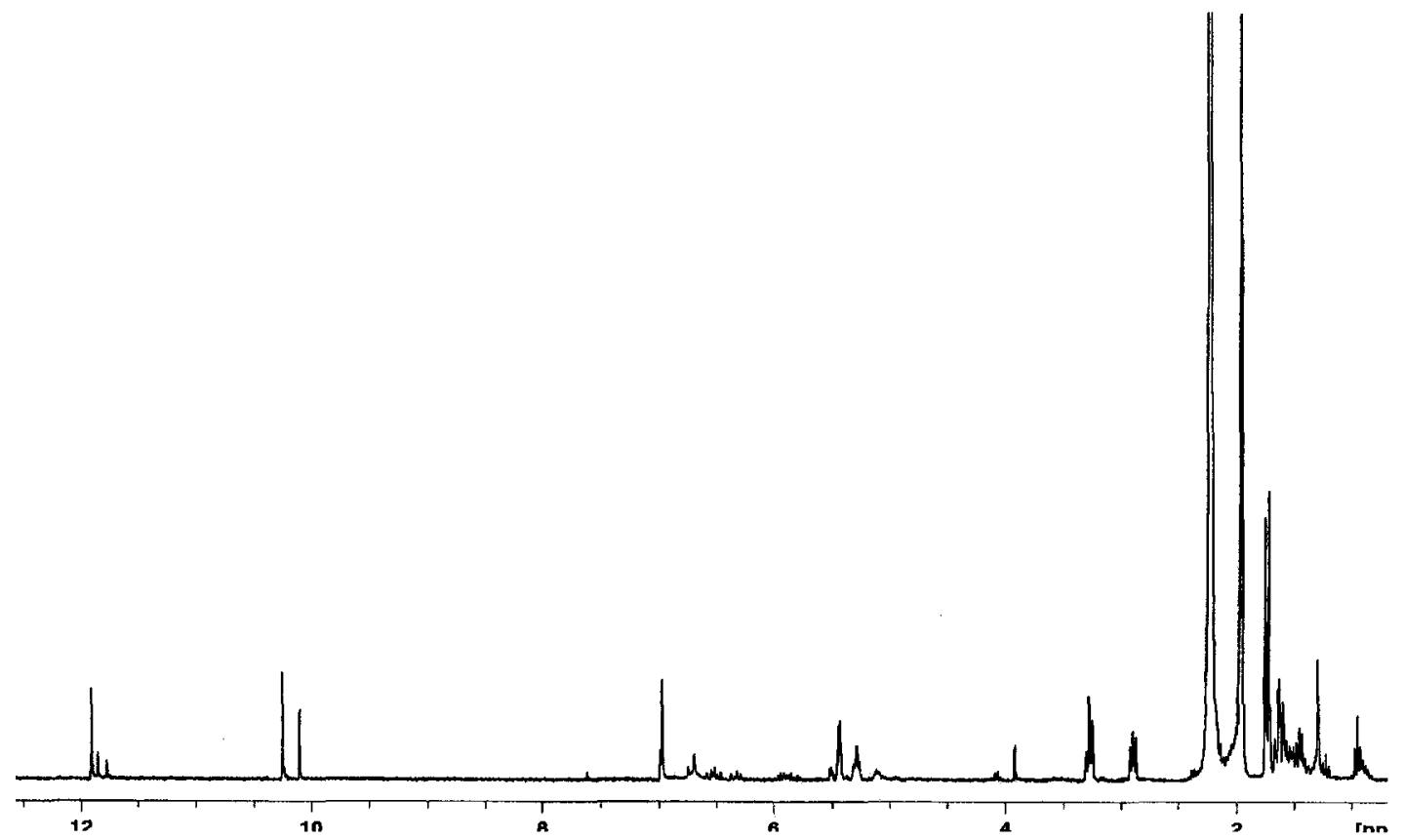

isotetrahyroauroglaucin (14)



TMC-120 A (15) 




TMC-120 C (16)

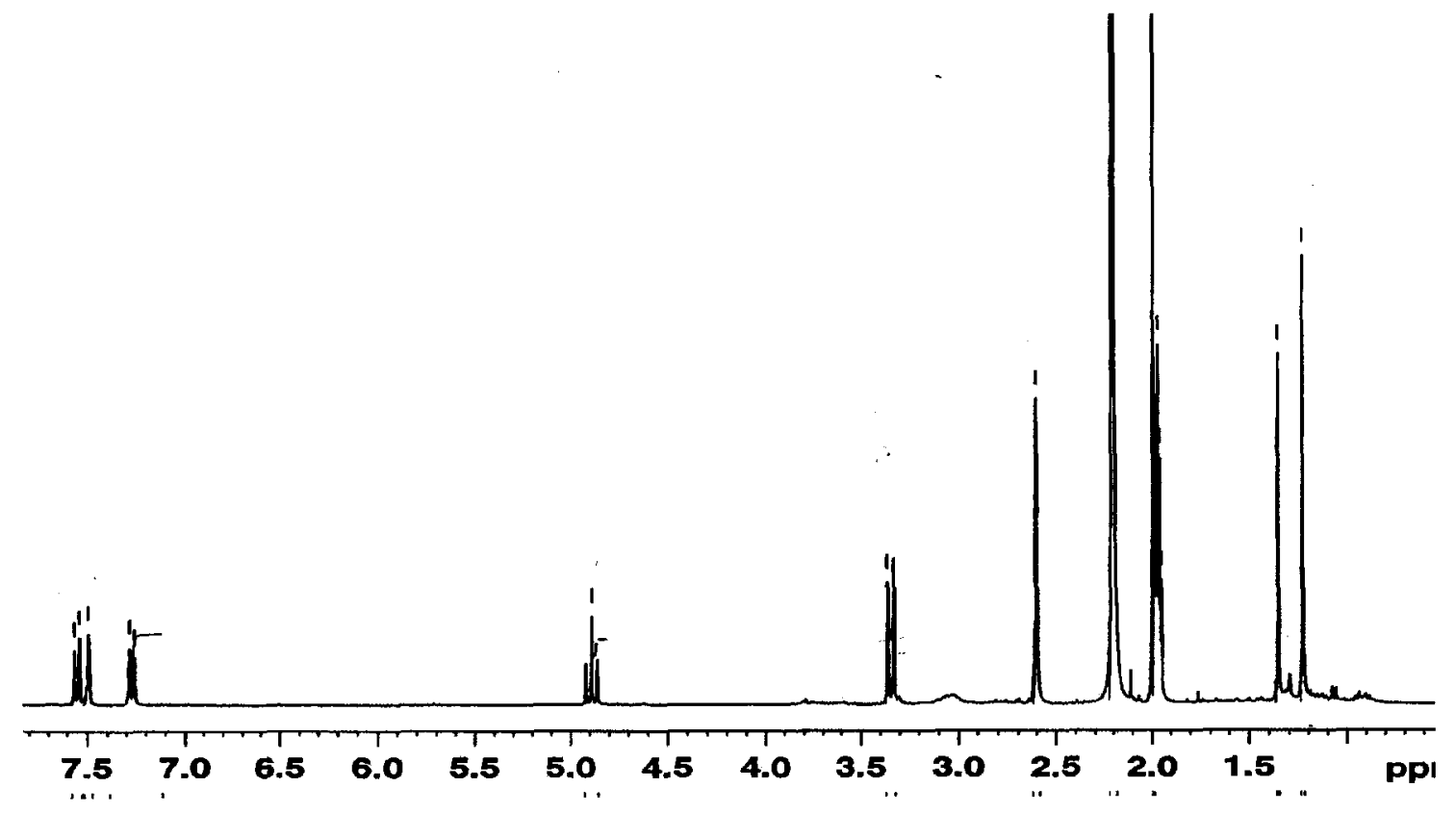

TMC-120 novel derivative (17) 


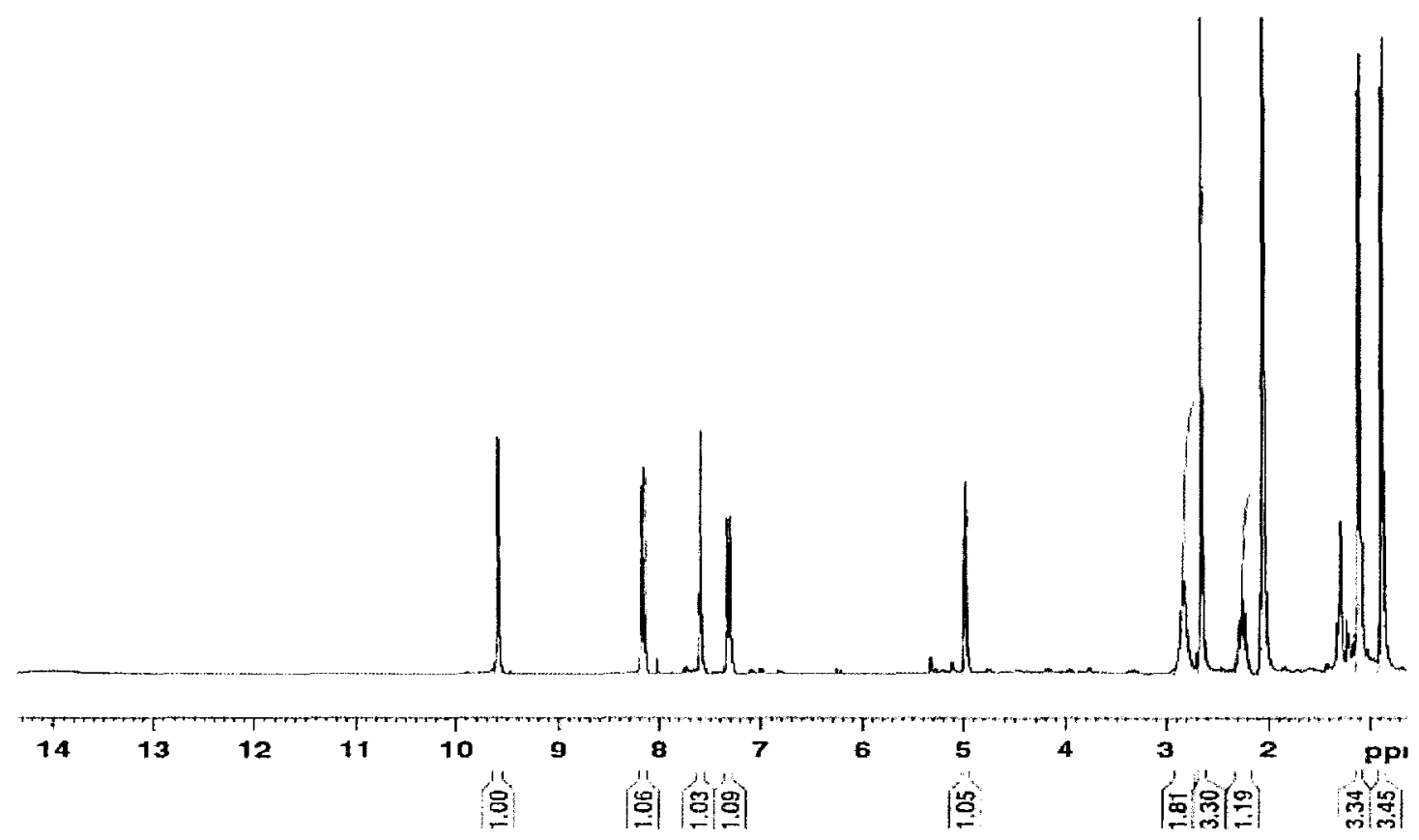

TMC-120 novel derivative (18)

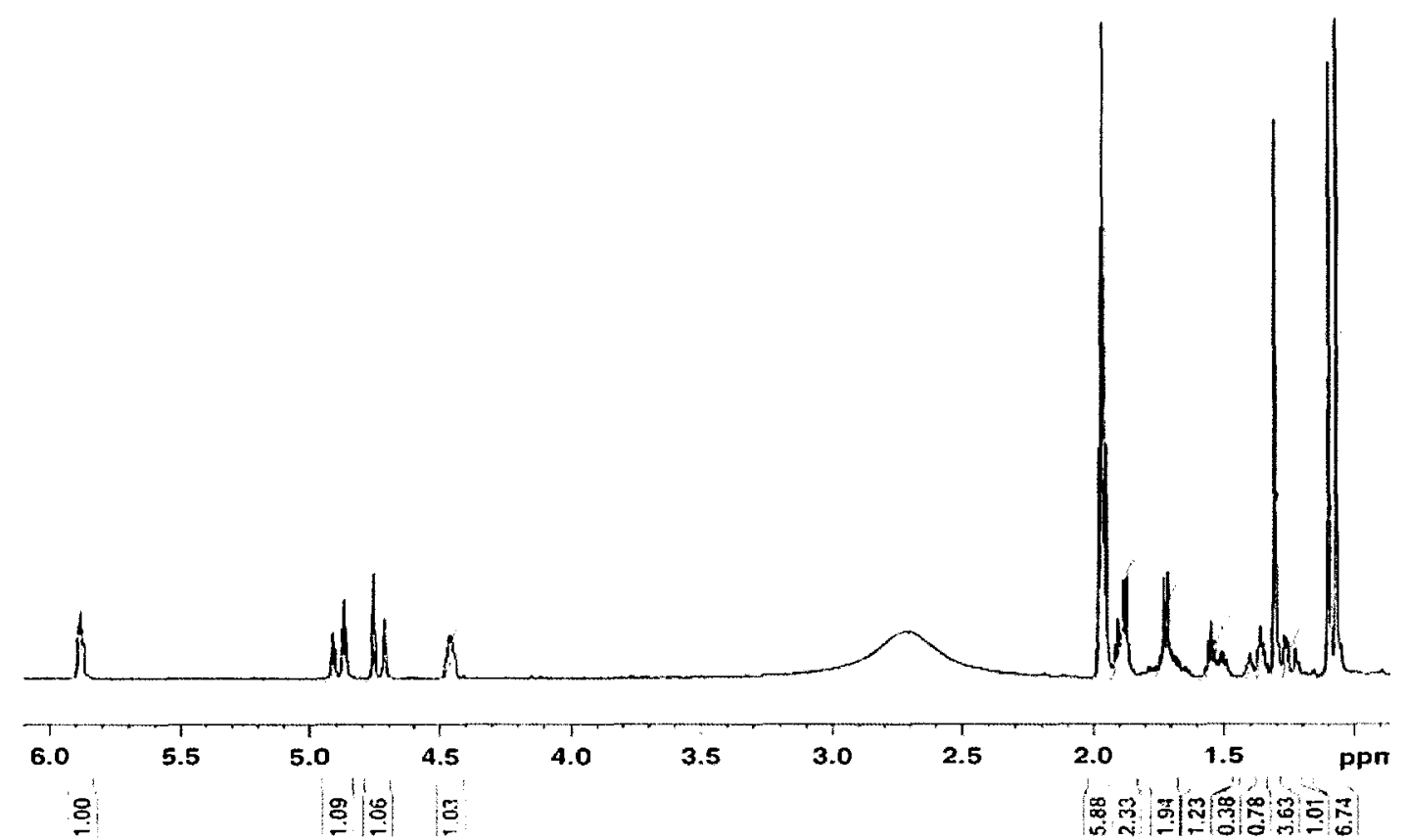

drimane (19) 